CG-D-09-92

DOT-VNTSC-CG-92-1

\title{
A Study of the Relationship Between the Risk of Fatality and Blood Alcohol Concentration of Recreational Boat Operators
}

\author{
Peter Mengert \\ E. Donald Sussman \\ Robert DiSario \\ Research and \\ Special Programs \\ Administration \\ John A. Volpe National \\ Transportation Systems Center \\ Cambridge, MA 02142-1093
}

Final Report

March 1992

This document is available to the public through the National Technical Information Service, Springfield, VA 22161

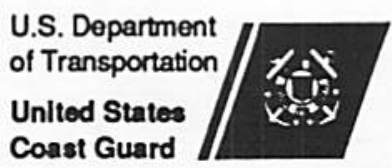

Office of Research and Development Washington, DC 20593 


\section{NOTICE}

This document is disseminated under the sponsorship of the Department of Transportation in the interest

of information exchange. The United States Government assumes no liability for its contents or use thereof.

\section{NOTICE}

The United States Government does not endorse products or manufacturers. Trade or manufacturers" names appear herein solely because they are considered essential to the object of this report. 


\begin{tabular}{|c|c|}
\hline $\begin{array}{l}\text { 1. Report No. } \\
\text { CG-D-09-92 }\end{array}$ & 3. Recipient's Catalog No. \\
\hline \multirow{2}{*}{$\begin{array}{l}\text { 4. Tite and Subtite } \\
\text { A Study of the Relationship Between the Risk } \\
\text { of Fatality and Blood Alcohol Concentration } \\
\text { of Recreational Boat Operators }\end{array}$} & $\begin{array}{l}\text { 5. Report Dato } \\
\text { May } 1992\end{array}$ \\
\hline & $\begin{array}{l}\text { 6. Performing Organization Code } \\
\text { DTS }-45\end{array}$ \\
\hline $\begin{array}{l}\text { 7. Author(s) } \\
\text { Peter Mengert, E. Donald Susman, Robert DiSario }\end{array}$ & $\begin{array}{l}\text { 8. Pertorming Organization Report No. } \\
\text { DOT-VNTSC-CG-92-1 }\end{array}$ \\
\hline 9. Perlorming Organization Name and Address & 10. Work Unit No. (TRAIS) \\
\hline \multirow{2}{*}{$\begin{array}{l}\text { U.S. Department of Transportation } \\
\text { Research and Special Programs Administration } \\
\text { John A. Volpe National Transportation Systems Center } \\
\text { Cambridge, MA } 02142-1093\end{array}$} & CG274/B2067 \\
\hline & 11. Contract or Grant No. \\
\hline \multirow{2}{*}{$\begin{array}{l}\text { 12. Sponsoring Agency Name and Address } \\
\text { U.S. Coast Guard } \\
\text { Office of Navigation Safety and Waterway Services } \\
\text { Office of Engineering Logistics and Development }\end{array}$} & $\begin{array}{l}\text { 13. Type of Report and Periad Covered } \\
\text { Final Report }\end{array}$ \\
\hline & $\begin{array}{l}\text { 14. Sponsoring Agency Code } \\
\text { G-NAB }\end{array}$ \\
\hline
\end{tabular}

15. Supplementary Notes

16. Abstract

A previous study reported that in a data set of recreational boating fatalities 308 of the victims had blood alcohol concentrations above .108 by volume. These data alone did not permit estimation of increased risk of fatality due to intoxication because the prevalence of intoxication among recreational boat operators was unknown. The current study involved interviewing and breath testing recreational boat operators at several boat ramps and marinas in California in order to obtain the "exposure" data needed to estimate the increased risk of fatality associated with intoxication. A large percentage of those people who were approached willingly agreed to the interview and to the breath test. Combining the data from this exposure sample and the fatality data from the previous study enabled computation of a relative risk estimate. The best estimate of relative risk resulting from this research is 10.65 , that is, boat operators with a blood alcohol concentration above .108 are estimated to be 10.65 times as likely to be killed in a boating accident than boat operators with zero blood alcohol concentration. A 958 lower confidence bound on this estimate is 4.74. Several possible sources of bias and their effects on the relative risk estimate are considered.

\section{Key Words}

Boating, Alcohol, Risk, Exposure
18. Distribution Statement

DOCUMENT IS AVAILABLE TO THE PUBLIC THROUGH THE NATIONAL TECHNICAL INFORMATION SERVICE, SPRINGFIELD, VA 22161
19. Security Classification (of this report) UNCLASSIFIED
20. Security Classification (of this page) UNCLASSIFIED
21. No. of Pages 70
22. Price 


\section{PREFACE}

Alcohol has been suspected of being a major contributor to boating accidents for many years. In a previous study "Alcohol in Fatal Recreational Boating Accidents", reliable data on the blood alcohol concentrations of fatal boating accident victims was assembled and analyzed for the first time. In the present study this data is augmented by data on the blood alcohol concentration of boaters not involved in fatal accidents - i.e. corresponding "exposure" data - enabling estimates of relative risk to be calculated for the first time. The work was performed by the U.S. Department of Transportation, Research and Special Programs Administration, Volpe National Transportation Systems Center (VNTSC) and under contract to VNTSC by Dunlap Inc. This study was conducted for the U.S. Coast Guard, Office of Navigation Safety and Waterway Services; the project was sponsored by the Office of Engineering Logistics and Development.

The authors are grateful to Robert Ulmer and Carol Preusser formerly of Dunlap (now of Preusser Research Group) for their superb work in planning and carrying out the data collection, Paul Hoxie of VNTSC for his many contributions in the early stages of the work and to Dr. Jerome Boden of the Coast Guard for his support, advice and guidance throughout this project. 


\section{METRIC I ENGLISH CONVERSION FACTORS}

\section{ENGLISH TO METRIC}

\section{LENGTH urroxoximatr)}

1 inch $(\mathrm{in})=2.5$ centimeters $(\mathrm{cm})$

1 foot $(\mathrm{t})=30$ centimeters $(\mathrm{cm})$

1 yard $(y d)=0.9$ meter $(m)$

1 mile $(\mathrm{mi})=1.6$ kilometers $(\mathrm{km})$

AREA (APPMOXIMATE)

1 square inch (sq in, in 2$)=6.5$ square centimeters $\left(\mathrm{cm}^{2}\right)$

1 square foot $\left(\mathrm{sq} \mathrm{tt}_{\mathrm{t}} \mathrm{t}^{2}\right)=0.09$ square meter $\left(\mathrm{m}^{2}\right)$

1 square yard (sq yd, ydi) $=0.8$ square meter $\left(\mathrm{m}^{2}\right)$

1 square mile (sq $\left.\mathrm{mi}_{1} \mathrm{mi}\right)=2.6$ square kilometers $\left(\mathrm{km}^{2}\right)$

1 acre $=0.4$ hectares (he) $=4,000$ square meters $\left(m^{2}\right)$

MASS - WEICHT (RPROXIMATE)

1 ounce $(0 z)=28$ grams (gr)

1 pound (lb) = A5 kilogram (kg)

1 short ton $=2,000$ pounds $(1 \mathrm{~b})=0.9$ tonne (t)

VOLUME (LPROXIMATE)

1 teespoon (tsp) $=5$ milliliters (ml)

1 tablespoon (tbsp) $=15$ millilisers $(\mathrm{ml})$

1 thuid ounce (fl oz) = 30 milliliters (ml)

1 cup $(e)=0.24$ liter (I)

1 pint $(p t)=0.47$ liter $(1)$

1 quan (qt) $=0.96$ liter (I)

1 gallon $(g a 1)=3.8$ liters (I)

1 cubic foot (cu $\left.f, f^{3}\right)=0.03$ cubic meter $(\mathrm{m})$

1 cubic yard (eu yd, yd2) $=0.76$ cubic meter $(m)$

TEMPERATURE $([\times 2 \%)$

$[(x-32)(5 / 5)]^{\circ} F=y^{\circ} \mathrm{C}$
METRIC TO ENGLISH

LENGTH (APMACXmate) 1 millimeter $(\mathrm{mm})=0.04$ inch $(\mathrm{in})$ 1 centimeter $(\mathrm{cm})=0.4$ inch (in)

9 meter $(m)=3.3$ teet $(\mathrm{t})$

1 meter $(m)=1.1$ yords $(y d)$

9 kilometer $(\mathrm{km})=0.6$ mile $(\mathrm{mi})$

- AREA (RProximatr)

1 square centimeter $\left(\mathrm{cm}^{2}\right)=0.16$ square inch (sq in, in:)

1 square meter $\left(\mathrm{m}^{2}\right)=1.2$ square yards (sq yd, ydz)

1 square kilometer $(\mathrm{km})=0.4$ square mile (sq $\mathrm{mi}, \mathrm{mi}$ )

i hectare (he) $=10,000$ square meters $\left(m^{2}\right)=2.5$ acres

\section{INASS - WEIGHT (RPPRCXIMATT) \\ $1 \mathrm{gram}(\mathrm{gr})=0.036$ ounce (cz) \\ 1 kilogram (kg) $=2.2$ pounds (bb)}

1 zonne $(\mathrm{z})=1,000$ kilograms $(\mathrm{kg})=1.1$ short sons

VOLUME (aPOROXIMATU)

1 millititer $(\mathrm{ml})=0.03$ fluid ounce $(\| \mathrm{loz})$

I liter $(1)=2.1$ pints (pt)

I liter (I) $=9.06$ quarts (qi)

- $\quad$ liter $(1)=0.26$ gallon (gal)

1 cubic meter $\left(m^{3}\right)=36$ cubic feet (eu $\left.f^{\prime}, t^{3}\right)$

1 cubic meter $\left(m^{2}\right)=1.3$ cubic yards (cu yd, yd3)
TEMPERATURE. $1(\mathrm{x} \times \mathrm{CT}$

$[(9 / 5) y+32]^{\circ} \mathrm{C}=x^{\circ} \mathrm{F}$

\section{QUICK INCH-CENTIMETER LENGTH CONVERSION}

INCHES

CENTIN.ETERS

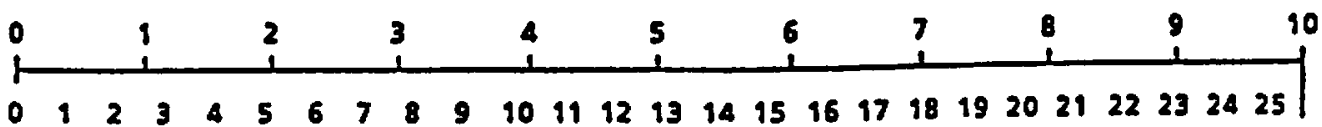

QUICK FAHRENHEIT.CELCIUS TEMPERATURE CONVERSION

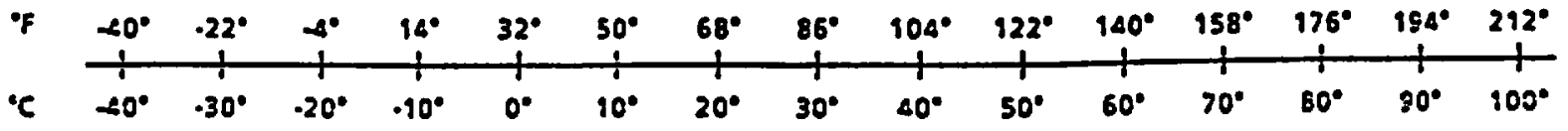

For more exact and or cahet conversion factors, see NES Miscellaneous Publication 286. Units of iveights and Measures. Price 52.50. SO Caralog No. C13 $102 E 6$. 


\section{TABLE OF CONTENTS}

Section

Page

1. INTRODUCTION $\ldots \ldots \ldots \ldots \ldots \ldots \ldots \ldots \ldots$

2. SITE SELECTION $\ldots \ldots \ldots \ldots \ldots \ldots \ldots \ldots \ldots$

3. DATA COLLECTION PROCEDURES $\ldots \ldots \ldots \ldots \ldots$

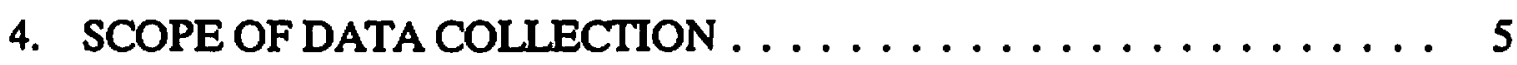

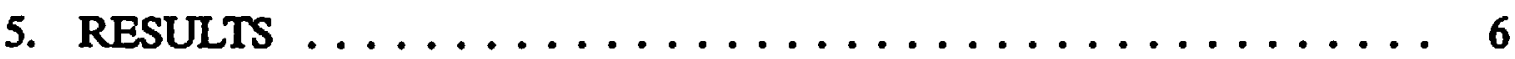

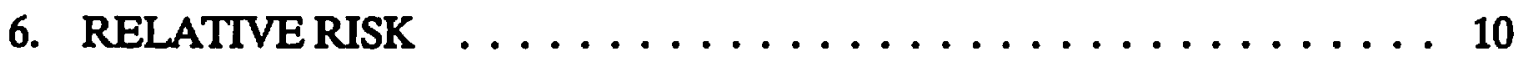

7. STATISTICAL STABILITY $\ldots \ldots \ldots \ldots \ldots \ldots \ldots$

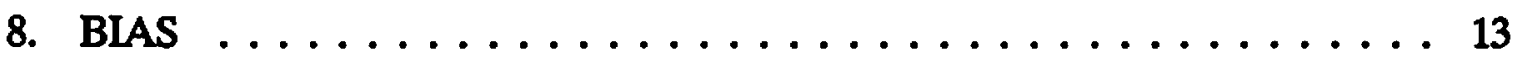

9. RELATIVE RISKS AT OTHER BAC LEVELS . . . . . . . . . . 17

10. COMPARISON WITH HIGHWAY AND PEDESTRIAN

RESEARCH . . . . . . . . . . . . . . . . . . . . 19

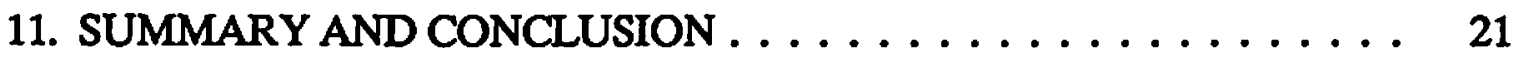

12. RECOMMENDATIONS . . . . . . . . . . . . . 22

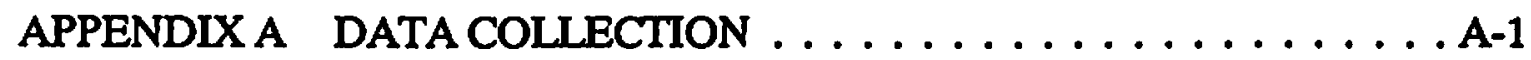

APPENDIX B SURVEY DATA - DETAILED $\ldots \ldots \ldots \ldots \ldots \ldots$. . . .

APPENDIX C ACCIDENT DATA-DETAIILD . . . . . . . . C-1

REFERENCES . . . . . . . . . . . . . . . R-1 


\section{LIST OF FIGURES}

Figure

Page

1. CUMULATIVE BAC DISTRIBUTION ............... 8

2. INVERSE BAC DISTRIBUTION . . . . . . . . . . . . . . . . . 9

3. RELATIVE RISK VS. BAC ... . . . . . . . . . . . . . . 18

\section{LIST OF TABLES}

Table

Page

1. SUMMARY OF TESTING BY UNIT $\ldots \ldots \ldots \ldots \ldots$

2. SUMMARY OF NUMBER OF BOAT OPERATORS SURVEYED AND TESTED (CALIFORNIA 1988-1989) $\ldots \ldots \ldots \ldots \ldots$

3. SUMMARY OF OPERATOR EXPOSURE DATA (CALIFORNIA 1988-1989) . . . . . . . . . . . . . 6

4. SUMMARY OF OPERATOR FATALITY DATA (CALIFORNLA 1984-1985) . . . . . . . . . . . . . 7

5. HIGHWAY RISK (BORKENSTEIN ET AL.) . . . . . . . . . . . . 19

6. PEDESTRIAN RISK (NHTSA / DUNLAP) . . . . . . . . 20 


\section{EXECUTIVE SUMMARY}

A previous study reported that in a data set of recreational boating fatalities $30 \%$ of the victims had blood alcohol concentrations above .10\% by volume (Alcohol in Fatal Recreational Boating Accidents (Reference 1)). These data alone did not permit estimation of increased risk of fatality due to intoxication because the prevalence of intoxication among recreational boat operators was unknown. The current study involved interviewing and breath testing recreational boat operators at several boat ramps and marinas in California in order to obtain the "exposure" data needed to estimate the increased risk of fatality associated with intoxication. A large percentage of those people who were approached willingly agreed to the interview and to the breath test. Combining the data from this exposure sample and the fatality data from the previous study enabled computation of a relative risk estimate. The best estimate of relative risk resulting from this research is 10.65 , that is, boat operators with a blood alcohol concentration above $.10 \%$ are estimated to be 10.65 times as likely to be killed in a boating accident than boat operators with zero blood alcohol concentration. A 95\% lower confidence bound on this estimate is 4.74. Several possible sources of bias and their effects on the relative risk estimate are considered. 
i

$\dot{D}$ 


\section{INTRODUCTION}

In order to study the severity and extent of the problems associated with alcohol use in recreational boating the Coast Guard established a program with the Volpe National Transportation Systems Center (VNTSC) to collect and analyze exposure data to be used with fatal accident data to estimate the relative risk of intoxication versus being sober for fatal boating accidents. (Relative risk is an estimate of the factor by which the fatality rate is larger for intoxicated boaters than for sober boaters. The concept is more precisely defined in section 6 and examined further in later sections.) Exposure data characterizes the extent and level of intoxication of the recreational boater in non-accident situations. Such data is taken under conditions which are as similar as practical to conditions under which fatal accidents have occurred.

In a previous study entitled Alcohol in Fatal Recreational Boating Accidents it was reported that $30 \%$ of the recreational boating fatalities available to that study had blood alcohol concentrations (BACs) in percent by volume above .1 (all BAC's referred to in this report are expressed as percent by volume although the percent symbol will be omitted) and another $21 \%$ had BACs above .04 but below .1. These numbers suggest that alcohol consumption raises the risk of fatality in boating accidents, as it appears that the BAC levels of the fatalities are higher than those usually seen in typical samples of boaters. Further analysis in that report suggested that the types of accidents involving drunk victims could be expected to be influenced by the degree of intoxication. Nevertheless the fatality data alone do not establish a relative risk for alcohol intoxication in recreational boating. Since prior to the present study there was no known data on the BAC distribution of persons involved in recreational boating, a quantitative estimate of relative risk could not be developed at that time.

The need for the distribution of BACs in an exposure sample has long been recognized in the context of highway accidents. In the 1960's R.F. Borkenstein et al (Reference 2) conducted a large study in Grand Rapids, Michigan to determine BAC distributions and relative risk for traffic accidents due to various levels of intoxication. The risk estimates derived from this study were of tremendous value in establishing highway BAC limits and in focussing law enforcement efforts on what was revealed to be perhaps the single greatest source of accident fatalities in the United States.

It must be realized that only as a result of such exposure studies can relative risk be calculated and only with objective estimates of relative risk can the size of the recreational boating alcohol problem be adequately gauged for resource allocation purposes.

The fatal boating accident data used in this report had been assembled and analyzed by VNTSC in a previous report, Alcohol in Fatal Recreational Boating Accidents \#DOT-CG-D04-88. This data was gathered primarily from California and North Carolina and includes information on the accident, boaters, vessel, setting, time and date, as well as the BACs of the fatally injured. 
The original plan called for collecting exposure data in both California and North Carolina, but budget limitations required that the study be confined to California. Before exposure data could be collected, the program plan was submitted to the Office of Management and Budget (OMB), as is required for any federal survey. OMB approval was granted contingent on using only recreational boat operators as subjects (no passengers).

The remainder of the report documents:

- Rationale for the selection of the sites and times for collecting data

- Sites selected for data collection

- Procedures for interviewing subjects and collecting data

- Risk calculation

- Statistical stability and sources of bias 


\section{SITE SELECTION}

Appropriate site selection is a critical first step in developing exposure data. Unlike the highway situation, it not practical to simply wait at the accident location and solicit breath samples from passing boaters because too few boaters would pass any particular spot. It was determined that sufficient quantities of samples could only be obtained by collecting data on shore at boating ramps and marinas. For the purpose of this study the site is the body of water or segment there of where the fatal accident occurred. The actual data collection is conducted at the ramp which services the accident location.

In the selection of sites for collecting exposure data the possibility of collecting too much data from sites that have little danger of fatal boating accidents with or without alcohol use constitutes a threat to validity. One solution, which is not perfect theoretically but certainly cuts down on the low risk sites, is to choose only sites where a boating fatality actually occurred. In this case there should be a mix of sites according to the BAC of the victim. That is, some sites should correspond to victims with high BAC, some with moderate $B A C$, and some with zero BAC. There does not seem to be a theory for the exact mix of sites. The important thing to do is to avoid systematically favoring high or low victim BAC sites.

The study was divided into three units of data collection (described more fully in Section 4). The actual sites for Units 2 and 3 are listed in Appendix A together with the BAC of the associated fatality. These BACs are a representative mix. The first unit was gathered as part of the OMB required pretest procedure. The methodology used in the pretest was successful and was used in the second and third units. Because the methodology proved valid it was possible to use the data from this unit with that of the other two.

The choice of sites which actually had boating fatalities led in most cases to ramps or marinas which had a substantial boating population which could be surveyed. However, in some cases there were few or no boat operators to survey and so the site could not be profitably used.

By timing the data collection to well overlap the time of the fatality it was hoped that representative times would be obtained in the tested BACs. There were very few boat operators leaving the water by the boat ramps after dark although a sizable fraction of the fatalities occurred after dark. Therefore an attempt was made to emphasize night testing in unit 2 . Nevertheless, nighttime interviews and BAC data were scarce. This was not because of a higher refusal rate but because the traffic at the boat ramps falls off sharply after dark. In the analysis section a means of correcting for a possible bias due to under-representation of nighttime boating in the exposure sample is applied to the data. 


\section{DATA COLLECTION PROCEDURES}

The details of data collection are given in Appendix A. The data collection was conducted by Dunlap and Associates under contract to VNTSC. Collection was carried out by a team of two. The investigators surveyed the sites, contacted local law enforcement officials, and obtained permission from the site operators to collect data.

The investigators were informally dressed and waited for boat operators to leave the launch ramp after having brought their boat out of the water. The operator was approached in a friendly, low key, reassuring manner. The boat operators were interviewed prior to breath testing. The interview provided data on the boat operator, boating party, boat, and outing (the questionnaire is shown in Appendix $A$ and the resulting data elements are described in Appendix $B$ which contains the resulting data base). The success of this procedure is demonstrated by the fact that only one person refused the interview out of over 350 boat operators approached.

The investigators used an Intoxylizer 5000 (breath analyzer). This relatively large instrument is quite stable and was calibrated before each of the three units (see Section 4) of the study. This device provides a printed record of the measured BAC. The BAC reading was not revealed to the boat operator being tested unless the operator specifically requested it (see Appendix A). The investigators did not look at the results until after the completion of data collection for the day.

The great majority of boat operators $(91 \%)$ provided valid breath samples. The very high degree of cooperation on the interview and the high degree of cooperation on the breath test is no doubt attributable largely to the skill of the interviewers. 


\section{SCOPE OF DATA COLLECTION}

The data collection consisted of 3 units, each approximately 2 weeks in duration. Each unit involved data collection on approximately 7 days (about 6 hours a day). Each day was at a different site (with one exception no site was visited twice). The first unit was an OMB required pilot study to determine the feasibility of the data collection effort. Because of the success of the procedure the methods were continued unmodified for the second and third units. Therefore the data for all three units could be pooled and used in the analysis. The first unit was conducted in October of 1988, the second in June of 1989, and the third in August of 1989.

The three units of testing are summarized in Table 1 . The abbreviated column titles are expanded below:

1. Unit $-1,2$, or 3

2. Month in which unit was performed.

3. How many sites were visited in the unit - each site was visited on a different day.

4. How many total boaters (subjects) were interviewed in the unit.

5. How many of the sites yielded more than 10 boater interviews (subjects).

6. How many boaters refused to take the breath test to determine their true BAC.

7. How many sites were visited on Fridays.

8. How many of the Friday sites had nighttime testing.

9. Number of Saturday sites.

10. How many of the Saturday sites had nighttime testing.

Table 1. Summary of Testing by Unit

\begin{tabular}{|c|c|c|c|c|c|c|c|c|c|}
\hline Unit & Month & Sites & Subs & $\begin{array}{c}\text { Sites with } \\
>10 \text { Subs }\end{array}$ & $\begin{array}{c}\text { BAC } \\
\text { Refusals }\end{array}$ & $\begin{array}{c}\text { Friday } \\
\text { Sites }\end{array}$ & $\begin{array}{c}\text { Fri. } \\
\text { Night } \\
\text { Sites }\end{array}$ & $\begin{array}{c}\text { Saturday } \\
\text { Sites }\end{array}$ & $\begin{array}{c}\text { Sat. } \\
\text { Night } \\
\text { Sites }\end{array}$ \\
\hline 1 & $10 / 88$ & 7 & 118 & 7 & 11 & 0 & 0 & 2 & 0 \\
\hline 2 & $6 / 89$ & 8 & 146 & 6 & 11 & 1 & 1 & 2 & 2 \\
\hline 3 & $8 / 89$ & 7 & 92 & 6 & 7 & 1 & 1 & 2 & 0 \\
\hline \multicolumn{2}{|c|}{ Totals } & 22 & 356 & 19 & 29 & 2 & 2 & 6 & 2 \\
\hline
\end{tabular}




\section{RESULTS}

The results of the data collection effort are presented in Tables 2 and 3 . Table 2 summarizes the number of operators surveyed and the breakdown according to the success of the interview and the test. Three hundred fifty-seven boaters were approached; one refused the interview, 28 refused to take the BAC test. Of those who agreed to the breath test, nine provided unusable samples. The unusable samples appeared to be related to equipment or procedural problems. There were consequently 319 good tests.

The 319 good tests are distributed in BAC as shown in Table 3: 244 boaters showed zero BAC. Of the 75 with a BAC greater than zero, 35 had BAC's greater than or equal to $.04,12$ had BAC's greater than or equal to .08 and 9 had BAC's greater than or equal to .10 .

\section{Table 2. Summary of Number of Boat Operators Surveyed and Tested (California 1988-1989)}

\begin{tabular}{|c|c|c|c|c|}
\hline $\begin{array}{c}\text { Total Boat } \\
\text { Operators }\end{array}$ & $\begin{array}{c}\text { Refused } \\
\text { Interview }\end{array}$ & Refused Test & Bad Test & Good Test \\
\hline 357 & 1 & 28 & 9 & 319 \\
\hline
\end{tabular}

Table 3. Summary of Operator Exposure Data (California 1988-1989)

\begin{tabular}{|c|c|c|c|c|}
\hline Zero BAC & BAC $>0$ & BAC $\geq .04$ & BAC $\geq .08$ & BAC $\geq .10$ \\
\hline 244 & 75 & 35 & 12 & 9 \\
\hline
\end{tabular}

Appendix B lists the complete data base. It presents the BAC related to the characteristics of the boat operators, their passengers, boats, and trips.

In addition to the BAC distribution of the exposure sample (those boat operators interviewed and tested in the course of collecting data during the three units in California) the relative risk calculation requires information on the BAC distribution of boating fatalities. A listing of cases from a data base of California boating fatalities from 1984 and 1985 with known BAC is given in Appendix C. Data on operator fatalities will be used in the current study, and that information is briefly summarized in Table 4 . 
Table 4. Summary of Operator Fatality Data (California 1984-1985)

\begin{tabular}{|c|c|c|c|c|c|c|}
\hline Total & Unknown & Good Test & Zero BAC & BAC $>0$ & BAC $\geq .04$ & BAC $\geq .10$ \\
\hline 70 & 17 & 53 & 28 & 25 & 18 & 11 \\
\hline
\end{tabular}

Figure 1 shows the observed cumulative distributions of BAC for three populations.

1. The boat operators tested during the data collection ( 319 observations). This distribution is indicated by small squares.

2. Boat operators killed in fatal boating accidents in California in 1984 and 1985 for whom there was a BAC determination (cases indicated by a downward pointing triangle).

3. Boaters (operators and passengers) killed in fatal boating accidents in California in 1984 and 1985 for whom there was a BAC determination (cases indicated by upward pointing triangle).

Figure 2 is essentially the previous plot turned upside down for ease in visualizing and explaining the relative risk calculations. The lower plot in Figure 2 labelled by small squares shows the percent of boat operators (survey sample) with BACs above a given amount. For example, it is seen that about $23 \%$ of the survey sample had BACs over zero while somewhat under $10 \%$ of these subjects had BACs over .05 .

From Figure 2 it can be seen that all boaters and boat operators in the fatality data had very close to the same BAC distribution while boat operators in the survey sample had relatively much smaller numbers at the higher BACs (For example, for the fatal accident sample about $20 \%$ of the boaters, whether operators or passengers, had BACs over .1 while for the survey sample less than $3 \%$ of boaters had BACs over .1).

Since at low BACs a given fraction of survey boaters corresponds to a relatively small fraction of the fatal accident boaters while at high BACs a given fraction of survey boaters corresponds to a relatively large fraction of fatal accident boaters, it appears that the chances of being killed in a boat outing goes up with BAC. In the next section we consider estimates of the relative risk of fatality due to alcohol impairment which quantifies this observation. At the same time the factors which could bias our estimate of this relative risk are also considered and their effect is estimated in a later section. 


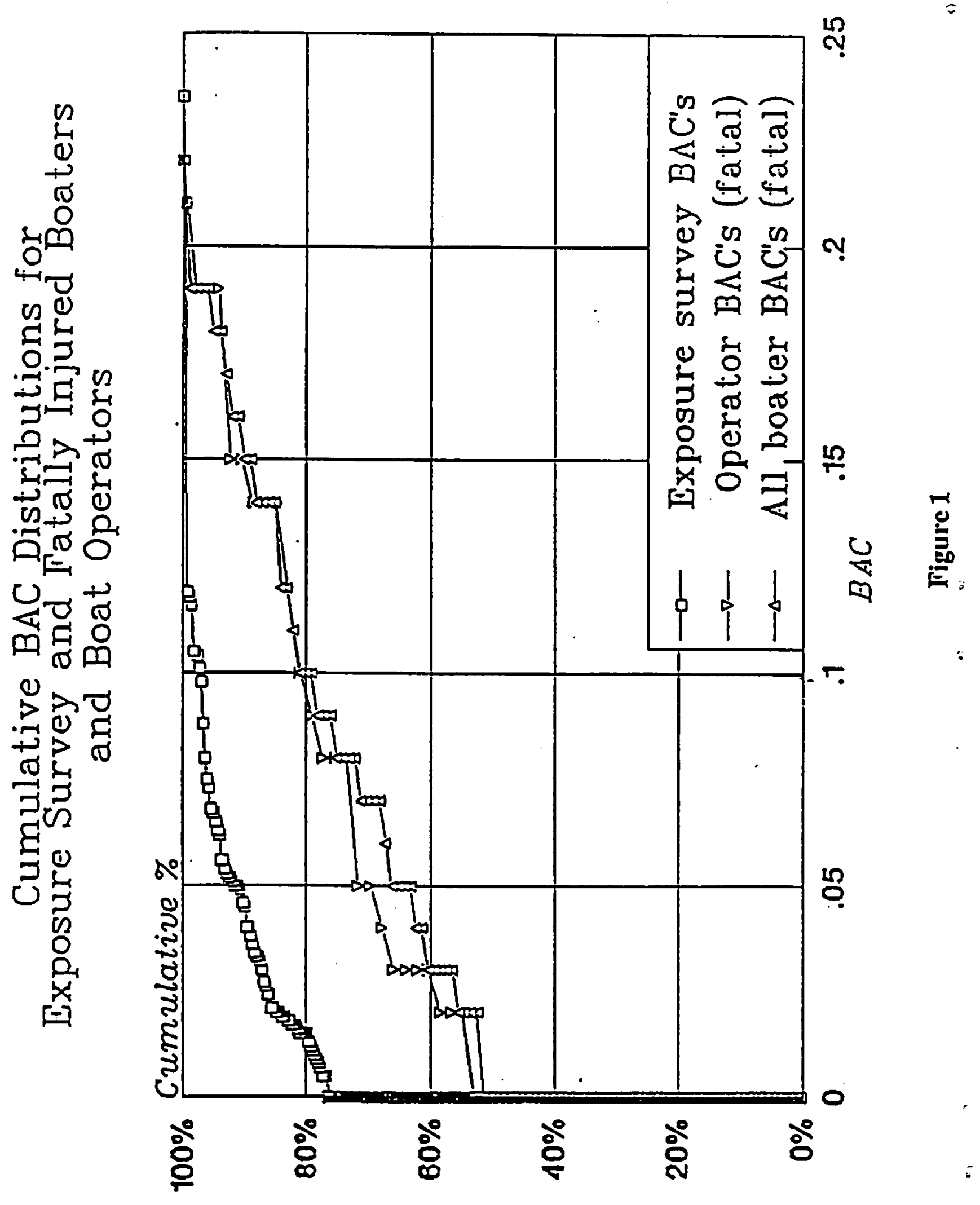




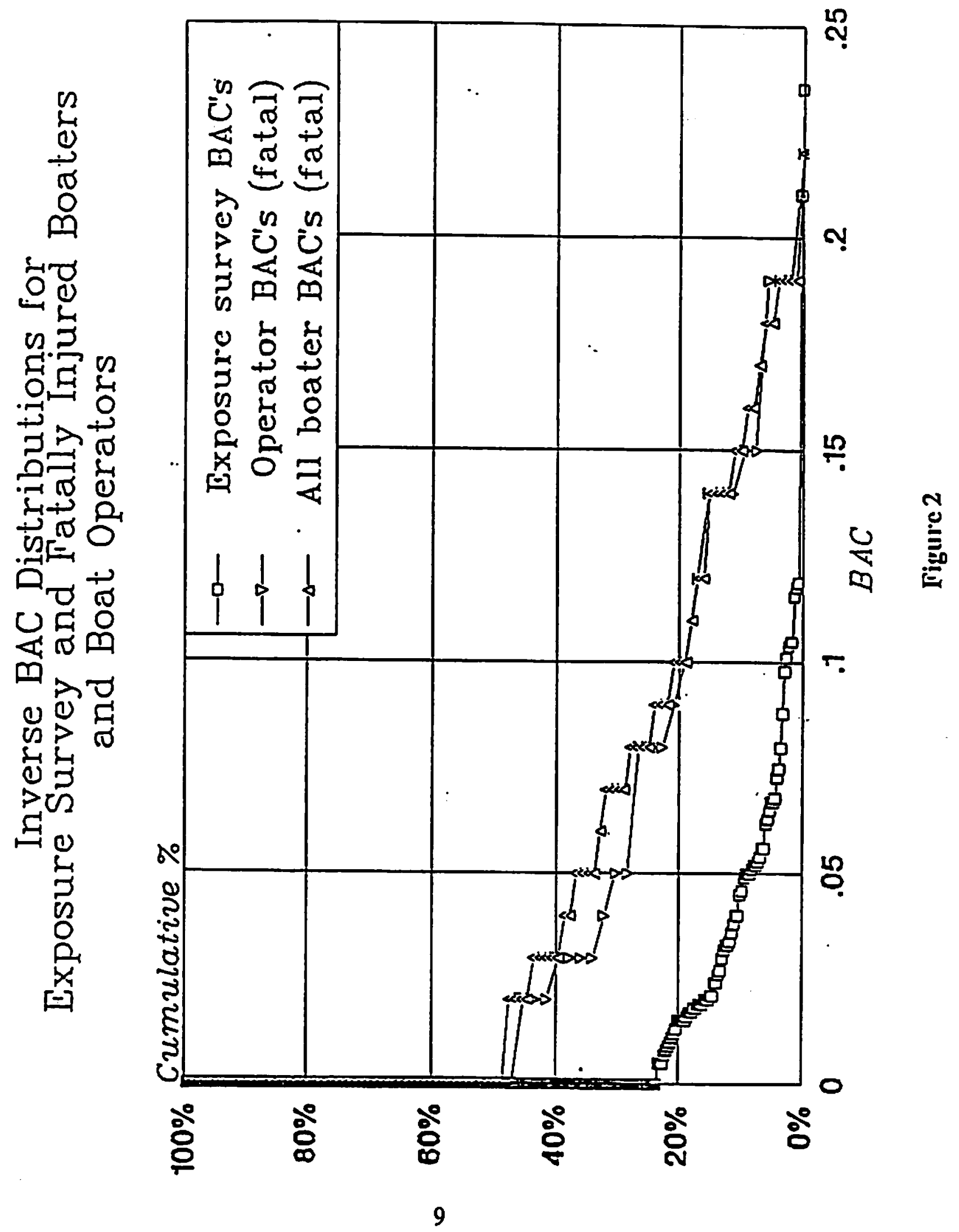




\section{RELATIVE RISK}

The relative risk for boat operators for BAC over .1 compared to the risk for BAC equal to = zero is defined as follows:

$$
R=\frac{(\text { Fatalities } \geq .10) /(\text { Exposure } \geq .10)}{(\text { Fatalities zero } B A C) /(\text { Exposure zero } B A C)}
$$

"Fatalities $\geq .10$ " means the number of boat operators with BAC's greater than or equal to .10 in the fatality data set. "Exposure $\geq .10$ " means the number of boat operators with BAC's greater than or equal to .10 in the exposure data set (the whole survey data set). "Fatalities zero $B A C$ " and "Exposure zero BAC" are defined similarly. These four quantities will be abreviated $F_{Z .1}, E_{z_{1.1}}, F_{O}$, and $E_{o}$ respectively.

If we plug into this formula the appropriate entries from Tables 3 and 4 for California boat operators the result is:

$$
R=\frac{(11 / 9)}{(28 / 244)}=10.65
$$

This is to be interpreted as meaning that our best estimate is that boat operators with BAC's at or over .10 are about ten and a half times as likely (per outing) to die in a fatal boating accident as boat operators with zero BAC.

Note that the ratio in the numerator of $R$ i.e. (Fatalities $\geq .10$ ) / (Exposure $\geq .10$ ) would be a fatality rate for boat operators with BAC $\geq .10$ if the exposure were measured over the entire population of boat operators whose fatalities are included. The same holds true of the denominator. The entire population in either case is based on the entire boating population of California. The exposures as measured here are a sample of the total exposure. Therefore the numerator and denominator are both estimates of quantities proportional to the corresponding fatality rates. The constants of proportionality should be the same and cancel. Therefore $\mathbf{R}$ should be an estimate of risk defined as the ratio of fatality rates for drunk compared to sober.

The rest of this report will be primarily concerned with assessing the accuracy of this estimate. Specifically we shall address the statistical stability and bias (if any) of the estimate. 


\section{STATISTICAL STABILITY}

There are two aspects of statistical stability in this estimate: Site to site variation and the variation due to the small numbers of accident victims and of exposure subjects.

In this study, site to site variation will be discussed under possible sources of bias. (Since we have 20 sites, if they are representatively chosen, site variability should have a small effect on the result).

The statistical variation in the relative risk due to the finite numbers of observations is readily estimated. Consider first the formula for relative risk and its (natural) logarithm:

$$
\begin{aligned}
& R=\frac{\left(F_{Z_{.1}} / E_{Z_{.1}}\right)}{\left(F_{0} / E_{o}\right)} \\
& \log R=\log F_{Z_{.1}}-\log E_{Z_{.1}}-\log F_{o}+\log E_{o}
\end{aligned}
$$

Each of the numbers $F_{\geq .1}, E_{\geq .1}, F_{0}$, and $E_{o}$ should be approximately independent and Poisson distributed ${ }^{1}$. If $\mathrm{N}$ is Poisson distributed and large (much larger than one) then the variance in $\log N$ can be estimated by $1 / N^{2}$ Consequently, the variance in $\log R$ can be estimated by

$$
\hat{v a r}(\log R)=\frac{1}{F_{\geq_{.1}}}+\frac{1}{E_{\geq_{1}}}+\frac{1}{F_{0}}+\frac{1}{E_{0}}
$$

and the standard error in $\log R$ is estimated as

$$
\hat{s e}(\log R)=\left[\frac{1}{F_{\geq_{1}}}+\frac{1}{E \geq_{.1}}+\frac{1}{F_{o}}+\frac{1}{E_{o}}\right]^{1 / 2}
$$

Substituting the appropriate values into the above formula produces an estimate of the standard error of .491765 .

Then a lower $95 \%$ confidence limit for $\log \mathrm{R}$ is approximately

$$
\log R_{\text {true }} \geq \log R_{\text {est }}-1.645 \hat{\text { se }}\left(\log R_{\text {est }}\right)
$$

1 The arrival of boaters to be interviewed and the occurrence of accidents (in any fixed category) are both of the nature of "arrival" processes which are generally considered to be Poisson (or "completely random") processes unless there is evidence to the contrary (such as evidence of bunching). See Feller (1966) p. 11 and Doob (1953) p. 98.

2 N represents any integer random variable and so this statement is true of $F_{21}, E_{21}, F_{0}$ and $E_{0}$ to the extent that they are much greater than one and Poisson distributed. 
or

$$
R_{\text {true }} \geq R_{\text {est }} \exp \left[-1.645 \hat{s e}\left(\log R_{\text {est }}\right)\right] \text {. }
$$

Since $R_{\text {est }}=10.65$ and $\hat{s e}\left(\log R_{\text {est }}\right)=.491765$, this means that with $95 \%$ confidence we can assert that the true value of $R$ is greater than 4.74. In other words 4.74 is a lower $95 \%$ confidence limit on Rtrue 3 .

Of course the most likely value from this point of view is still 10.65 and the true value is as likely to be higher than as lower than 10.65 . This analysis ignores bias which will be dealt with in the next section.

3 For the most part this report does not distinguish between $\mathbf{R}_{\text {true }}$ which is the overall true relative risk and Rest based only on the data analyzed here. Only in this section are the two quantities distinguished by notation in order to express the confidence limits for $R_{\text {inue. }}$ 


\section{BIAS}

There are a number of possible sources of bias to the relative risk calculated above:

1. Those who refused the breath test might have had a different BAC distribution from those who took the test.

2. There could be insufficient night exposure data.

3. The sites might possibly be unrepresentative.

In discussing the possible sources of bias particular attention will be paid to estimating how much a particular source could have lead to an overestimate of the relative risk and where possible a lower bound to the relative risk in the face of the particular source of possible bias will be considered. ${ }^{4}$

\section{Possible bias in the Relative Risk Estimate due to a Different BAC Distribution for Those 28 Boat Operators Who Refused the Breath Test.}

It is necessary to make some assumption about the BAC distribution of those who refused to take the breath test. We prefer to make a conservative assumption in the sense that it is likely to overestimate the number of boat operators above a given BAC and therefore leads to a relative risk which is underestimated, i.e., again we seek a lower bound on the relative risk.

Two different assumptions will be considered leading to two different estimates of the relative risk. It is suggested that both of these may be considered conservative. In the first assumption we make use of observational data that the observers recorded for those operators refusing the breath test. They coded their judgment based on interview and observation of the subject as a rating of 1,2 or 3 as follows:

\section{Intoxication Ratings:}

1. No indication of alcohol impairment.

2. Person not likely impaired by alcohol.

4 There are many sources which could potentially reduce the accuracy of our estimates of risk. For instance, while all BAC measurements were made at the end of the boat operator's trip, it was impossible to determine the exact timing of the drinking. It was assumed that the BAC measured was a valid estimate of the level of intoxication during the trip. This procedure would result in an underestimate of intoxication only if the boat operator ceased drinking hours before returning to shore. Because that is unlikely, this procedure should either accurately represent the operator's BAC or overestimate it. An overestimation of BAC would lead to a conservative estimate (i.e., an underestimate.) of risk. 
3. Possible that person was impaired by alcohol.

The conservative assumption, assumption 1, to be made is that all (not tested) boat opera- " tors, except those showing no indication of alcohol impairment (category 1), are to be categorized as having BAC over .1.

The observational judgments concerning the sobriety of the BAC non-participants (individuals who were interviewed but would not take the BAC test) were not available for the first unit. In the first unit there were $10 \mathrm{BAC}$ non-participants. We assumed that the distribution of ratings obtained for the second and third units hold in the first unit as well. Of the 18 interviewees who refused the breath test for the second and third units the observations were:

- 16 were given a rating of 1

- 2 were given a rating of 2

- None were given a rating of 3

By our assumption the fraction of BAC non-participants at .1 or above is the fraction rated 2 or 3 i.e., $2 / 18=.111$. It was more difficult but less important ${ }^{5}$ to decide what fraction of the 16 below .1 BAC was at zero. An arbitrary assumption was that $1 / 2$ (ie. 8 of 16) were at zero and the other $1 / 2$ ( 8 of 16) were between zero and .1. Notice in Table 3 that there were 244 at zero and 66 between zero and .1. Therefore the assumption is conservative because it claims that only $50 \%$ of those who were below .1 were at zero versus $80 \%$ in Table 3. So of the 18 refusals for which observational judgments are available, 2 are assumed to be above .1 and 8 are assumed to be at zero. Inflating these estimates to the 28 total refusals implies that 3 are assumed to be above .1 and 12 are assumed to be at zero.

If we combine the results with the known data for the tested subjects we get a new expanded set of complete data from which we get a new value of the relative risk (for BAC at .1 or higher).

$$
R=\frac{11 /(9+3)}{28 /(244+12)}=8.38
$$

To summarize and simplify: suppose that all (3) non-participants not certified as sober are to be treated as intoxicated (assumption 1). Then relative risk $=8.38$.

5 Estimation of the number of interviewees who were intoxicated was more critical than estimation of the number who were at zero BAC because the intoxicated interviewees represented a very small portion of the total sample. 
For assumption 2 we assume that half of all those who refuse the test are intoxicated (i.e., at $.10 \mathrm{BAC}$ or higher). This is a very conservative assumption because there are numerous legitimate reasons sober people would refuse the test. Recall also that less than $3 \%$ of those who took the test were over .1 and that over $92 \%$ of the people took the BAC test. If $1 / 2$ of the refusing people refused because they were unwilling to reveal a high BAC this would mean that only $4 \%$ refused for all other reasons - a very small percentage. Therefore, we consider this assumption very conservative. To increase the conservativeness (i.e., further lower the relative risk estimate) we assume that all those who refused the test had BACs above zero. With these assumptions we get a modified estimate of the relative risk:

$$
R=\frac{11 /(9+14)}{28 /(244+0)}=4.17
$$

The distortion implied by assumption 2 almost surely goes too far. This is not to say that the relative risk cannot be this low since there are other possible biases and the statistical stability issue which also affect the true value of relative risk. It is only to say that the correction for this type of bias is probably excessive in this estimate.

\section{Possible Bias Due to Insufficient Night Exposure}

Another possible source of bias is insufficient night testing, i.e., there may be more boating at night than represented in our exposure sample.

In the exposure data there were 28 breath tests taken at night and 319-28 $=291$ breath tests during the day. In the boat operator fatalities there are 11 in the night period and 43 in the day period. Therefore the ratio of night to day samples is $28 / 291=.0962$ for the exposure data and $11 / 43=.256$ for the boat operator fatality data. For this purpose define day as the time period 0700 to 1859 and other times as night.

There are two possible reasons for the difference between these ratios:

- The true nighttime exposure may be higher relative to daytime exposure than we have measured (i.e. the night period was undersampled),

- The difference is appropriate: fatality data should show more cases than the exposure data since nighttime boating is inherently more dangerous.

In order to bound the possible bias that may be present in our relative risk estimate due to possible under-sampling at night we develop separate weights for the day and night exposure data.

Let the weight for the day exposure data be $W_{d}$ and that for the night exposure data be $W_{n}$. Since the ratio of night to day cases is .256 for the fatality data and .0962 for the exposure data we require that $\mathrm{W}_{\mathrm{n}} / \mathrm{W}_{\mathrm{d}}=.256 / .0962=2.66$. 
This will bring the exposure data in line with the accident data in the ratio of day to night quantity of data. We can choose $W_{d}=1$ and $W_{n}=2.66$ because the relative risk is not affected by an overall normalization of the exposure data. In order to calculate the relative risk the following numbers are relevant:

Total Exposure Sample at Zero BAC Tested After 19:00 $=20$

Total Exposure Sample at or Over .1 BAC Tested After 19:00 = 3

Total Exposure Sample at Zero BAC Before 19:00 = 224

Total Exposure Sample At Or Over .1 BAC Tested Before 19:00 $=6$

Therefore the relative risk with this type of correction is estimated as:

$$
R=\frac{\left(F_{Z_{1}} / E_{Z_{.1}}\right)}{F_{0} / E_{0}} \quad \text { with } F_{Z_{.1}}=11, F_{0}=28
$$

as before but for $E_{z_{.1}}$ and $E_{o}$ we use the following modified values (only the ratio is intended to be approximately correct).

$$
\begin{aligned}
& E_{Z_{.1}}=3 W_{n}+6=13.98 \\
& E_{o}=20 W_{n}+224=277.2
\end{aligned}
$$

so $\mathrm{R}=7.790$.

If the nighttime exposure is undersampled by a factor of 2.66 as estimated by the nighttime proportion of fatalities, then this estimate may be more accurate than the original unmodified estimate for this relative risk. However, if nighttime boating is more dangerous in itself than daytime boating, then the nighttime exposure may not be under-estimated so much and a value nearer the original 10.65 would be preferred.

\section{Possible Bias Due to Unrepresentative Sites}

There could be some concern that the sites were somehow not representative. The sites were all chosen to correspond to accidents in the accident data base. There is no reason to believe they are generally low BAC sites. The BAC values for the accident corresponding to each site is available only for units 2 and 3 . In those units, seven of the fifteen sites corresponded to operator fatalities with a BAC of .10 or higher. This is in contrast to the proportion of all operator fatalities in our database which have BACs over .10. This proportion is .20 (based on the known BACs). Thus the proportion of sites corresponding to BACs over .1 is really quite large $(7 / 15=.467$ compared to .2 for the accident sites). This suggests that if the sites are unrepresentative then they are biased towards high alcohol sites. Therefore, we need not calculate a lower bound on the relative risk due to possible bias in site selection - the unadjusted value 10.65 serves this purpose. 


\section{RELATIVE RISKS AT OTHER BAC LEVELS}

So far we have concentrated on calculating relative risk for BAC greater than or equal to .10 compared to BAC equal to zero. Because of the small accident sample and exposure sample it is necessary to compute relative risk for intervals which extend over all BACs higher than a certain level. However, this level can be changed.

Computed relative risks at various levels are plotted in Figure 3. The plotted points have a $B A C$ value as the abscissa and the estimated relative risk for $B A C$ at or over that value (compared to zero BAC) as the ordinate. The estimates become very noisy over a BAC level of .12 (because of small numbers). The plotted curve is only for convenience and is not to be taken as having a precision independent of the plotted points.

Since the cases of BAC above one level are also above any lower level the statistical stability of these estimates is decreasing. In particular the estimates of relative risk at very high BACs (.12 and above) are based on few cases and are therefore potentially quite inaccurate. 


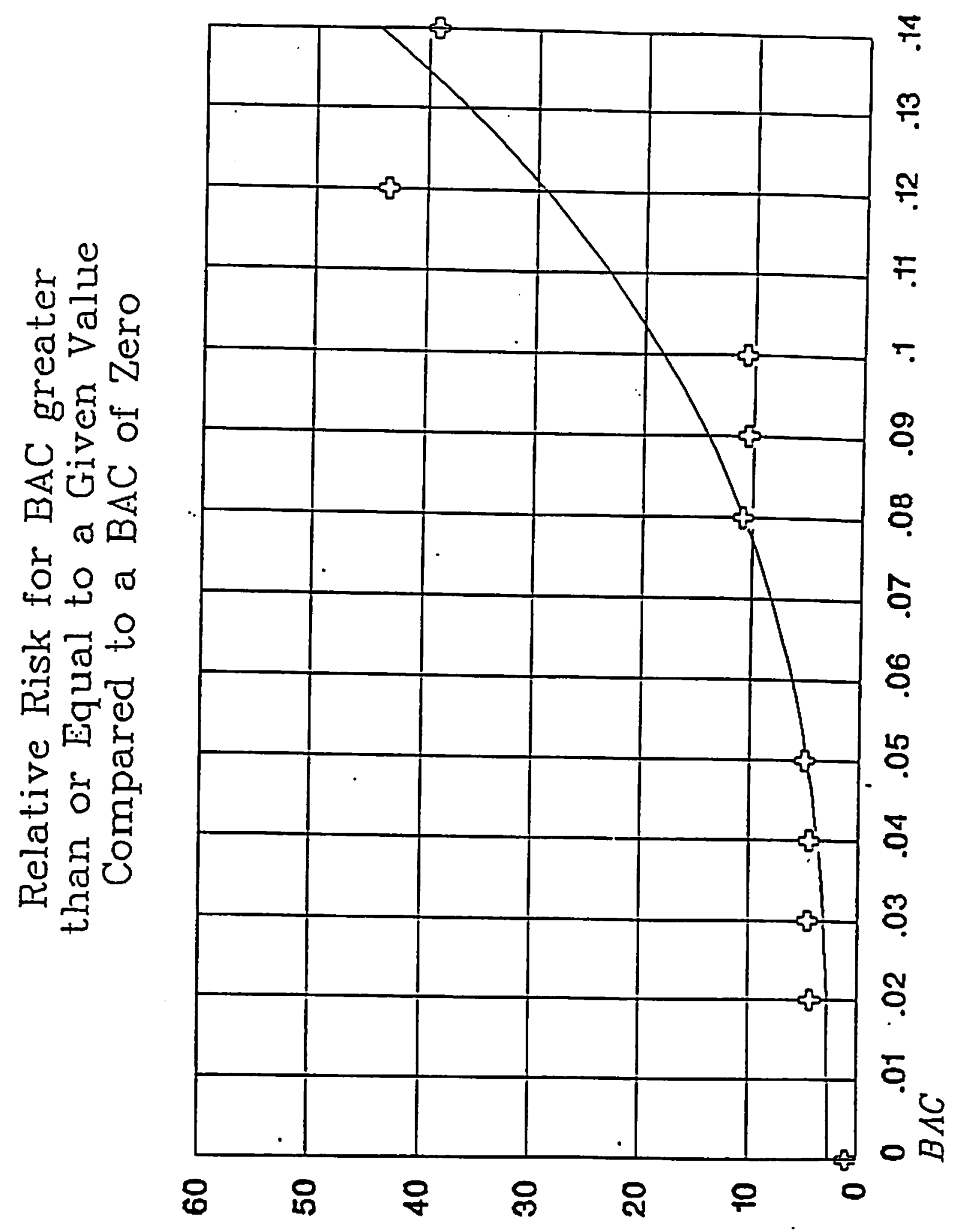

xร?บ an?7गาay 


\section{COMPARISON WITH HIGHWAY AND PEDESTRIAN RESEARCH}

Borkenstein et al (Reference 2) studied the relative risk of intoxication for highway accidents. Although their results are primarily shown in different ways than employed here they may nevertheless be expressed as relative risks of the same type as calculated in this report and as such are shown in Table 5. The relative risk for BAC $\geq .10$ is comparable to that calculated in this report for the boating environment (i.e., 8.80 versus 10.65). For $B A C \geq .12$ or BAC $\geq .15$ the agreement is not so good (cf. Figure 3 ).

One reason the estimated risk for the boating environment is much larger than that for the highway environment for certain high ranges of $\operatorname{BAC}(\geq .12)$ could be that the boating environment is especially dangerous to persons with a high level of intoxication. A second reason for the difference could be the very small numbers of boaters surveyed who had very high BACs, resulting in a relatively statistically unstable samples for very high BACs.

Table 5. Highway Risk (based on Borkenstein, et al. p. 230)

\begin{tabular}{|c|c|c|c|}
\hline BAC Range & $\geq .10$ & $\geq .12$ & $\geq .15$ \\
\hline Relative Risk & 8.80 & 10.42 & 18.46 \\
\hline
\end{tabular}

A study conducted by Dunlap Inc. for the National Highway Traffic Safety Administration (NHTSA) (Reference 3) studied the relative risk of alcohol intoxication for pedestrians. Their study used site matching similar to Borkenstein's and to a lesser degree to ours (because of the nature of boating accidents they do not have such precisely defined sites as highway accidents). In addition the Dunlap study also considered age and sex matching (this was not considered in the present study because the exposure sample was not large enough). The relative risks for certain ranges of BACs with and without age/sex matching is shown in Table 6. The basic observation is that the relative risks appear to be smaller than in the boating $^{6}$ environment and this may be due to the nature of pedestrian injury accidents compared to fatal boating accidents or it may be due to the statistically unstable nature of the boating risk data at the higher BACs.

6 For example the pedestrian risk exceeds 10 only above .25 compared to above .1 in the boating data. 
Table 6. Pedestrian Risk (NHTSA / Dunlap p. 71)

\begin{tabular}{|c|c|c|c|c|}
\hline BAC Range & $.100-.149$ & $.150-.199$ & $.200-.249$ & $.250+$ \\
\hline $\begin{array}{c}\text { Age / Sex / Site } \\
\text { Matched }\end{array}$ & 1.72 & 2.12 & 5.19 & 37.86 \\
\hline Site Matched & 2.79 & 5.11 & 9.04 & 11.25 \\
\hline
\end{tabular}




\section{SUMMARY AND CONCLUSION}

Based on boating fatality BAC data from California for the years 1984-1985 and a survey of recreational boat operators' BACs conducted at 21 sites in California, relative risks of fatality as a function of BAC were computed.

- The best estimate of relative risk of a boating fatality for a BAC of .10 or higher, compared to a BAC of zero, is 10.65 .

- Assuming Poisson distributions for the data, the lower bound estimate (95\% confidence) is 4.74 .

Simplifying assumptions (see Section 8 for details) were made to adjust for the following potential sources of bias; these adjustments provide lower bound estimates of relative risk.

- If the non-participants had higher BACs than the boat operators providing samples the adjusted relative risk would be 8.38 (Section 8.1).

- If insufficent night data were collected, the adjusted relative risk would be 7.79 (Section 8.2)

One potential unadjusted source of bias which may have affected the risk estimate is site selection.

- If the sites selected had higher BACs than average sites (and Section 8.3 shows that the victim BACs tended to be high at the selected sites) the relative risk would actually be higher than calculated.

Compared to the highway situation, relative risk for BACs over .10 compared to zero BAC are about the same if one uses the Borkenstein (Reference 2) data. At higher BACs the present data suggest that the relative risk in the boating context may go up even more rapidly than in the highway context. Relative risks for higher values of BAC are estimated to be larger but are more uncertain because of limited data above .10 (especially the exposure data). 


\section{RECOMMENDATIONS}

The recommendations provided below are based on both the results of this study and a previous study which was concerned with boating fatality data specifically. (The previous study is Reference 1 which resulted from the first part of this project.)

State and local governments should be encouraged to develop and conduct intervention and counter-measure programs to reduce the number of fatalities associated with operating recreational boats while intoxicated.

The results of this project indicate that a recreational boat operator with a BAC in excess of $0.10 \%$, has a fatality risk ten times that of a sober operator.

The effectiveness of these countermeasures and interventions should be measured. This will require more complete collection of boating fatality data.

Complete and unbiased fatality data is critical to any state or other government agency that wishes to measure the effectiveness of its intervention. When the first part of this study was performed, only two states collected blood alcohol data which was useable for assessment of the impact of intoxication on boating fatalities.

Alcohol countermeasure programs should not ignore situations which appear to be relatively benign for boaters who are not intoxicated.

In the first part of this project we found that disproportionatly large numbers of intoxicated boaters as compared to sober boaters died in what should be relatively safe conditions, i.e., in calm protected water as opposed to rough unprotected water, due to simply falling overboard as opposed to collisions or capsizings, and where there were other passengers in the boat who should have been able to provide aid.

It is important to make the public aware that these kinds of apparently innocuous situations can be very dangerous to the intoxicated boater. 


\section{APPENDIX A}

This appendix consists of two memoranda written by Robert G. Ulmer of Dunlap and Associates Inc. The first gives a detailed description of the second unit of data collection (in June of 1989) and the second gives a similar description of the third unit (in August of 1989). These memoranda contain detailed information on site selection, site description and data collection procedures.

The sites visited during unit 1 (not covered in the succeeding memos) were as follows (also indicated are date in 1989 and abbreviation used in Appendix B):

\begin{tabular}{|c|c|c|}
\hline Abbreviation & Site & Date \\
\hline DB & Discovery Bay & $6 / 16$ \\
\hline BI & Brannan Island & $6 / 17$ \\
\hline L & Laritzen's Yacht Harbor & $6 / 18$ \\
\hline DR & Delta Resort & $6 / 19$ \\
\hline MC & Lake McClure & $6 / 21$ \\
\hline M & Milleston & $6 / 22$ \\
\hline E & Lake Elsinore & $6 / 24$ \\
\hline P & Lake Perris & $6 / 25$ \\
\hline
\end{tabular}


July 19,1989

Memorandum

To: Peter Mengert, Transportation Systems Center

From: Robert G. Ulmer, Dunlap and Associates, Inc.

Subject: Alcohol and Boating Safety Data Collection, June 16 - June 25, 1989

During the latter part of June 1989, R. Ulmer and C. Preusser from Dunlap and Associates were on site in California to collect additional data for the Transportation Systems Center (TSC)/Coast Guard study of alcohol use among recreational boaters. Basically, the data collection activity involved interviewing recreational boaters and obtaining breath tests to determine Blood Alcohol Concentrations (BACs). The purpose of this memorandum is to describe this effort in terms of the procedures employed and the results obtained.

\section{Site Selection}

Inherent in the overall study design, is the adoption of a sampling plan calling for data collection to take place at bodies of water that have experienced (or are similar to those that have experjenced) fatal boating accidents in which the BACs of the victims are known. Other stated requirements for establishing the sampling plan are:

- Collection of data on weekends at sites where the associated accident occurred on a weekend, and during weekdays at sites where the accident occurred on a weekday.

- Collection of data primarily in the hours during which the associated accident occurred. Also, the extension of data collection into the later night hours so that this time period is represented.

- Employing an approximately equivalent number of sites where the associated accident did or did not involve alcohol use.

- Avoiding sites related to "Open" ocean accidents.

- Collection of data at launch ramps, marinas and other on-shore facilities so that various power boat types, sizes and use pattern are covered."

Site selection was based on a listing of fatal boating accidents provided by TSC. This listing is shown in Table 1. The site selection process began by developing various tentative schedules which met the requirements noted above and were feasible in terms of uravel distances.

- During early stages of the study, on-the-water testing was considered. Because of cost, Jogistical and other considerations, and the likely low sample sizes that would be obrained, this approach to daca collection was abandoned. 
Table 1

California Boating Fatalities

Input Data

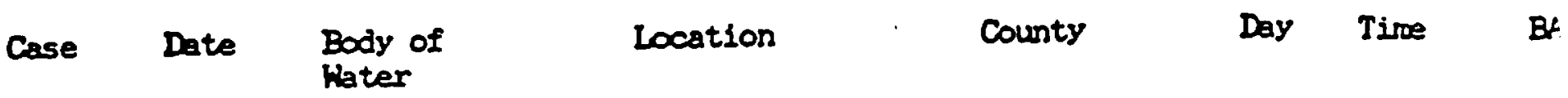

Operators

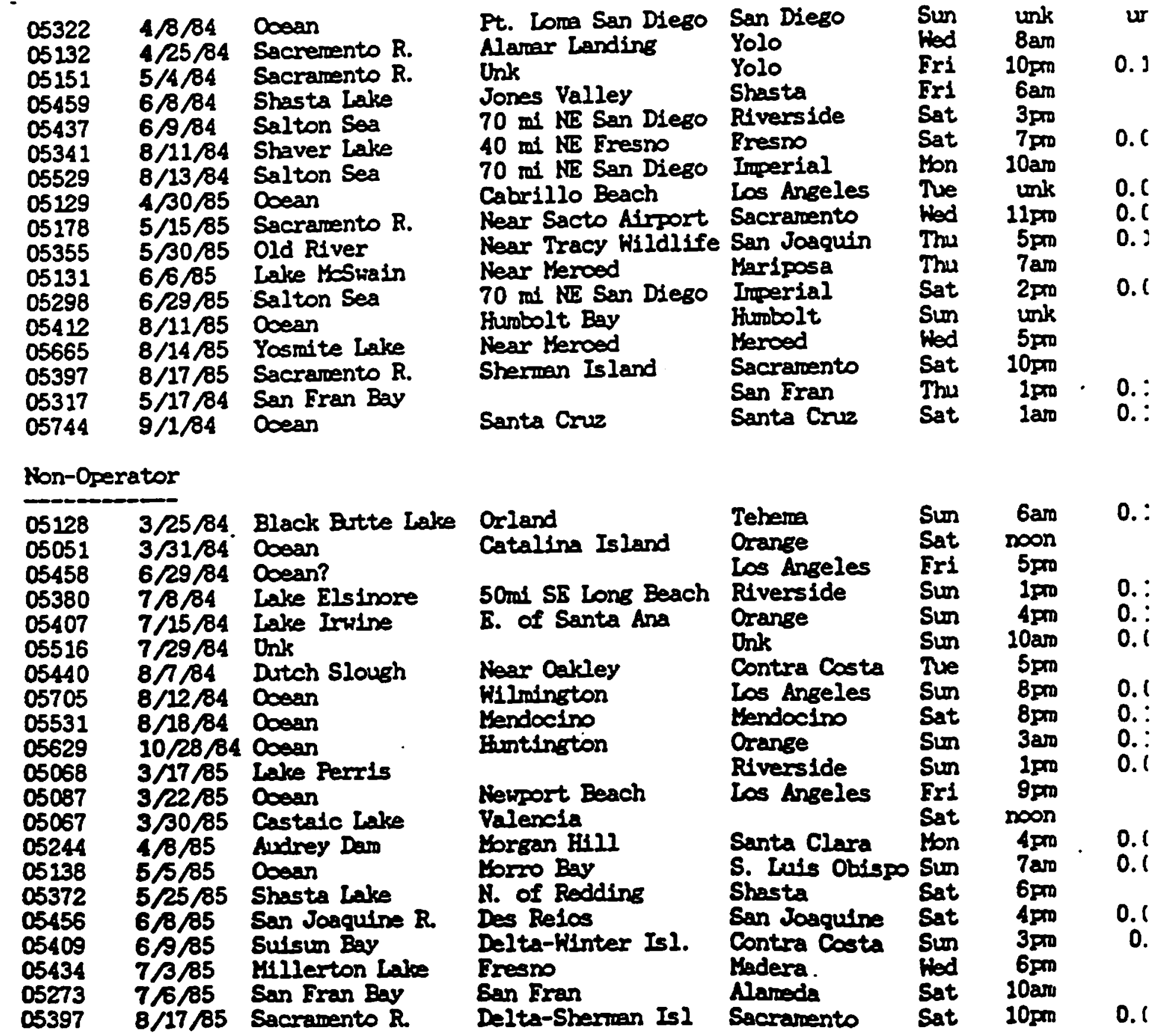


As in the fall 1988 data collection, telephone contacts were then made with officials in the counties in which the various bodies of water were located. This process. usually began with the County Sheriffs Department where we spoke with someone knowledgeable (e.8., a boating enforcement officer) regarding the possible use of the body of water for data collection purposes. Recommendations concerning specific collection sites, referrals to persons directly involved with the body of water, and in some cases, recommendations against particular sites resulted from these contacts. Further contacts were then made to obtain specific approvals to use various public and private facilities. As was the case last fall, we found that all of the individuals contacted were extremely interested in the study and willing to cooperate.

\section{Schedule}

Table 2 indicates the data collection schedule that was employed. The entries in each cell of the table are as follows:

- The date of data collection

- The TSC case number

- The body of water at which sampling occurred

- The day of week and time of day of the associated accident

- The BAC of the accident victim

- The name or type of facility involved

- Whether data collection was at a marina/ramp type of facility or a ramp (only) facility

- The approximate time period of the data collection

- The number of interviews/the number of breath tests obtained

Data collection on Friday, June 16th took place at Discovery Bay Yacht Club. Discovery Bay is a relatively large, designed residential area approximately 15 miles west of Stockton in the Delta region. Many of the homes have backyard docks for boat mooring. In addition, the yacht club has moorings for larger vessels and dry storage for smaller boats. Hoists are used to launch and retrieve these latter boats when the owners wish 80 use them. There is also a public launch ramp but the launch fees have been set at 530 and outside use is minimal, therefore. The chanbel from the yacht club leads to the Old River, which was the site of the associated accident. Discovery Bay was recommended to us by Sgt. Jim Wood of the San Joaquin County Sherifr's Department. Richard Zaro, the Harbor Master, granted permission for use of the site. He indicated that on a Friday most of the traffic would be "after work" boating, so the hours of 2 - $8 \mathrm{pm}$ were selected for data collection. The data collection location was the marina's gas dock and we sought inbound traffic. The weather was suany and hot. Traffic volume was light and only 6 boaters were interviewed, with all providing a breath test.

On Saturday, June 17th, data collection took place at the Brannan Island State Recreation Area, which is located on the Sacramento River in the Delta region, approximately 10 miles northeast of Pittsburg. The site was known to us as it had been used in the fall 1988 data collection (but selected for a different accident). It was 
able 2

seplly Sctatele

\begin{tabular}{|c|c|c|c|c|c|c|}
\hline $\operatorname{sondy}$ & Iondy & resdy & wowdy & Dordes & Isldes & Siturdes \\
\hline & & & & $\cdot$ & 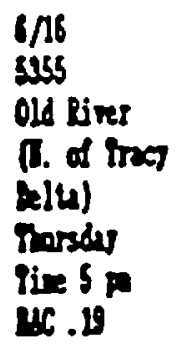 & 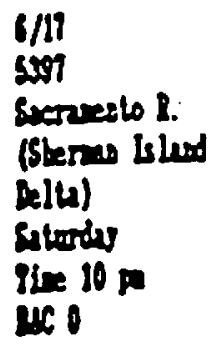 \\
\hline & & & & & $\begin{array}{l}\text { Deoren by } \\
\text { brin/rup } \\
\text { if } 8 \\
16\end{array}$ & 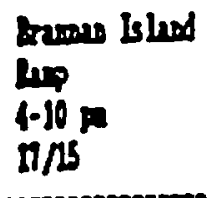 \\
\hline 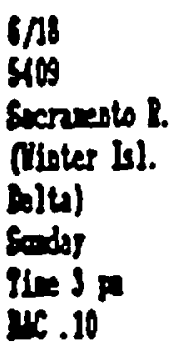 & 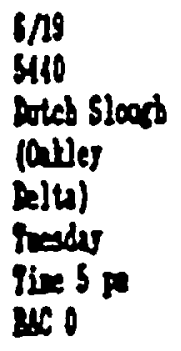 & ad $\cdot \operatorname{mn}]$ & 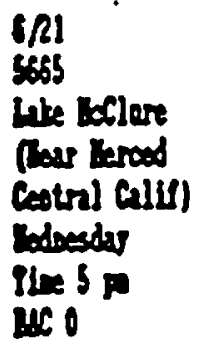 & 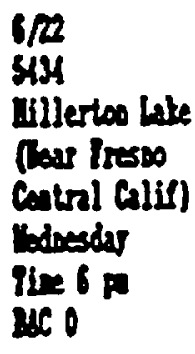 & ofl - inrel & 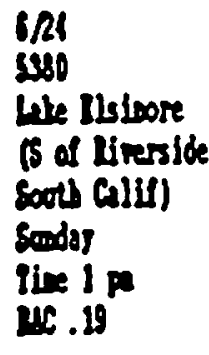 \\
\hline 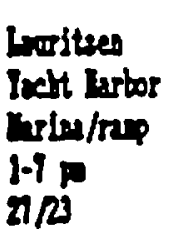 & 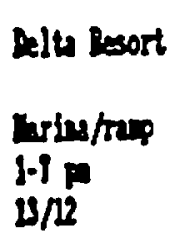 & & 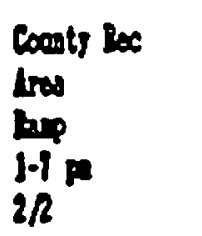 & 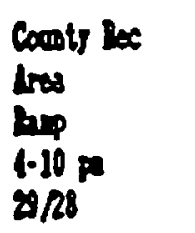 & & 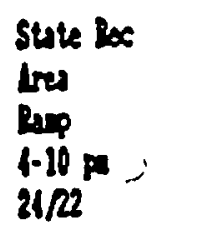 \\
\hline
\end{tabular}

$6 / 25$

401

Lite perris

(s) of liesside

coots callif)

cods

II $1 \mathrm{p}$

IC. 16

Ctale bx

tou

in

1-1 $\mathrm{P}$

$2 / 40$ 
chosen on the present occasion because of its proximity to its associated accident. The District Superibtendent for the Delta District, Susan Ross, granted permission 10 use the site. A dighttime collection period of $4-10 \mathrm{pm}$ was employed. The $10 \mathrm{pm}$ end time was chosen because the area closes at that hour. The test site was in a large parking lot Dear the facility's laupch ramp. The ramp area itself was wide and could accommodate at least six simultapeous boat launches or retrievals. The weather was clear and warm unlil sunset, when the temperature dropped considerably. A total of 17 interviews were completed and 15 breath tests were obtained. Virtually all of the boaters had left the area by sunset, so there were few contacts after dark. Only one boater was contacted between 7:45 and 10:00 pm (a BAC of .104 was later noted for this case).

Lauritzen's Yacht Harbor, located about midway between Antioch and Oakley, was the site of testing on Sunday, June 18th. The facility provides access to the junction of the Sacramento and San Joaquin Rivers. Sgt. Carpenter and Deputy Gray of the Codtra Costa Sheriffs Departmedt recommended the site as the most active marina type facility near the associated accideat. This was a private establishment with permission for use being granted by the owner, Chris Lauritzen. The facility proved to have covered moorings for those repting slips, as well as a for fee launch ramp with a two-boat capacity. Our collection sjte was located in a parking lot so that both types of uses could be covered. However, during the $1-7 \mathrm{pm}$ sampling period, no boats returned to moorings, and all contacts, therefore, were with those in-bound from the launch ramp. The weather was sunny and hot coupled with the aroma of a Dearby paper processing factory. Twenty seven interviews and 23 breath rests were obtained.

The accident which dictated site selection for Monday June 19th, occurred in Dutch Slough, which is part of the Delta waterways east of Oakley. Personnel from the Contra Costa Sheriff's Department recommended the Delta Resort as a busy facility serving both Dutch Slough and the Franks Tract Recreational Area. Delta Resort is a privately owned facility. Gay Salizar, the manager, granted permission for jts use. The facility proved to have a two-boat capacity launch ramp, some rental slips, dry storage and public moorings for those who wished to use the property's general store. Because of its layout, the site proved difficult to handle. Ultimately, the Intoxilyzer 5000 was located in an area where it was logical for boaters leaving the launch ramp to stop. As this location was not in view of the water, the study team sat at the head of the launch ramp so that we could observe its use along with activity at the docking area. The S-D2 portable breath tester (see below) was brought into play at this location, as it was unreasonable 10 expect boaters to walk from the dock area to the site of the Intoxilyzer. When a boater was about to trailer away from the launch ramp, the study team would leave its vantage point and move down a hill to the Intoxilyzer location and attempt to "intercept" the boating party. The Intoxilyzer was used in these instances, while the S-D2 tests came from the dock area. The weather was sunny, warm and very windy. Sampling took place between 1 and $7 \mathrm{pm}$, with 13 interviews and 12 breath tests being obrained.

Tuesday, Jupe 20 was a travel day as the team moved south from the Delta. The central valley of California and the Sierra Nevada foothills contain aumerous natural and man-made lakes that are used for recreation, irrigation and other water supply purposes. These lakes tend to be under the jurisdiction of regional water districts, or state or county recreational districts. The accident to be covered on Wednesday, June $2 /$ st occurred in Yosmite Lake near Merced. A Curt Royer of the patrol division of the Merced : County Parks and Recreation Department, indicated that the lake is small with little mid-week use. He suggested that a better site would be Lake McClure, a coupty operated recreational area located about 12 miles away. Bruce Irwin, the Park Manager granted 
permission for the site's use. On arrival, we learned that there were two possible launch ramps to use. Based on local advice, we chose the northern most of these. The location had a large paved parking area and a steep roadway about $1 / 4$ mile long down to the lake. About two-thirds of the way down, there was a turn arouod for boats and trailers and some hillside parking. We selected the paved parking lot as the collection site in the hope that most boaters would come all the way up the hill before stopping to attend to their rigs. The weather was sunny and hot with data collection taking place between 1 and $7 \mathrm{pm}$. The site proved to be a poor choice for study purposes. Only two interviews and two breath tests were obtained. Other boats left the area during this time. However, because of the site layout and distances involved, it was not possible so make contact with these boaters.

The data collection site on Thursday, June 22nd was Millerton Lake, a state recreation area located northeast Fresno. Steven Horvitz of the San Joaquin Valley District granted permission for use of the site. Sampling was carried out at the launch ramp between $3: 30$ - $10 \mathrm{pm}$ (the closiog hour of the facility). At the outset, the weather was sunny, with temperatures topping 105 degrees. After sunset, the temperature declined considerably. The collection location was in a parking lot near a very wide launch ramp area that could accommodate numerous boats simultaneously. A total of 29 interviews and 28 breath tests were obtained.

Friday, June 23rd was a travel day as we moved into southern California. Data collection on Saturday, June 24th took place at Lake Elsinore, located approximately 20 miles south of Riverside. Jack Roggenbuck, the Chief Ranger for this state recreation area granted permission for its use and the use of Lake Perris, the following day. Data collection took place neas the relatively wide launch ramp which was capable of handling at least six boats simultaneously. Collection commenced at $3 \mathrm{pm}$ and was to have continued until $10 \mathrm{pm}$, when the site closed. However, in the late afternoon, the winds became very strong, it turned quite cool and the lake water became rough. We were faced with a mass exodus of boaters until after $6 \mathrm{pm}$, by which time the parking area was deserted. Collection was terminated at this point, therefore. Twenty-four interviews and 22 breath rests were obtained.

The accideat related to data collection on Sunday, June 25th occurred in Lake Irwine which is located in Orange County east of Santa Ana. Personnel from the Orange County Sherifr's Department indicated that this is a private body of water used for irrigation purposes and has a small boat reatal concession. Based on this information, we substituted Lake Perris, located about 20 miles to the east, as the collection site. As just Doted, this lake is under the same jurisdiction as Lake Elsinore. The facility contains three virtually identical and side-by-side launch areas, each with its own ramp and parking lot areas. We set up in a driveway leading from the launch ramp to the parking lot as bosters were encouraged by signs to use this drive 10 stow gear after leaving the ramp. The start of data collection was delayed somewhat because of difficulty in finding our point of contact at the site. Data collection continued until approximately 7 pm, with 29 interviews and 26 breath tests obtained.

Daracollection

The basic data collection procedures involved a member of the study team approaching boaters and asking for their anonymous cooperation with a boating safety survey. At launch ramp facilities, this was done with boaters leaving the perticular body of water. Based on prior observations, most boaters who trailer, will load their boats 
onto the trailer at the ramp and then drive a short distance away to stow gear. The interviewer approached the boater at this point. At gasoline and other docks, in-bound boaters were approached once they had tied-up to the facility. At these latter facjlities, the operator of the boat was known and approached. At launch ramps, the interviewer sought out the person who had done the primary boat operating during the daj. No boster approached, refused to participate in the interview portion of data collection.

The interview form employed was that used previously and is shown in Figure 1. One addition to the form, is the inclusion of the numerals $1,2,3$ just above the line for recording the reason(s) for breath test refusal. When a boater refused the breath test, the interviewer circled the $l$ if the judgment was that there was no indication of alcohol impairment, circled the 2 if it appeared that it was not likely that the person was impaired by alcohol, or circled the 3 if it was possible that the person was impaired by alcohol.

Following completion of the interview, the interviewer sought the cooperation of the boaters in providing a breath test, and for those that agreed, then escorted the persons to the breath test location. Breath testing was accomplished using an Intoxilyzer 5000 powered by a portable geperator. The Intoxilyzer was configured so that the test results could not be seen by the boater or the team mernbers. In a small number of cases, breath testing was done using the portable Lion Laboratories Alcolmeter S-D2 device. This is a hand-held instrument of the type used by police in pre-arrest screening in DWI cases. The S-D2 was employed only when an Intoxilyzer 5000 based test could not be obtained. Such instances arose when the distance from the interview site (e.g., at a dock) to the fixed Intoxilyzer location was so great that the boater could not be expected to walk the distance, or when the boater refused to make the walk. In such cases, the S-D2 was employed only when it was clear that the person would not be driving in the near future.

A second use of the S-D2 was on a few occasions when a person agreed to an Intoxilyzer 5000 test only if they could learn the test results. To maintain our stated position that Intoxilyzer 5000 rests could not be read immediately after testing, an S-D2 test was offered if the person was not about to drive a vehicle. This occurred in about four instances. In each case, subsequent comparison of the Intoxilyzer and S-D2 results showed complete agreement to two decimal places.

Each breath test result was recorded on a card by the Intoxilyzer or hand written for the S-D2 tests. Each card contains a code number that corresponds to the related interview form. Interview forms without this code number are breath test refusals. In some cases, more than one member of a boating party who had been operating the boat, volunteered to be tested. In these instances, the same test number was employed followed by an $A, B$, etc. Note that the test times recorded on the card are correct local California times. All interview forms and test cards have previously been transmitted to TSC. Overall, 147 interviews were completed, with breath tests being obtained in 134 of these (91.2\%). Of the 13 persons who refused, 11 indicated they had consumed some alcoholic beverage while boating and two sajd they had not. (Based on all of the interviews conducted, we believe this self reporting to be highly reliable.) Twelve of the refusals were judged as showing no sign of alcohol impairment (a rating of 1), and one person was judged as not likely to have been impaired by alcohol (rating of 2).

The topic of breath test refusals in the study is an extremely ioteresting one. A common initial reaction of peers hearing the study's method, is to sugsest that persons who have consumed considerable alcohol would be unlikely to provide a breath test, while 
Figure l Intervieus Sorn

stren

2. Interviewer

3. Date

4. Curreni Time

5. Subject sex: $M-F$

6. Any slgns of alcohol consumpilon: $Y-N$

If res: Cans/Bottles __ Alcohol on breath

Other

Confldentla Interview -- a few minutes

If refused, whyt

7. Your age:

8. Bost type: power

sail

other

9. Boat length:

10. Englne horsepower:

11. Zlp code where you live:

12. Your boatlng actlvity roday: Ilshing crulsing sking other

13. Water condltions today: calm sough strong curjent

14. How many people in your party:

13. What tlme did you start out rodays

16. Did you take any alcoholic beverages out with yous $\mathrm{Y}-\mathrm{N}$ If res: How many in the party drank: How much did you drink: What unlts: Did others in the party driak wore less same a you
Brath Test: Inducement $Y$
N
1
2
3

If no. Whys If jest Have rou bad a drink within the last 15 minutess $Y$
If ges. palt 25 minutes

N

Have you bad a clgarette withln the last 3 minutest $Y$ N If yes. walt 3 minutes

17. Test subject aumber (recorded on breath test card) 
those who have had little or nothing to drink, would be more inclined to submit to the test (i.e., the suggestion is that selection bias would slant the study results toward finding less alcohol use than actually existed). Based on our experience, the reasons for test refusals are far more varied and complex than this hypothesis.

We have found that more than half of the boaters approached, readily consent to the breath test. Many, but by no means all, in this group have had little or Dothing to drink and often express considerable interest in the study and boating safety in general. Others who cooperate readily, express amusement about or interest in being tested ("Ive Dever done this before and I'd like to see how it works"). Still others, who have indicated they have been drinking, wish to know their BAC level as a learning experience (as noted, we began employing an S-D2 to provjde this feedback, if the person was not a driver).

A sizeable minority of the boaters approached do not injtially agree to be tested. It is at this point that the truly bard work of study begins, as each situation must be handled uniquely, with different approaches, dialogs, cajoling, and occasionally monetary inducement being required. We have come to jdentify a number of subgroups among those initially disibclined to be tested. These include:

- The affronted - the interview form contains items dealing with how much the boater had to drink. Among those who report little or no alcohol use, there is a sizeable subgroup who feel that the request for a breath iest somehow questions the veracity of their answers regarding drinking. A diseussion along the lines that the quantitative evidence regarding alcohol and boating safety comes from the breath test and that it is extremely important that those with a zero BAC be represented, often overcomes this initial reaction. This subgroup, howeve; is among the most difficult to persuade and accounts for a considerable number of refusals.

- The wary - this subgroup includes the aaturally suspicious as well as many boaters who have been drinking and who initially react that the request for 2 breath test is part of a law enforcement activity. A detailed description of the study, the identification of the study team as being from out-of-state and similar conversation usually overcome this reaction. However, this subgroup contains those whose wariness cannot be quelled and leads 10 refusals. Note for example, that in the present data, there is a refusal based on the belief that there "are too many police around".

- The appearance of police units is the vicinity of the data collection sites was a relatively common occurrence during this data collection unit. For example. Discovery Bay turned out to be one of the refueling locations for the County Sherifrs marine units; an unrelated disturbance caused nearby police presence at Brannan lsland; sheriff and Coast Guard patrol boats were seen in the waters off various test locations. Personnel at the state and county recreation areas were extremely cooperative with the study and recognized the possible negative impact of the appearance of their enforcement units. At these locations, patrol units were instructed to minimize their appearabces in our vicinity. At other sites, we had no control over patrol activities. When a patrol unit was judged to be "too close" to elicit boater participation, sampling was suspended unsil the patrol unit moved away. 
- The irate and harried - recreational boating is not always a pleasant experjence and a small group of boaters is composed of those who have not had a good day" (e.8., engines have failed and they have been towed in, the boat is not sitting correctly on the trailer, they are sun burned or injured, there has been disagreement among members of the boating party, etc.). Sympathetic conversation and the monetary inducement are employed bere. However, refusals have come from this group because some persons cannot be distracted from their immediate concerns.

- Dissuaders - we have experienced several occasions when a boater being interviewed seems inclined to, or already has consented to the breath test, when another individual intercedes and attempts to dissuade them from participating. The most common instance of this occurs with couples, when one partoer appears to become overly protective of the other. In other instances, persons from other boating parties and even passersby have interceded. The success in overcoming this situation depends in part on whether the interviewer can get into a position to convinue contact with the boater and denect the person who is interceding. Another factor here appears to be the distance to the Intoxilyzer. That is, if the distance is short, the person being interviewed seems to be able to say that, "this will only take a few seconds". On the other hand, if the distance is relatively long, they appear to become more equivocal.

- The last, small subgroup is composed of those persons who are generally negative about contacts with strangers (e.8., the type of person who won't give you the time of day). They participate in the interview grudgingly and when asked for the breath test, just say no and break contact.

\section{Information Requests}

During the site arrangements, three individuals specifically requested copies of any report stemming from the project. We indicated that it would probably be some time before a final report would be produced and that we would ask the sponsor to include them in report distribution. These persons are:

J. Roggenbuck, Chief Ranger

California Department of Parks and Recreation

Los Lagos District

17801 Lske Perris Drive

Pertis, Califoraia 92370

Steve Horvitz, Supervising Ranger

Californis Deparment of Parks and Recreation

Sap Josquin Valley District

Millerton Lake State Recreation Area

P.O. Box 205

Friant, California 93626

Susan Ross, District Superintendeat

California Department of Parks and Recreation

Delta District

Branaan Island State Recreation Area

17645 State Highway 160

Rio Vistn, Califoraia 94571 
Septerber 7, 1989

Mernorandurs

To: Peter Mengert, Transportation Systems Center

From: Robert G. Olmer, Dunlap and Associates, Inc.

Subject: Alootol and Boating Safety Data Collection, Ausust 18 - August 27, 1989

During the latter part of August 1989, R. Ulmer and C. Preusser from Dunlap and Associates were on site in California to collect further data for the Transportation Systens Center (ISC) Coast Guard study of alcohol use arong recreational boaters and obtaining breath tests to determine Blood Alcohol Concentrations (BACs). The purpose of this menrandus is to describe the effort in terms of the sites selected, the procedures employed and the results obtained.

\section{Site Selection}

Inherent in the overall study desion, was the adoption of a sampling plan calling for data collection to take place at bodies of water that have experienoed (or are similar to those that have experienced) fatal boating accidents in which the BACs of the victins were lowkm. Other stated requirements for establishing the sampling plan are:

0

Collection of data on weekends at sites where the associated accident cocurred on a weekend, and during weekdays at sites where the accident occurred on a reeleday.

$\circ$

Collection of data prirarily in the hours during which the associated accident cocurred. Also, the extension of data collection into the later night bours so that this time period is represented.

- Enploying an approximately equivalent number of sites where the associated accident did or did not involve aloohol use.

- Avoiding sites related to "open" ocean accidents.

- Collection of data at launch raups, marinas and other on-shore facilities so that various poiver boat types, sizes and use pattern are covered.

In addition, the distances between various possible locations had to be considered in developing the sampling schedule. Because of the bulk of the equiprent employed, autombile travel was used for transportation to the various sites. This prevented sampling at widely separated locations on consecutive : days.

Site selection was based on a cormilation of fatal boating accidents provided by TSC. This overall listing is stown in Table 1. This 1isting was reduced by eliminating sites used in previous data collection, open ooean sites 
Table 1

California Boating Fatalities

Input Data

Case Date $\begin{aligned} & \text { Body of Location } \\ & \text { Water }\end{aligned}$ County Day Tire BAC

Operators

$=$

05322

05132

05151

05459

05437

05341

05529

05129

05178

05355

05131

05298

05412

05665

05397

05317

05744
4/8/84 Doan

4/25/84 Sacremento R.

5/4/84 Sacramento $R$.

$6 / 8 / 84$ Shasta Lake

6/9/84 Salton Sea

$8 / 11 / 84$ Shaver Lake

$8 / 13 / 84$

$4 / 30 / 85$

$5 / 15 / 85$

$5 / 30 / 85$

$6 / 6 / 85$

$6 / 29 / 85$

$8 / 11 / 85$

$8 / 14 / 85$

$8 / 17 / 85$

$5 / 17 / 84$

$9 / 1 / 84$
Salton Sea

Doean

Sacrarento R.

Old River

Lake Koswain

coean

Yosmite Lake

Sacrarento $R$.

Sar Eran Bay

Doean
Salton Sea
Unk

Jones Valley

$70 \mathrm{mi}$ NE San Diego

40 mi NE Fresno

70 mi NE San Diego

Near Sacto Airport

Near Tracy Hildlife

Near Merced

70 rot $\sqrt{E}$ San DIego

Hurobolt Bay

Near Kerced

Santa Cruz
Pt. Lom San Diego

Alarar Landing

Cabrillo Beach

Sherman Is land
San Diego

Yolo

Yolo

Shasta

Riverside

Presno

Inuerial

Los Angeles

Sacramento

San Joaquin

Marlposa

Iruperial

Humbolt

Kerced

Sacramento

San Eran

Santa Cruz

\begin{tabular}{|c|c|c|}
\hline $\begin{array}{l}\text { Sun } \\
\text { Hed } \\
\text { Eri } \\
\text { Eri } \\
\text { Sat } \\
\text { Sat } \\
\text { Hon } \\
\text { Tux } \\
\text { Hed } \\
\text { Thu } \\
\text { Thu } \\
\text { Sat } \\
\text { Sun } \\
\text { Hed } \\
\text { Sat } \\
\text { Thu } \\
\text { Sat }\end{array}$ & $\begin{array}{r}\text { unk } \\
8 \mathrm{am} \\
10 \mathrm{pm} \\
6 \mathrm{am} \\
3 \mathrm{pmo} \\
7 \mathrm{pmo} \\
10 \mathrm{am} \\
\text { unk } \\
11 \mathrm{pmo} \\
5 \mathrm{pm} \\
7 \mathrm{am} \\
2 \mathrm{pm} \\
\text { unk } \\
5 \mathrm{pro} \\
10 \mathrm{pm} \\
1 \mathrm{pm} \\
1 \mathrm{amp}\end{array}$ & $\begin{array}{r}\text { unk } \\
0 \\
0.19 \\
0 \\
0 \\
0.08 \\
0 \\
0.02 \\
0.03 \\
0.19 \\
0 \\
0.09 \\
0 \\
0 \\
0 \\
0.15 \\
0.14\end{array}$ \\
\hline
\end{tabular}

Sun

Tehera

Orland

Orange

Los Angeles

50mi SE Long Beach

B. of Senta Ana

Riverside

Orange

Onk

Near Oakley
Wilmington
Kendocino
Hintington

Nerport Beach

Valencia

Horgan Hill

Yorro Bay

N. of Redding

Des Relos

Delta-Ninter Isl.

Sutsun Bay

Millerton Lake

San Fran Bay

05273

05397
$7 / 6 / 85$

$8 / 17 / 85$
Sacramento $R$.
Eresno

San Eran

Contra Costa

Los Angeles

Hendocino

Orange

Riverside

Los Angeles

S. Luis Obispo

Delta-Sherman Isl
Santa Clara

Shasta

San Joagulne

Contra Costa

Madera.

Alareda

Sat

Eri

noon

Sum

Sum

Tue

Sun

Sat

Sun

Sun

Eri

Sat

Mon

Sin

Sat

Sat

Sun

hod

Sat

Sacrarento 6an

0.18

0.19

0.16

0.07

10am

$5 \mathrm{pm}$

$8 \mathrm{pm}$

$8 \mathrm{pm}$

3 aro

Iprn

9pm

noon

$4 \mathrm{pm}$

7 ard

$6 \mathrm{pm}$

4pro

$3 \mathrm{pm}$

$6 \mathrm{pm}$

10arn

10pm
0.08

0.07

0.17

0.14

0.05

0.0 :

0.0

0 .

0. 0 ! 
and sites already found to be unsuitable (e.g. , the Salton Sea). This reduced list is shom in Table 2 and becare the besis for the August site selection process.

As in previous data collection, telephone contacts were made with officials In the counties in which the candidate various bodies of water were located. This process usually began with the County Sheriffs Department where we spoke with someone knowledgeable (e.B., a boating enforcement officer) regarding the possible use of the body of water for data collection purposes. Recormendations conoerning specific sites, referrals to persons directly involved with the body of water, and in some cases, recormendations against certain sites resuited frorn these contacts. Further contacts were then made to obtain spocific approvals to use various public and private facilities.

In conparison with previous collection units, site scheduling for the August unit proved somewhat difficult. This was due, in part, to the relatively small number of accidents on the candidate list (Table 2) and, in part, to reluctance by some parties to erant us permission to test at certain locations. For exarople, accident 5244 in Table 2 cocurred in Santa Clara County, wost likely in Calero Reservoir. After a series of telephone conversations and written requests, county officials indicated that they could not cooperate with the study. The stated reason was that our study tear would not be uniquely identified by uniforms, signs, etc., in the manner of such activities as the : coast Guard Auxiliary's voluntary safety inspections. They felt that our presence could be vieved as an intrusion by local boaters.

As another exaruple, Shasta Lake is under the jurisdiction of the O.S. Forest Service and contains several private resorts with marinas and launch ralups, operated under license with the Forest Service. None of the private facilities contacted was willing to serve as a study site. Through the cooperation of the Forest Service, testing at Shasta Lake was conducted at launch raups under their direct oontrol. It should be noted that this was the only occasion in which experienced difficulty with privately ormed facilities. Testing in previous units and at one of the two marina sites in San Erancisco Bay in the August unit, was carried out at private facilities that readily agreed to cooperate. He suspect that marginal economic conditions at the private facilities at Shasta Lake contributed to the reluctance to cosperate.

As a final example, specific permission to test at one of the Sacramento sites was not obtained. In carefully chosen words, we were told that permission would not be given but we rould not be stopped from conducting the study.

schedule

Table 3 indicates the data collection schedule that was enployed. The entries in each cell of the table are as follows:

- The date of data collection

- The ISC accident case number

- The body of water at which sarpling cocurred 
Table 2

California Boating Fatalities

Potential Sites for August Unit

Case Date Location county Day Tire BaC

Operators

- -c--c-

\begin{tabular}{|c|c|c|c|c|c|c|c|}
\hline $\begin{array}{l}132 \\
151 \\
459 \\
341 \\
178 \\
131 \\
317\end{array}$ & $\begin{array}{l}4 / 25 / 84 \\
5 / 4 / 84 \\
6 / 8 / 84 \\
8 / 11 / 84 \\
5 / 15 / 85 \\
6 / 6 / 85 \\
5 / 17 / 84\end{array}$ & $\begin{array}{l}\text { Sacremento R. } \\
\text { Sacramento R. } \\
\text { Shasta Lake } \\
\text { Shaver Lake } \\
\text { Sacramento R. } \\
\text { Lake MoSwain } \\
\text { San Fran Bay }\end{array}$ & $\begin{array}{l}\text { Alamar Landing } \\
\text { Unk } \\
\text { Jones Valley } \\
40 \text { mi NE Fresno } \\
\text { Near Sacto Airport } \\
\text { Near Herced }\end{array}$ & $\begin{array}{l}\text { Yolo } \\
\text { Yolo } \\
\text { Shasta } \\
\text { Fresno } \\
\text { Sacramento } \\
\text { Mariposa } \\
\text { San Eran }\end{array}$ & $\begin{array}{l}\text { Hed } \\
\text { Fri } \\
\text { Eri } \\
\text { Sat } \\
\text { Hed } \\
\text { Thu } \\
\text { Thu }\end{array}$ & $\begin{array}{r}8 \mathrm{ar} \\
10 \mathrm{pro} \\
6 \mathrm{aro} \\
7 \mathrm{pro} \\
11 \mathrm{pro} \\
7 \mathrm{ard} \\
1 \mathrm{prn}\end{array}$ & $\begin{array}{r}0 \\
0.19 \\
0 \\
0.08 \\
0.03 \\
0 \\
0.15\end{array}$ \\
\hline
\end{tabular}

Non-Operator

\begin{tabular}{|c|c|c|c|c|c|c|}
\hline $\begin{array}{l}05128 \\
05516 \\
05067 \\
05244 \\
05372 \\
05456\end{array}$ & $\begin{array}{l}3 / 25 / 84 \\
7 / 29 / 84 \\
3 / 30 / 85 \\
4 / 8 / 85 \\
5 / 25 / 85 \\
6 / 8 / 85 \\
7 / 6 / 85\end{array}$ & $\begin{array}{l}\text { Black Butte Lake } \\
\text { Unk } \\
\text { Castaic Lake } \\
\text { Audrey Darn } \\
\text { Shasta Lake } \\
\text { San Joaquine R. } \\
\text { San Eran Bay }\end{array}$ & $\begin{array}{l}\text { Valencia } \\
\text { Morgan Hill } \\
\text { N. of Redding } \\
\text { Des Reios } \\
\text { San Fran }\end{array}$ & $\begin{array}{l}\text { Santa Clara } \\
\text { Shasta } \\
\text { San Joaquine } \\
\text { Alarada }\end{array}$ & & $\begin{array}{l}6 \text { am } \\
10 \mathrm{am} \\
\text { noon } \\
4 \mathrm{pm} \\
6 \mathrm{pro} \\
4 \mathrm{pm} \\
10 \mathrm{am}\end{array}$ \\
\hline
\end{tabular}


Pable J

Suplier Sebuedule

\begin{tabular}{|c|c|c|c|c|c|c|}
\hline Sundas & Coodas & fuesday & Modoesdas & Thursda & Irids & Suturtay \\
\hline & & & • & & 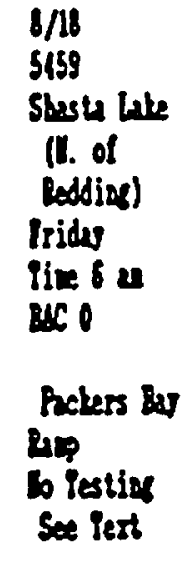 & 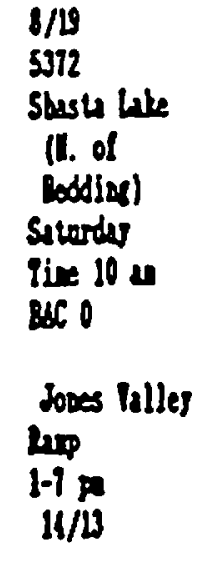 \\
\hline 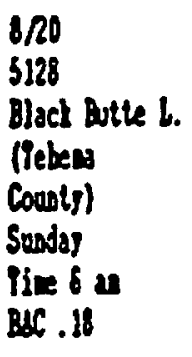 & $\begin{array}{l}8 / 21 \\
\text { Oft-irarel }\end{array}$ & 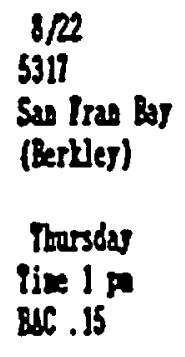 & 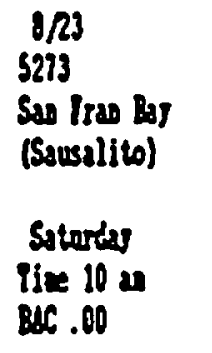 & Oll-Irarel & 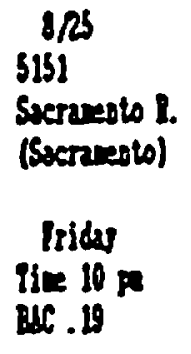 & 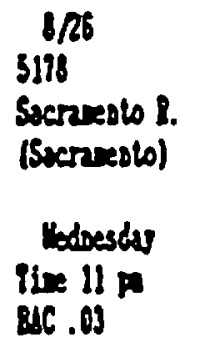 \\
\hline $\begin{array}{l}\text { Cafle Pass } \\
\text { Banp } \\
1-1 \text { p } \\
12 / 11\end{array}$ & & $\begin{array}{l}\text { Dertler } \\
\text { lariza } \\
\text { dariss/rap } \\
2-8 \cap \\
3 A\end{array}$ & $\begin{array}{l}\text { Clipper laebt } \\
\text { larbor } \\
\text { urias/rus } \\
1-1 \text { p } \\
10 / 8\end{array}$ & & $\begin{array}{l}\text { villet } \\
\text { Butt } \\
\text { Rup } \\
1-10 \text { p } \\
19 / 12\end{array}$ & $\begin{array}{l}\text { Discortn } \\
\text { But } \\
\text { 201 } \\
\text { 1-1 p } \\
28 / 26\end{array}$ \\
\hline
\end{tabular}

$8 / 29$

5516

Whe libere

(al/ker)

Boardes!

Susding

Iive 10 a

BuC .07

Lite

lorest

ing

1-9 $\mathrm{n}$

$14 / 14$ 
- The day of week and time of day of the associated accident

$\circ$ The BAC of the accident victir

$\circ$ The nave of facility involved

0 Whether data collection was at a marina/raru type of facility or a ranu (only) facility

- The approximate time period of the data collection

- The number of intervieus/the number of breath tests obtained

Shasta Lake

Two accidents in the databise (5459 \& 5372) cocurred in Shasta Lale on a Friday and Saturday respectively. These cases, coupled with the accident in Black Butte Lake (5128), formed the basis for planning the first weekend of data collection.

Shasta Lake is located in northern California approximately 175 miles north of Sacramento and is under the jurisdiction of the U.S. Forest Service. With a surface area of 30,000 acres, the lake is the largest man-made reservoir in the state.

Initial contact regarding the lake was with Lt. Ton loodges of the Shasta County Sheriffs Department. He indicated that there were several private resort/marina/aunch cormplexes around the lake and suggested several that might be suitable for the requirements of our study. A series of phone contacts was then made with a number of these locations but no copperation was obtained.

Lt. Hodges pext noted that there were several public launch ramps around the lake under the direct jurisdiction of the U.S. Forest Service and referred us to R. W. Eddy, a District Ranger with the Forest Service. Following several phone conversations, permission was Eranted for us to conduct data collection at the Packers Bay launch ramp on Eriday, August 16 th and at the Jones Valley rarup on Saturday, August 19th

He arrived in the Shasta Lake area on Thursday, Ausust 17th and checked in with the Rangers, received a description of the lake, inquired about the possibility of encounters with the bears, wountain lions and rattlesnakes that inhabited the vicinity (minimal), and visited the test sites.

Shasta Lake functions as a recreational area, a hydroelectric poter generator, as an Irrigation souroe and as the supply for the Sacramento River. A continual flow of ater, therefore, is released from the lake is dam, and during the sumer months, this causes the lake level to fall dramatically. the time of our visit, the lake was down approximately 90 feet from its fuil level.) To acommodate boaters during periods of declining water levels, the laumch ranus at the lake are sorrekhat unusual. At Packers Bay, the ranp has been paved at low water down the banks of the lake. As the lake level falls, previously underwater sections of the rarup are exposed. At the time we were there, the effect was a many humired foot long and steep raup, with a large parking lot at the top. 
As testing on Friday the 18 th was to have continued into the nighttioe hours, we arrived at approxinately $3 \mathrm{pro}$ and atterupted to set up in the parking lot area above the Packers Bay raup. Only a small number of trailers were observed in the parking area. Unfortumately at that tire, the generator began to leak gasoline and we were unable to solve this problem. He left the lake site and found a dealer in the nearest town but because of work backlog, he was unable to assist us. He located a nearby macharic who examined the generator and determined that the carburetor assembly had been dareged. However, he did not have the necessary parts to make repairs. Sarpling on Friday August 18th had to be abandoned, therefore. The following day, we purchased a new generator, obtaining a trade-in allowance on the dawaged unit.

The Jones Valley launch area at Lake Shasta was the data collection site on Saturday, August 18th. It consists of a series of ramps. The first paved ramp area and associated parking were high above the existing water level. The ramp in use was reached by a winding dirt road about a half-mile long that had been bulldozed into the exposed lake bank. A small paved ramp led to the water from this area, and a dirt parking lot was nearby. He understand that there was yet another similar arrangerent that would be brought into use when the lake fell even lower. He set up in the parking lot area. The weather was sunny, with tenperatures in the 90s. A total of 14 interviews and 13 breath tests were obtained.

Black Butte Lake

Accident 5128 in the database, led to the selection of Black Butte Lake as the collection site for Sunday, August 20th. This body of water is located in Glenn and Tehama countles approximately 70 miles south of Shasta Lake. It is under the jurisdiction of the U.S. Army Corps of Engineers and is one of a syster of flood control lakes developed by the Corps throughout northern and central California. The lake covers approximately 4,500 acres, with boating acoess being gained from three launch raups around the lake. As the lake also serves irrigation purposes, it is subject to being drawn down in the summer months. However, this effect was not especially noticeable and the primary ramps were in use at the tims of our visit.

Initial contact regarding the lake was with a Sgt. Nelson of the Tehara County Sheriffs Departrent who informed us that the Corps of Arruy Engineers has the primary Jurisdiction for the lake. Contact was then made with James Millert, the Park Manager for the Corps at the lake. Eoliouing completion by us of a request for a special use permit, permission was eranted for our study.

On Sinday, August 20th, we initially set up at the Buckhorn ranp on the northwestern shore of the lake. Shortly after our arrival, a Corps Park Ranger arrived at the site and after a detailed discussion of our procedures, recomrended that the Eagle Pass ralu on the northeastern shore might be more suitable for our purposes. Talding this advice, we moved to the Eagle Pass site. This location consisted of a paved rame and a long, relatively narrow parking area. Our location was in the flrst parking position next. to the ramp ares. The weather was sunny and in the mid BOs. Signs in the area warned against woving into shady areas without first checking for rattlesnakes and cautioned that poison oak was prevalent in the vicinity. Twelve intervieus were completed and 11 breath tests obtained. 
San Erancisco Bay

In the preliminary planning for the data collection unit, it had been hoped that the mid-reek locations would be San Francisco Bay (accident 5317) and Calero Reservolr in Santa Clara County (accident 5244). As roted above, Santa Clara County ultirately proved to be unililing to erant permission for testing. The decision was made, therefore, to substitute a second bay site as the other mid-week locale (accident 5273).

Testing on Tuesday. Ausust 22nd conducted at the Berkley Marina which is a city owned facility located on the eastern shore of San Francisco Bay, north of Oakland. Fermission to use the site was obtained from Kruger Hanson who is the Harbor Master. This is a large marina complex with slips for approxinately 1,000 boats. Marina personnel indicated that there is about a 75\% to $25 \%$ mix of sail to power boats berthed at the facility. Living aboard is rot permitted in the bay area.

As our test site, we chose a location near the marina's launch ramp from where we could contact raup users as well as permanent boaters leaving three of the dock access points. Unfortunately, a weather front crossed the California coast that day. On our arrival, fog and clouds covered the area, the tenperature was in the 60 s and a strong wind was blowing in from the $\infty$ ean. Later in the day, the fog lifted. However, wind and temperature conditions did not improve. Boating activity was mirimal, with 3 interviehs and 3 breath tests being obtained, all from raup users. No permanent boaters were seen leaving the marina slips we could observe.

At this site, began to experienoe minor difficulties with the Intoxilyzer. In its operating cycle, the Intoxilyzer first draws an air blank sample to test. The instrument began to report, "Invalid Test" at this stage and issued a raming to check ambient conditions. We suspected that the outside air tesuperature nay have been low for the instrument. A test immediately following the invalid test, functioned morrolly. He continued to experience this difficulty on cocasion throughout the remaining test sites. No tests were lost, however, and we do not believe that test readings were affected.

Testing on Wednesday, August 23nd was at the Clipper Yacht Harbor. This marina complex is a privately omed facility located in Sausalito, north of the Golden Gate Bridge. Our Initial plan was to work at the gas dock intil it closed at 5 pro and then seek out boaters returning to permanent moorings. (The gas dock was too far frow the mooring area to do both simultaneously.) Upon arrival, we noted the laumch ramp mas about 100 yards from the gas dock. De to the layout of the facllity, there no reasonable area in which we could set us the Intoxilyzer near the gas dock Also, because of the relatively large muber of poople moving about the area on foot (apparently tourists), we felt it would be unwise to leave the Intoxilyzer and generator unattended in the stopping area used by boaters leaving the rarup while we tested at the gas dock. We, therefore, decided to use the S-De for testing purposes and "shuttle" back and forth between the two locations when boaters appeared.

The weather was considerably inproved, with sunny skies and teroperature in the mid 70s. Between 1 and $5 \mathrm{pD}$, we had conducted six interviews at the ranp and 4 at the gas dock, with one refusal at each site bringing the number of breath tests obtained, to eight. No high BAC readings were reoorded. At 5 pro the gas dock closed and it was noted that the traller parking area was empty. 
Local personnel indicated that we could expect little, if any, traffic in the marina area later in the day. He moved to the berthing area and observed it for an extended tire period. No traffic was found and no further intervieus resulted.

\section{Sacramento}

Accidents 5151 and 5178 led to the selection of two test sites in the City of Sacramento for Friday, August 25th and Saturday, the 26th. Initial contact regarding testing sites for these accidents was with the Marine Unit of the Yolo County Sheriffs Department. Fersonnel from this agency indicated that sites in Sacramento would be higher volume locations and were basically "just across the river" from Yolo County. They specifically recormended Miller and Discovery Parks as busy launch rarup sites. Both of these facilities are on the Sacramento River and are under the jurisdiction of the City of Sacramento. In the case of Miller Park, the Harbor Master Indicated that they would not specifically approve our testing at the site but would not prevent us fros doing so. In the case of Discovery Park, Gary Kulktola, the Park Superintendent, approved our use of the site.

On Eriday, August 25th, we set up at Miller Park at about 3:30 pro. The day was sunny and mild. Our location was at the side of the roadway leading from the ramp area. The facility also contained a rourina mooring area. This could not be reached from our location, however, because of a waterway between the ramp site and the marina. All testing was done at the ramp, therefore. A total of 13 interviews and 12 breath tests were obtained. The last intervieu/test took place shortly after 8:30 pro. In the ensuing hour and one-half, no boaters used the ramp. As the park officially closed at $10 \mathrm{gx}$, we left the site at that time. (The few remaining trallers in the parking area were attributed to overnight boating parties. )

Testing on Saturday the 26th, was at Discovery Park during the hours of 1 to $7 \mathrm{Fm}$. He set up across from the laumch raup area; the weather was sunny and in the 80s. A total of 26 intervieks and 26 breath tests were obtained.

\section{Lake Tahoe}

Because of the small number of cases remaining in the database and their location, wound it impossible to schedule the final reekend day based on an actual accident situation. After considering various altermatives, (e.8. . testing for an additional day at one of the Sacramento sites), It was decided to test at Lalke Tahoe on Sunday, August 27 th. The rational was that this is a large and well known recreational area and would provide the most easterly site used in the study.

Lake Tahoe is located on the Califormia Alevada boarder approximately 120 miles east of Sacramento. Initial contact about the lake was with the Placer County Sheriffs Department (Lt. Hall), who referred us to the Latke Tahoe Sheriff's substation. Officer Baumgardier there, provided a detailed acoount of boating on the lake. He recommended using the Lake Forest ramp located on the northwestern shore. Gary Romano of the Parks and Recreation Department granted permission to use the raup site. 
He set up in the parking area adjacent to the ramp. The weather was surny with teroperatives in the mid-705. A total of 14 interviens and 14 breath tesis were obtained.

\section{Data Collection}

Deta collection procedures were the sare as in previous units. They involved a merber of the study tear aproaching boaters and asking for their anonymis coperation with a bating safety survey. At launch ramp fasilities, this was done with baters leaving the perticuler body of water when they stopped to stow gear after pulling away from the rans. At gasoline docls, ir-bound boters were epproached once they had tied-up to the facility. At these latter facilities, the operator of the boat was knom and apprsashed. At launch rawus, the intervie:er sousht out the person who had done the primary boat operating ouring the day. During the Ausust collection unit, no bater approsched, refused to participate in the interview portion of data collection.

Following corpletion of the intervie:, the intervie:ar sougtt the coperation of the boeters in providing a breath test, end for those that egreed, then escorted the persons to the bresth test location. Bresth testing was accorplished using an Intoxilyzer 5000 poiered by a portable generator. Tixe Intoxilyzer was configured so that the test results could not be seen by the beater or the tean renbers. In sore ceses, especielly at Clipper Yacht Herbor, breath testing wes done using the portable Lion Laboratories Alcolmeter S-D device.

As in the June unit, the S-De was elso used on a fei occasions witen a person agreed to an Intoxilyzer 5000 test only if they coild learn the test results. To maintain our stated position thet Intoxilyzer tests covild not be read imrodiately after testing, an S-De test wes offered if the person wies net about to drive a vehicle.

Each breath test result was reoorded on a card by the Intoxilyzer or hand witten for the S-De tests. Each card conteins a code number that corresponis to the related intervien form Interviek forms without a coje number are breath. test refusals. In some ceses, more then one merber of a boating perty who had been operating the bot, volunteered to be tested. In these instances, the sere test number ses employed followed by an A, B, etc. Note that the test times recorded on the cerd are correct locel Califormia times. All interview forms and test cards have been previously transmitted to TSC.

Overall, 92 interviews were corpleted, with breath tests being obtalned in 87 of these $(94.6 \%)$. Of the 5 persons who refused, 3 Indicated they had consured sore elooholic beverage while boating and tur sald they had not. Four of the refusals vere judged es stowing no siem of alcohol inpeirment (a rating of 1), and one person was judged as not likely to have been irapeired by alcohol (rating of 2 ).

Besed on those providing treath tests, 69.0 percent of the boaters had a Blood Alcohol Concentration (BAC) of .000, 20.7 percent had a BAC betiren a trace arount and .049\%, 6.9 percent of the boeters had a BAC in the $.050 \%$ - .099\% range, and 3.4 percent had a BAC of . $10 \%$ or higher. 


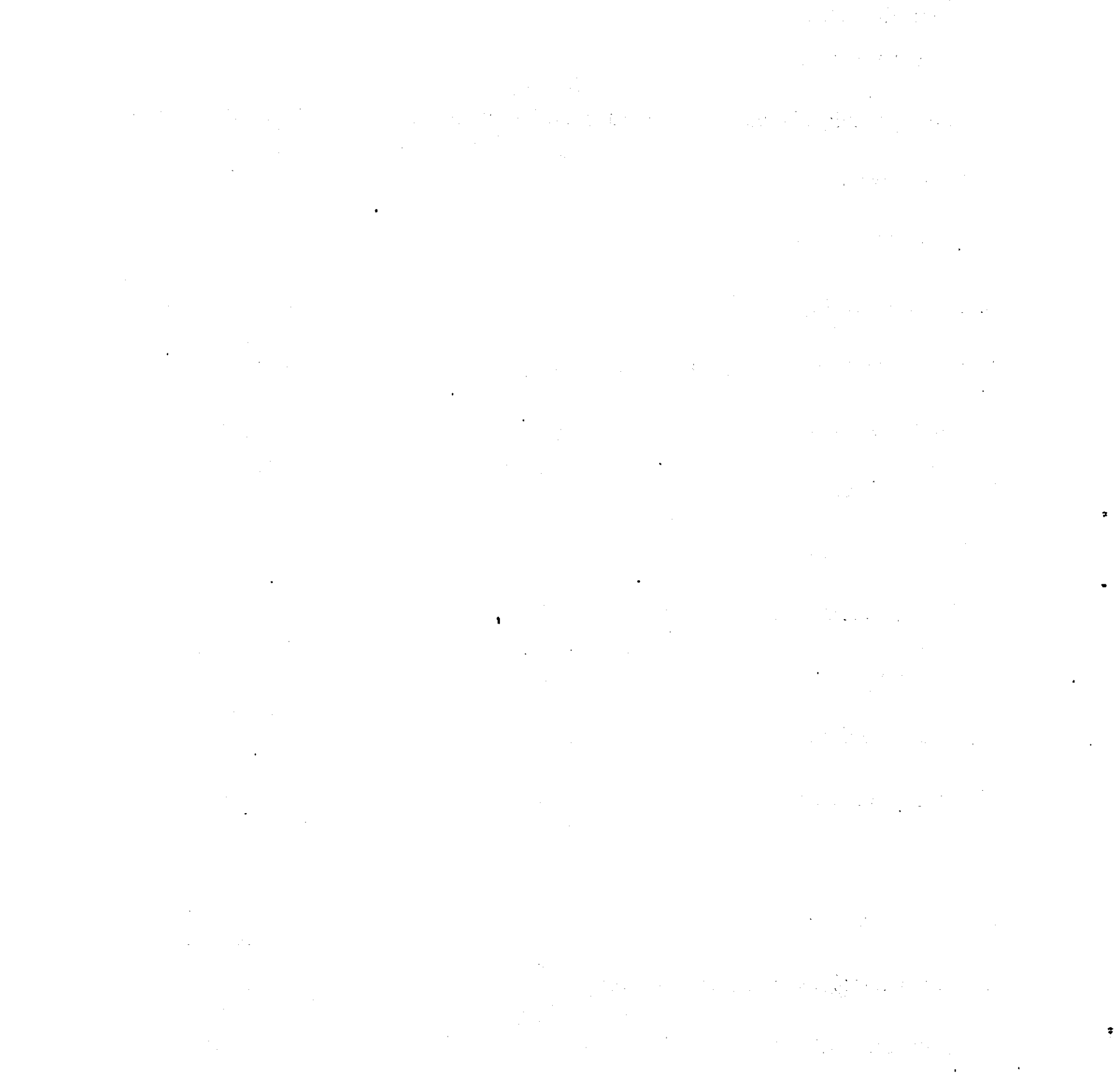
de

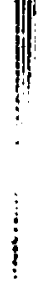




\section{APPENDIX B}

This appendix gives a complete listing of the boat operators survey database constructed for this project. The columns are headed by abbreviations which are intended to designate the following data elements:

1. Observation number

2. Site - abbreviated-see Appendix A for the full site names

3. Date of interview

4. Time of interview

5. Sex of boater (operator)

6. Signs of alcohol consumption yes or no

7. Age of boater

8. Length of boat

9. Horsepower of boat

10. ZIP code of boater's residence

11. Activity

12. Water conditions

13. Persons on board

14. Time that boating started

15. Were alcoholic beverages consumed?

16. Were alcoholic beverages taken with?

17. How much did respondent drink?

18. Blood alcohol concentration measured by breathlyzer - blank if no test 
્ֻ木

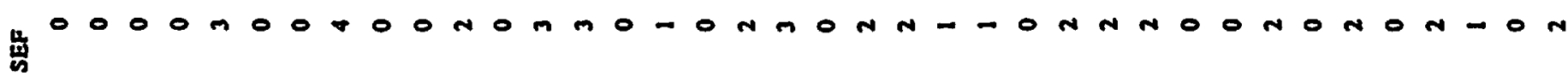

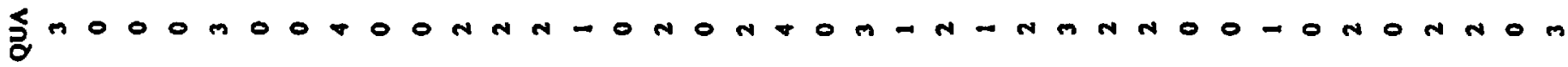

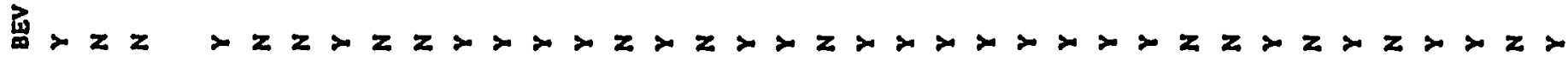
崖8 \&

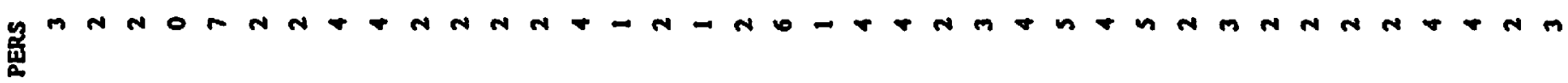

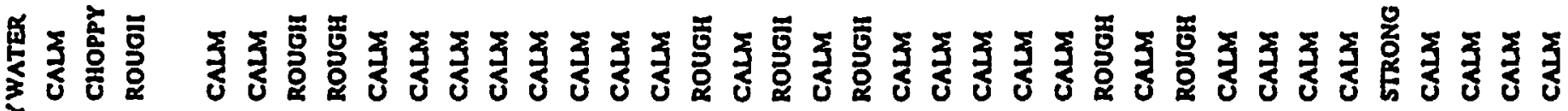

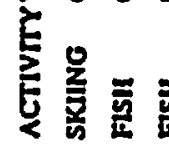

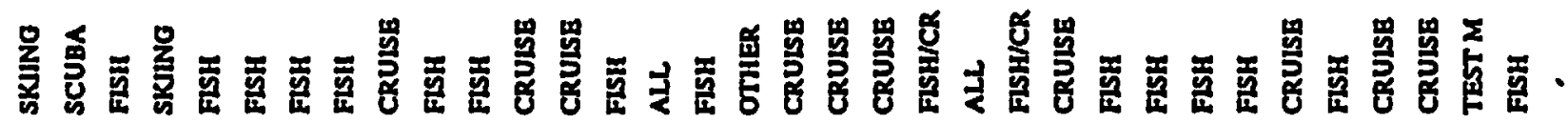

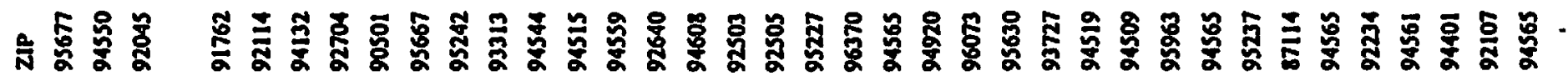

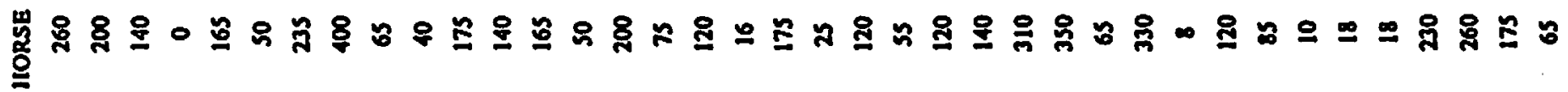

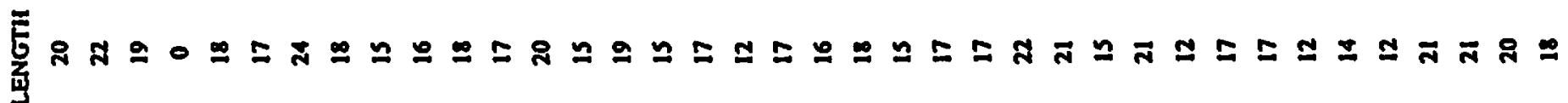

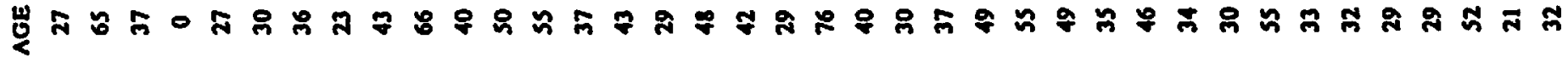
皆

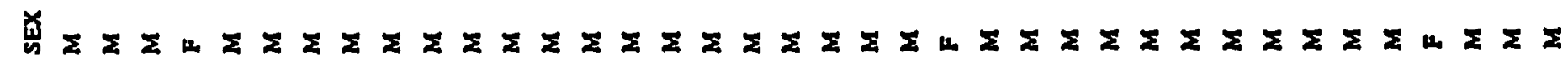

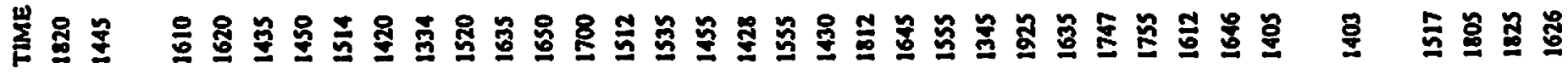

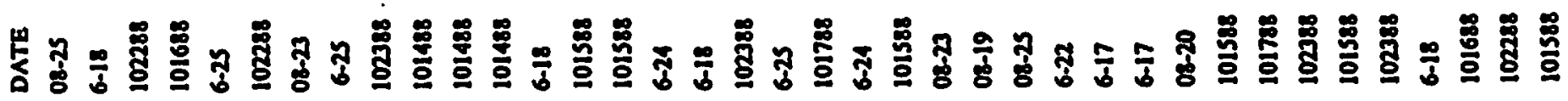

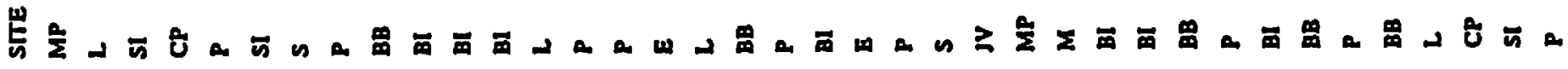
范 


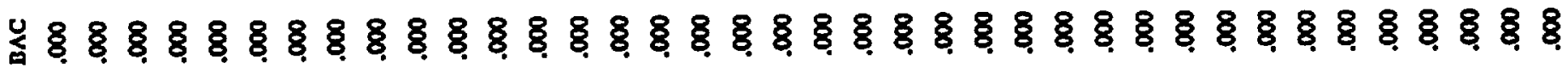

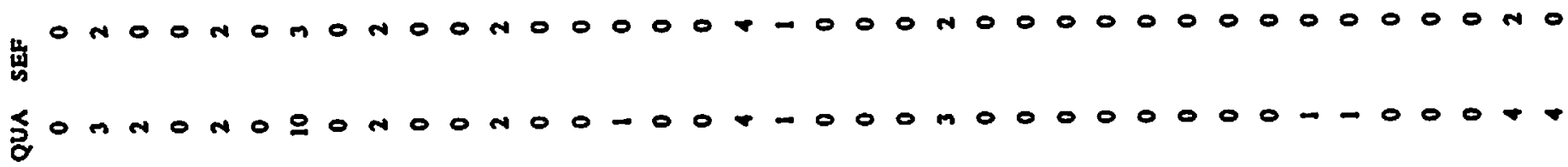

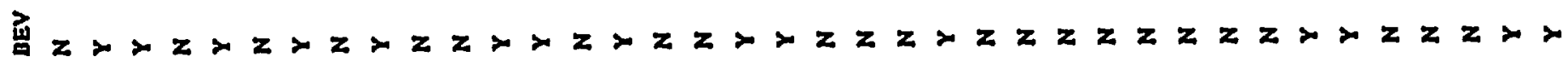

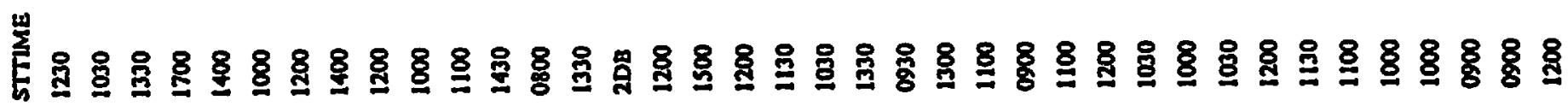

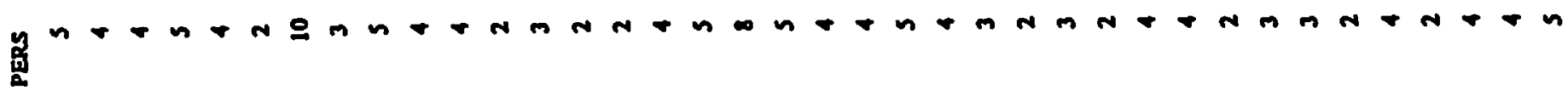

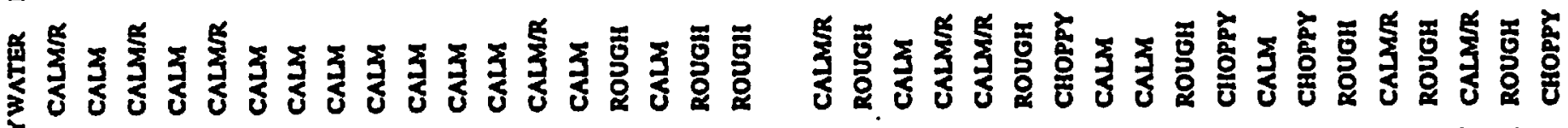

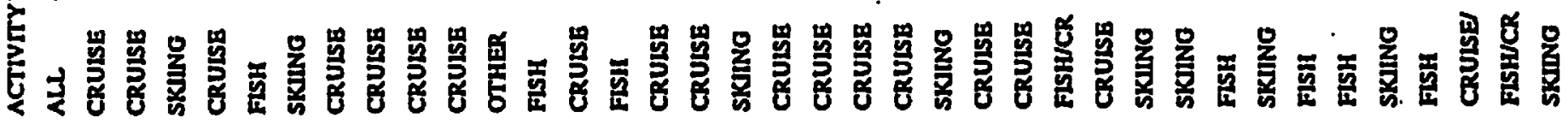

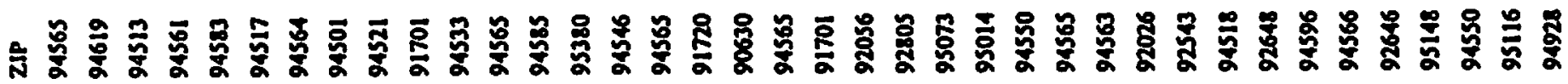

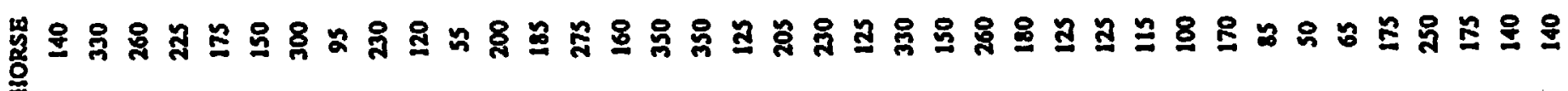

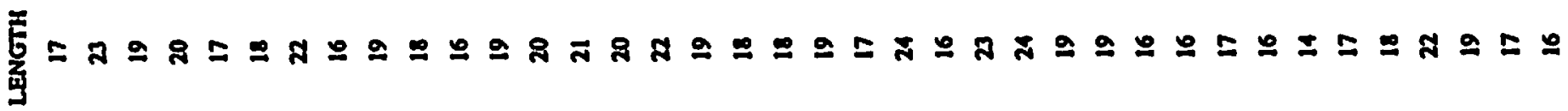
莫

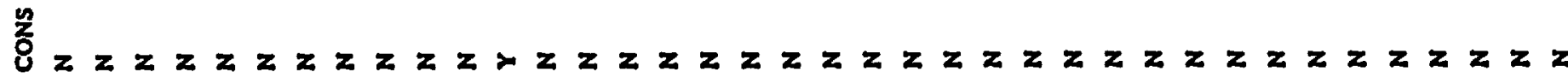

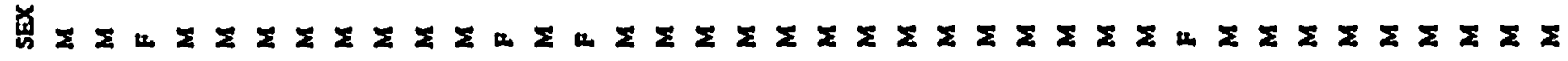

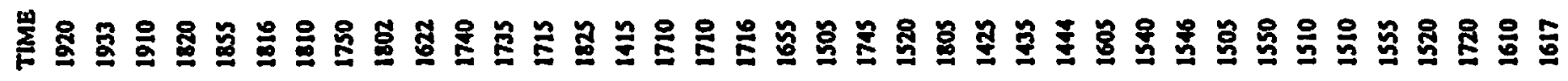

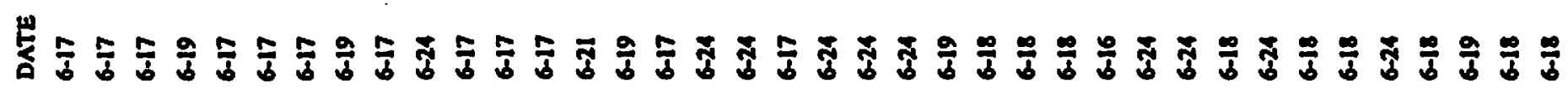

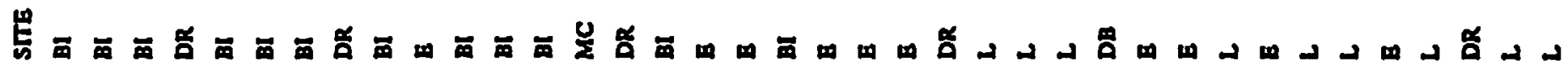

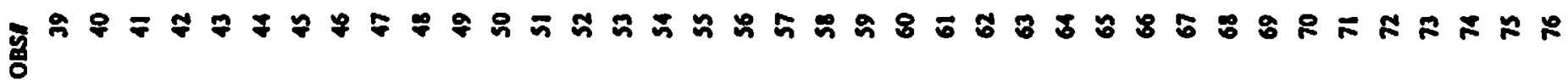




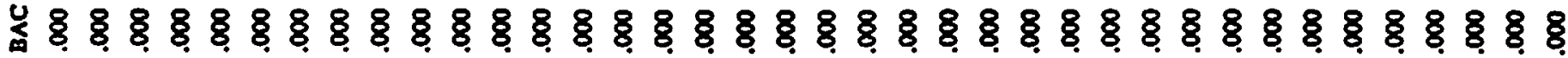

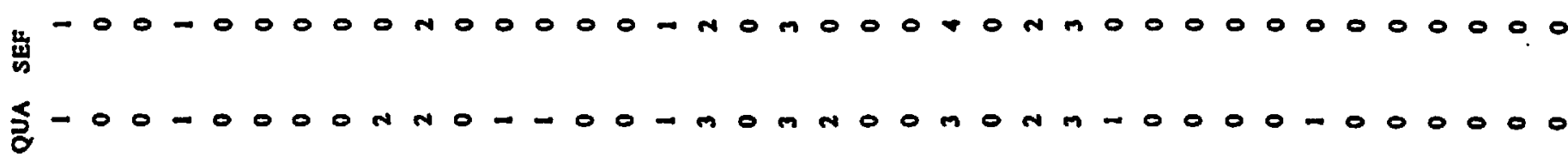

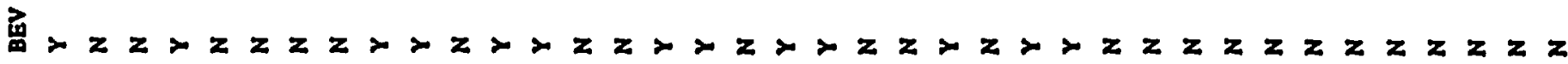

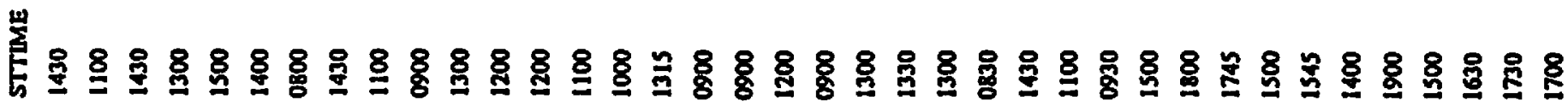
岁 息

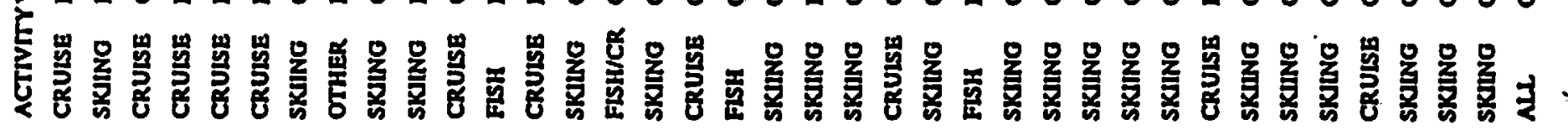

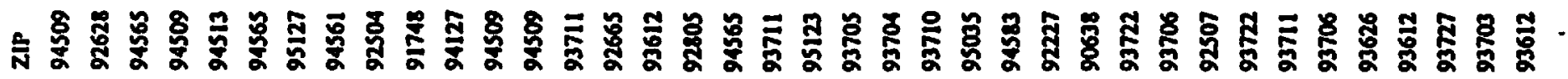

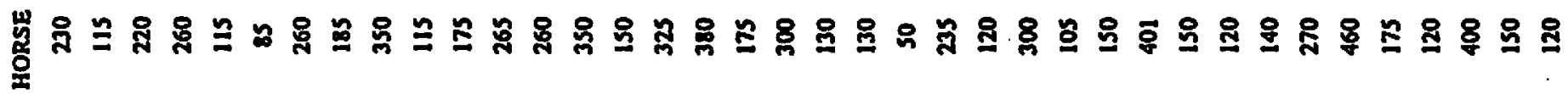

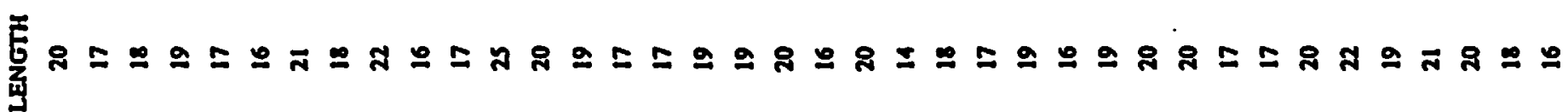

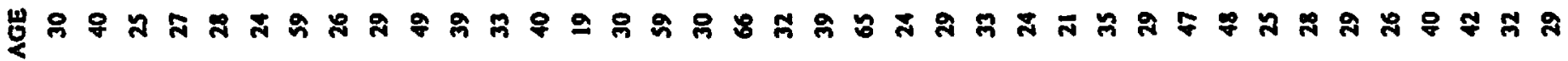
号 递zzzzzzzzzzzzzzzzzzzzzzzzzzzzzzzzzzzzzz

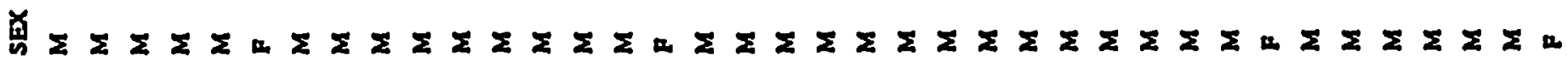

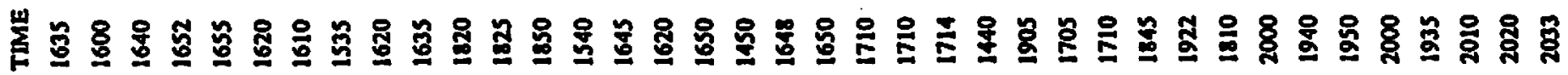

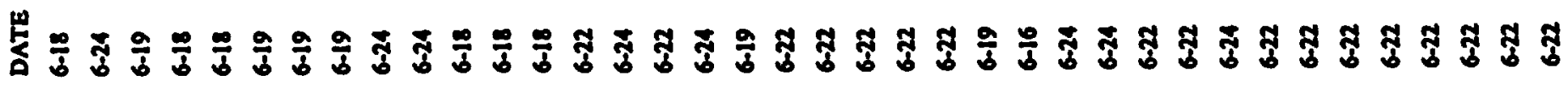

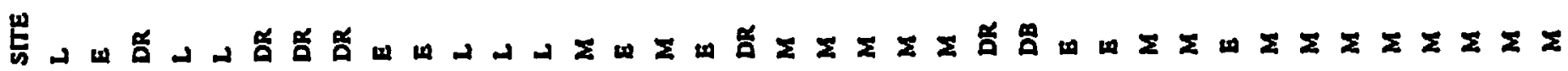

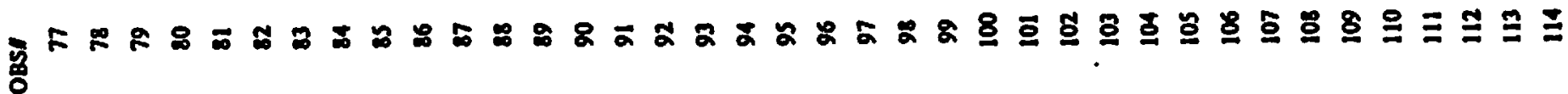




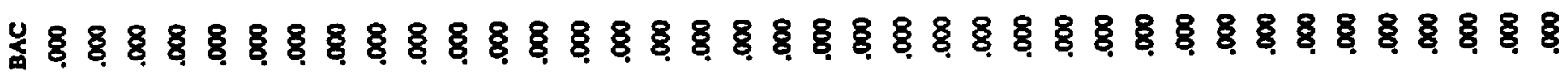

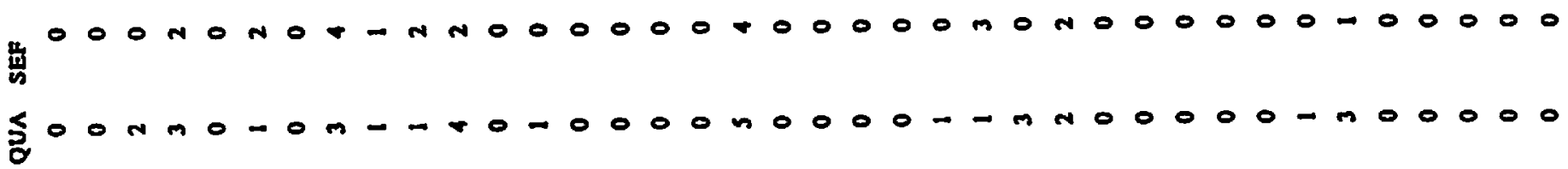

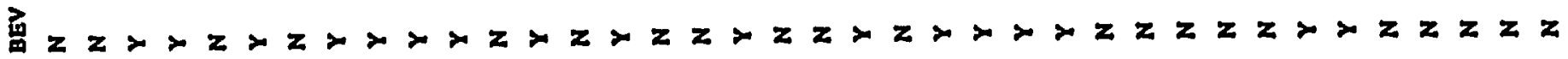

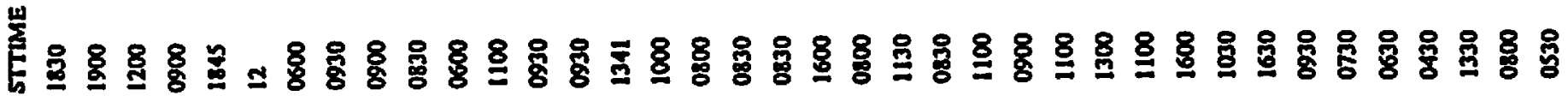
离

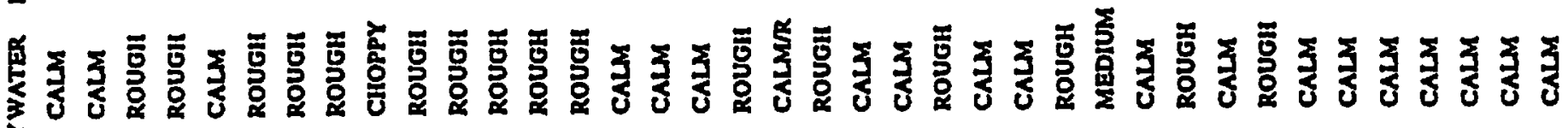

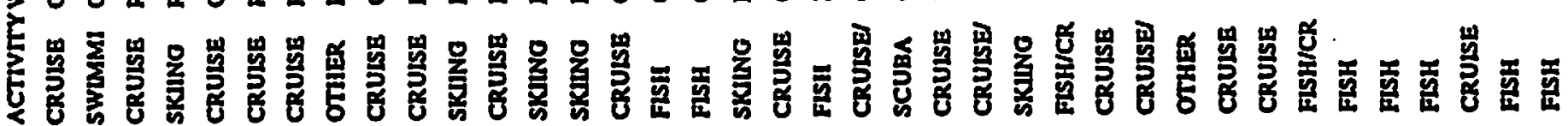

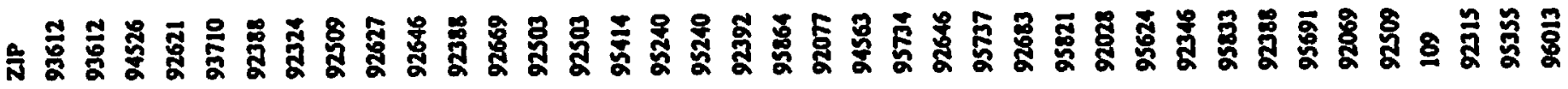

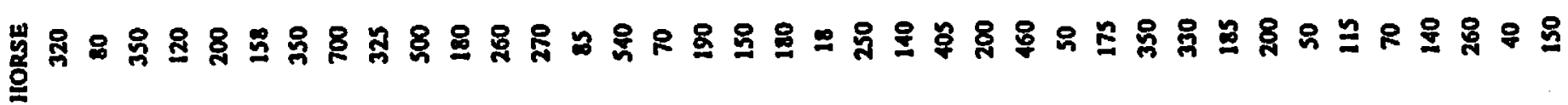

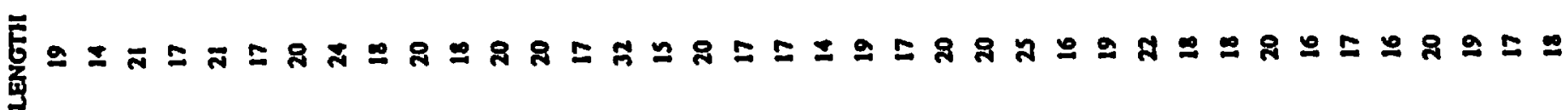

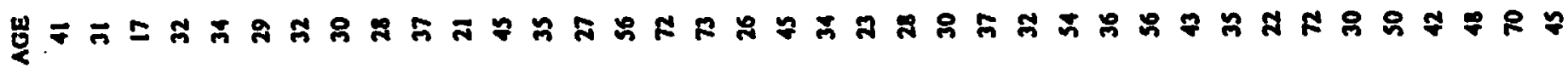

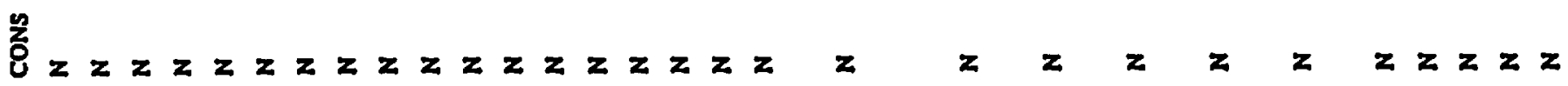

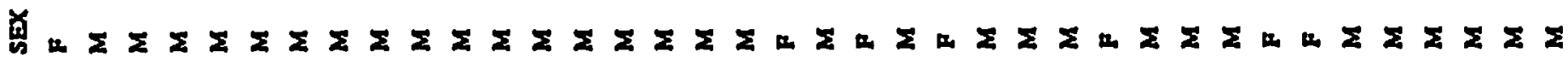

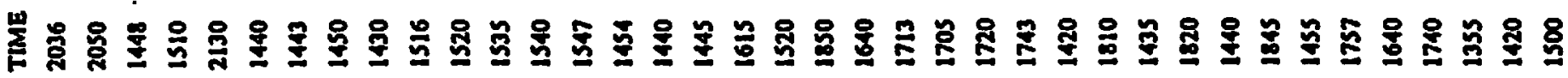

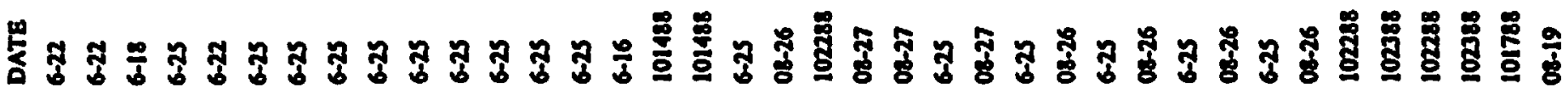

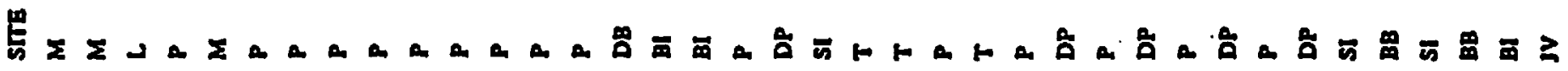
妾 


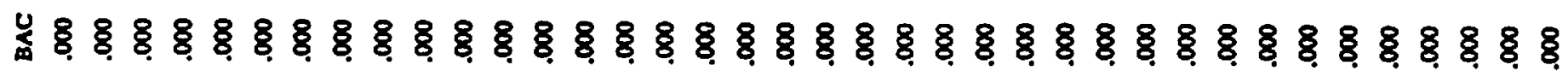

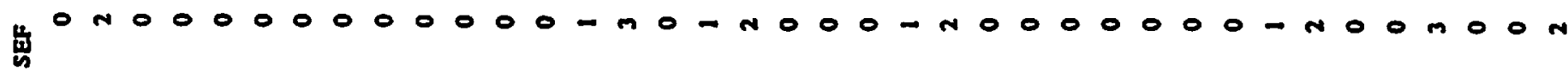

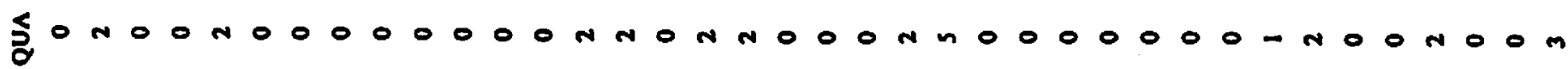

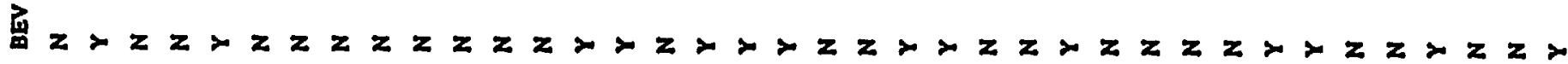

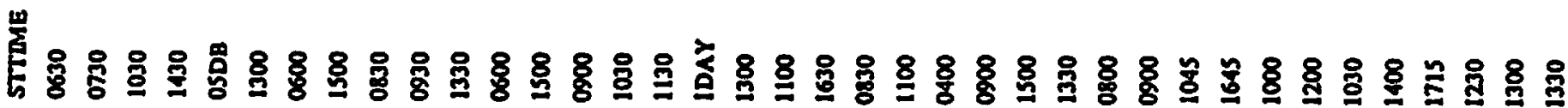

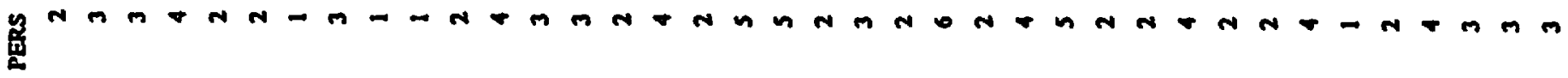

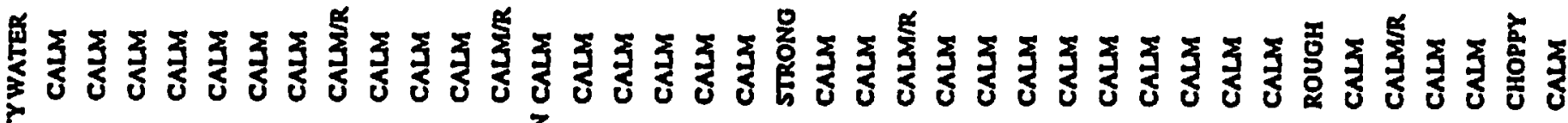

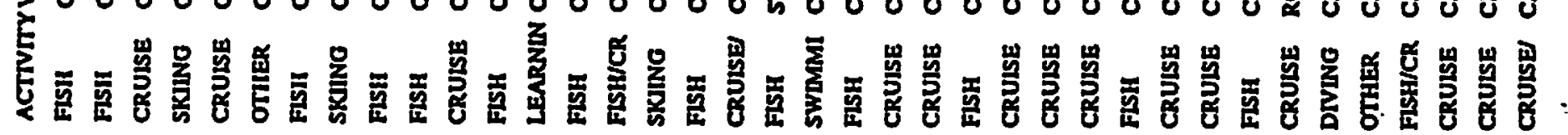

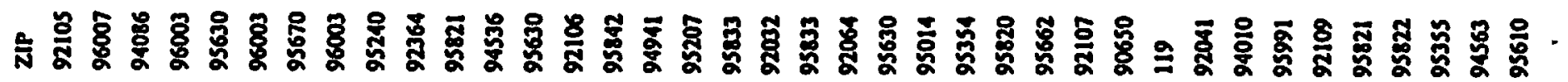

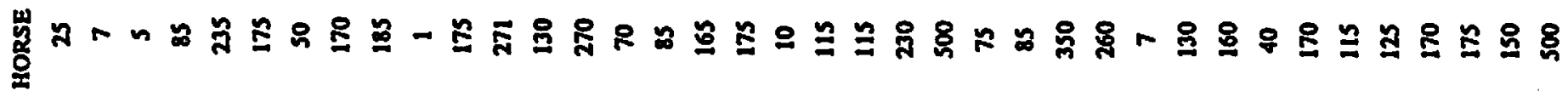

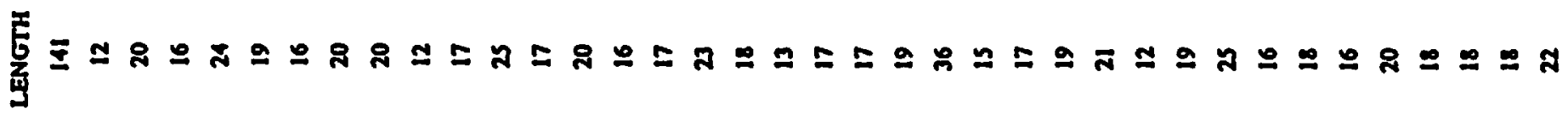

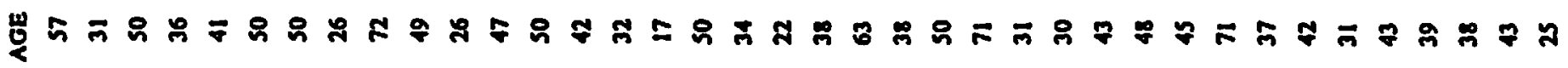

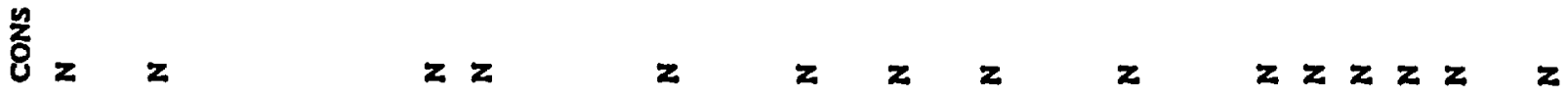

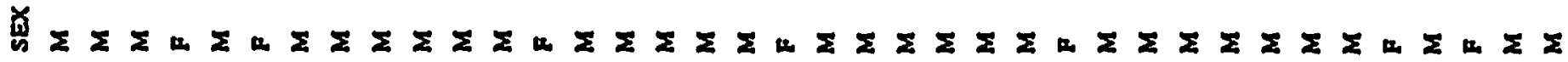

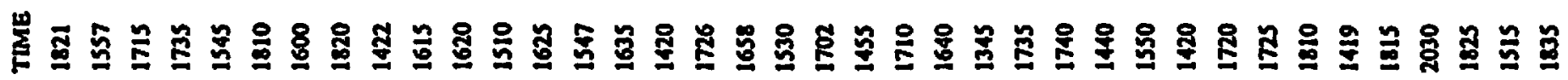

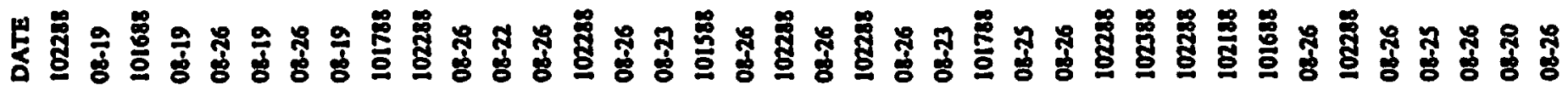

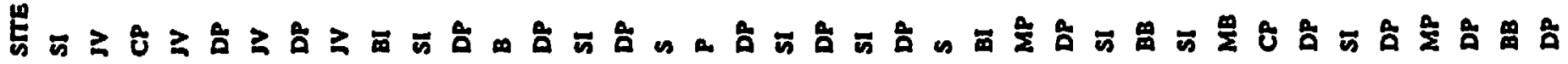
妾 


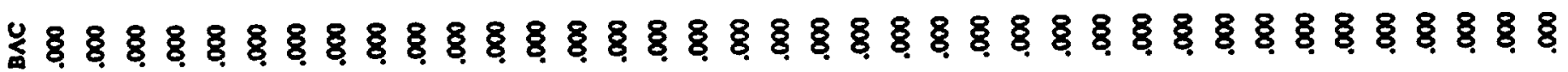
莒

g. $00000 n-00-m 000-00 n-000000,0000-0000000$

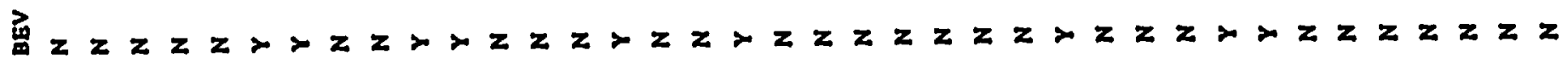

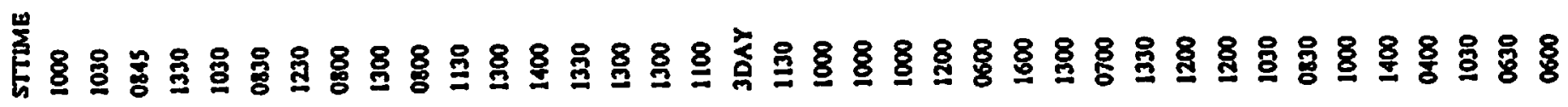
管

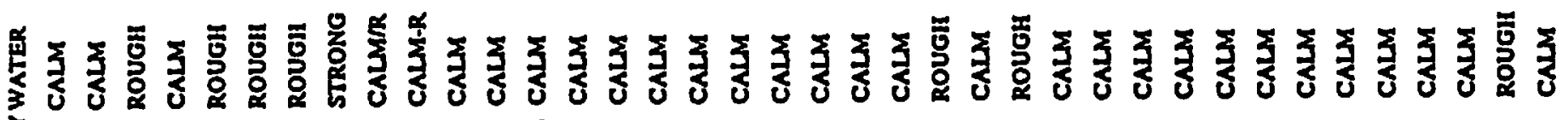

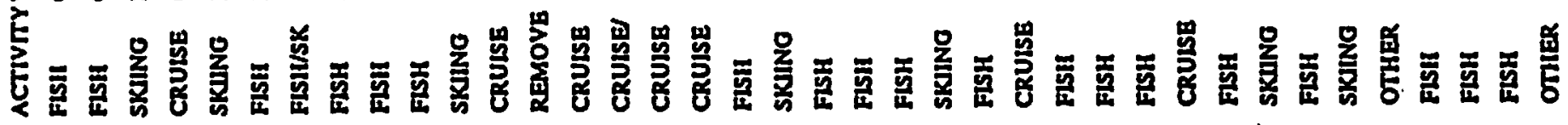

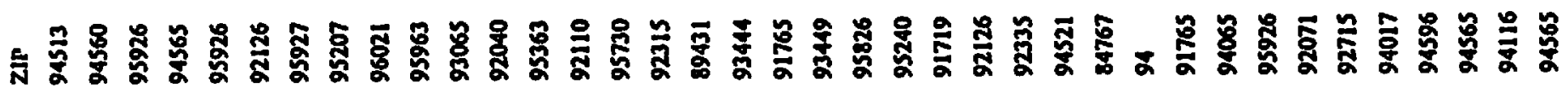

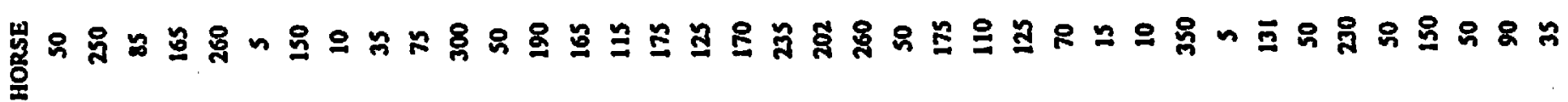

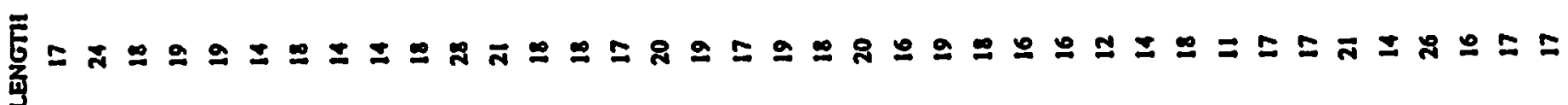

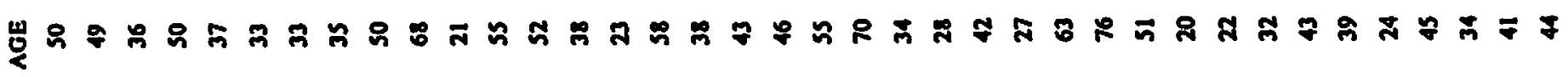

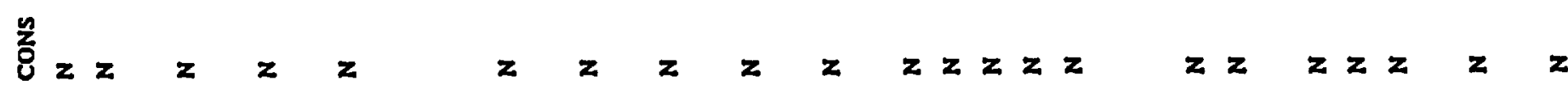

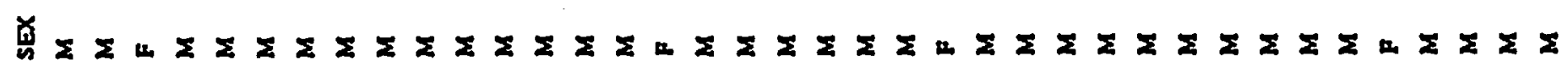

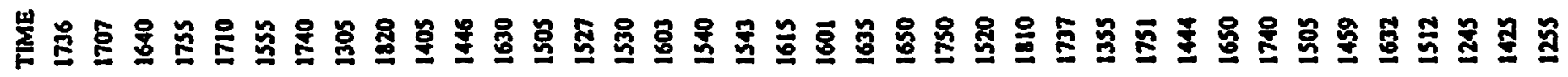

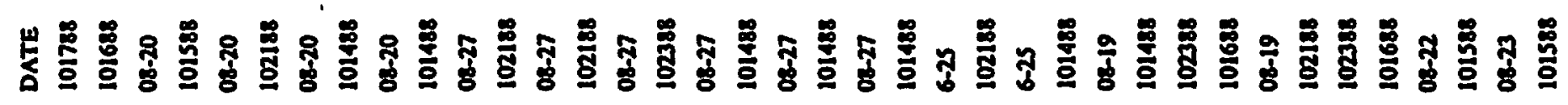

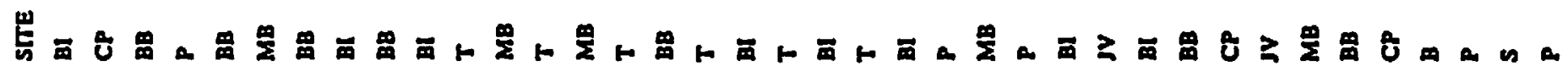

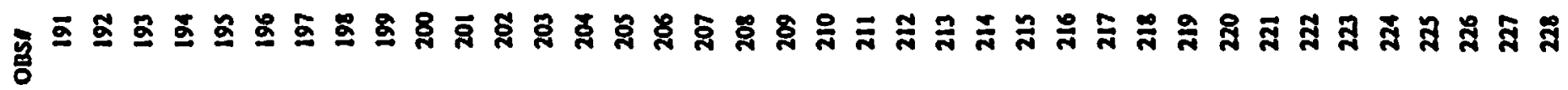


گ

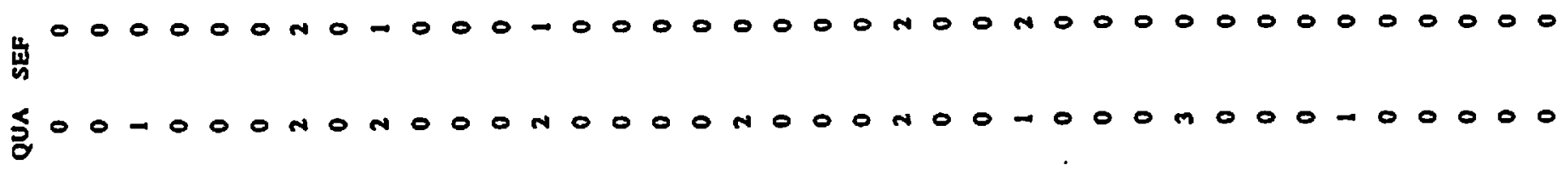

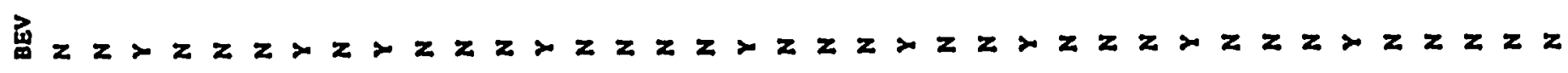

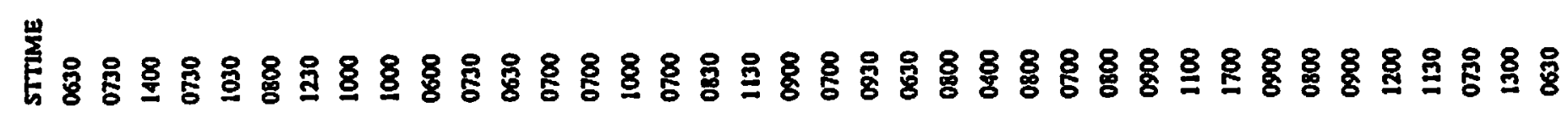

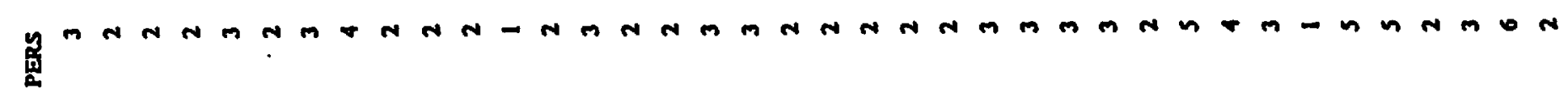

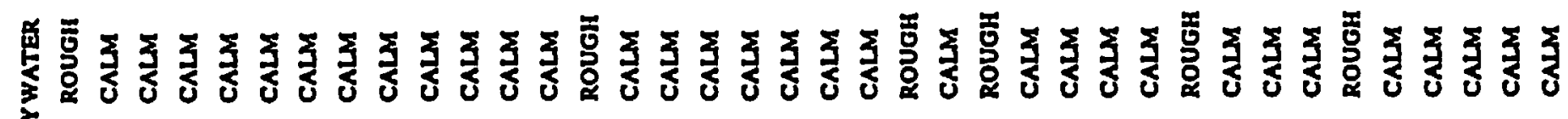

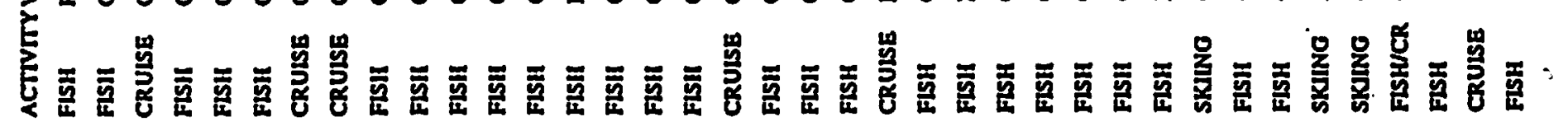

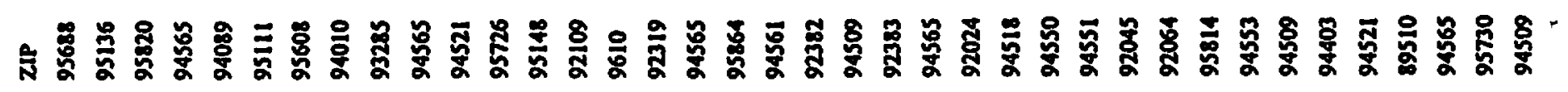

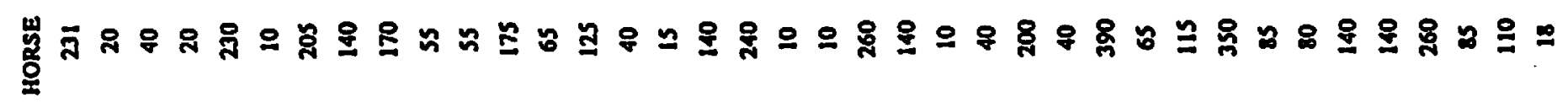
泵

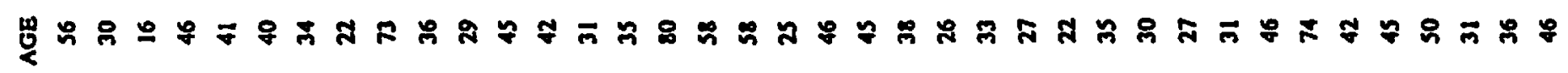
8 $z z z \quad z z z z z z z \quad z z \quad z z z z z z \quad z z z \quad z z \quad z \quad z$

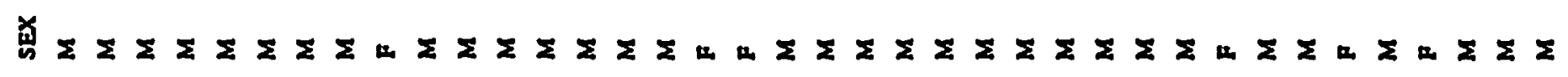

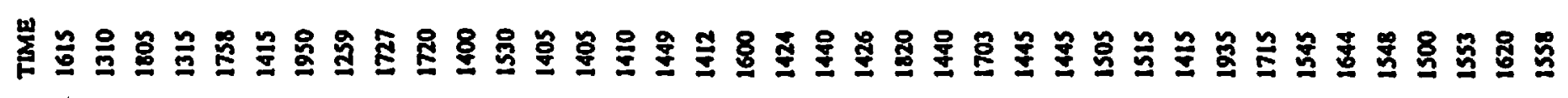

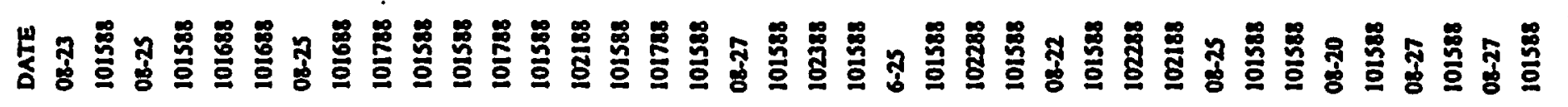

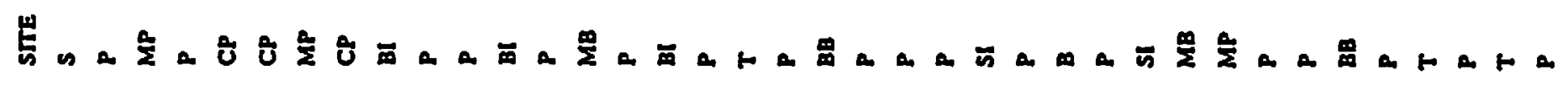

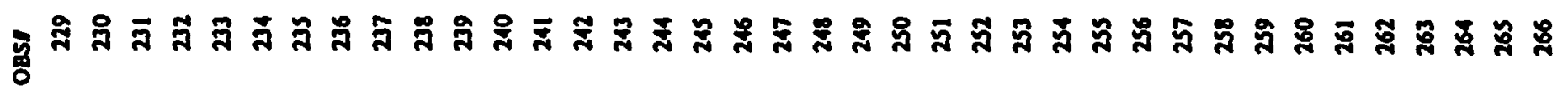




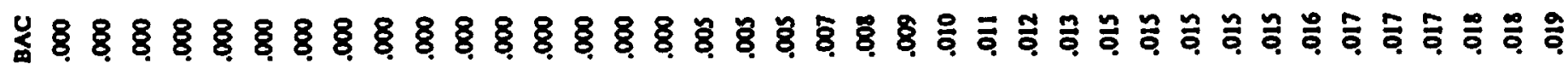

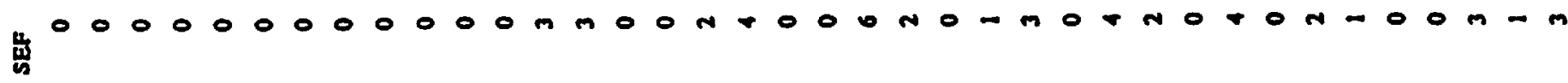

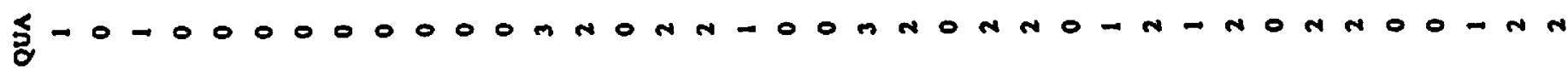

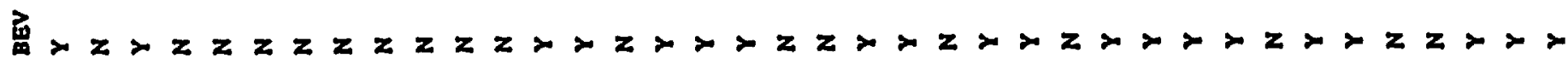

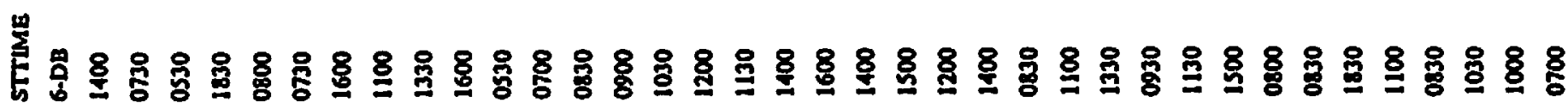
量

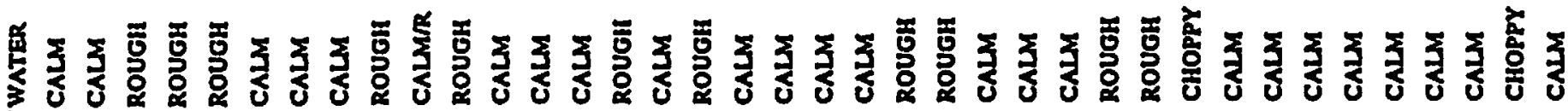

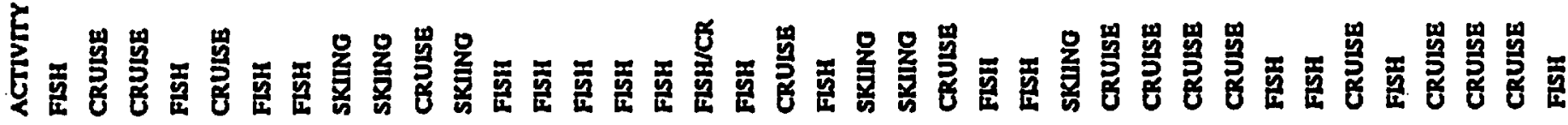

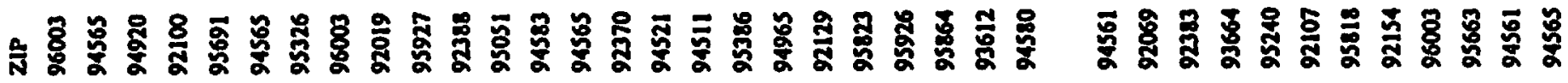
哭

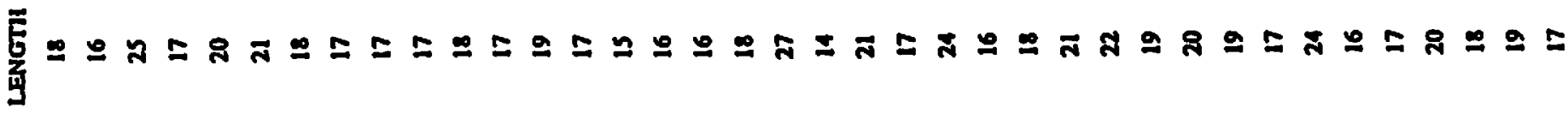

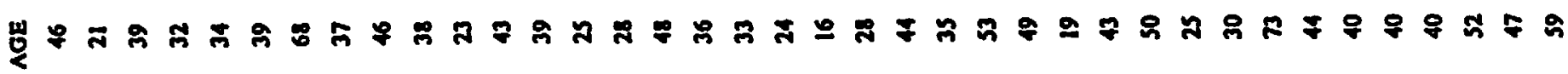

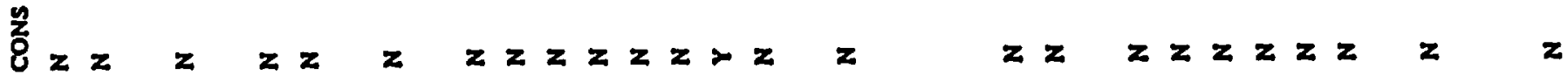

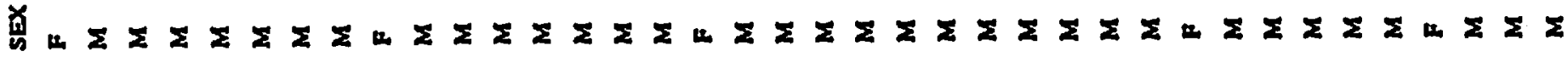

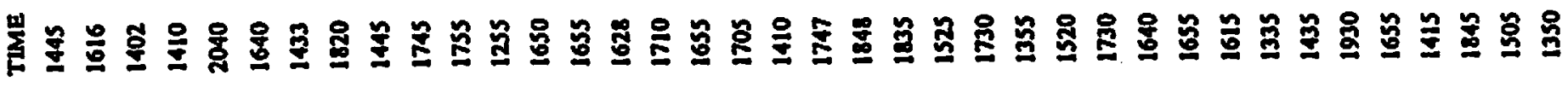

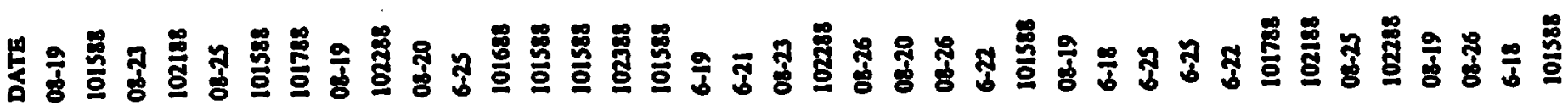

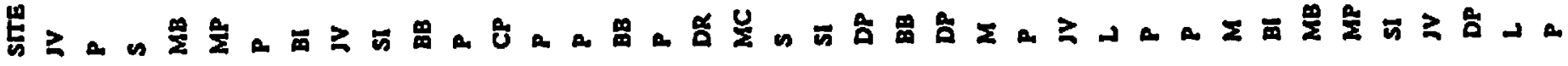

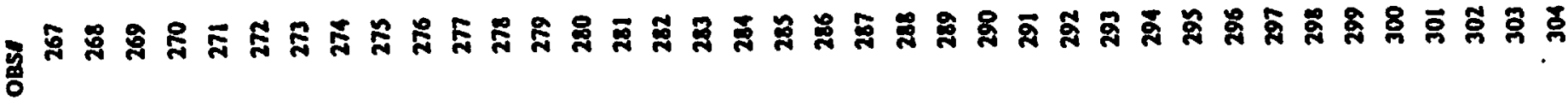


芒 岕

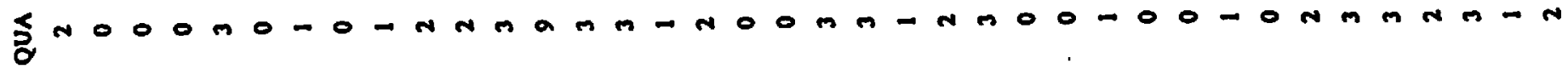

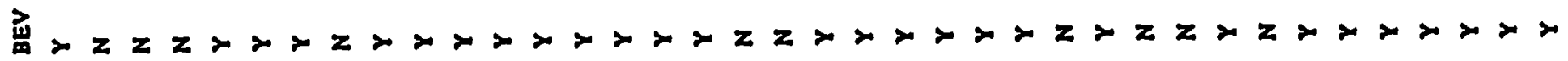

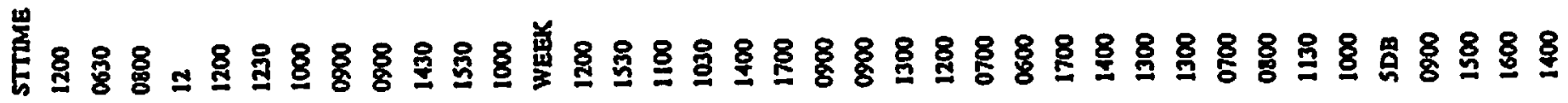

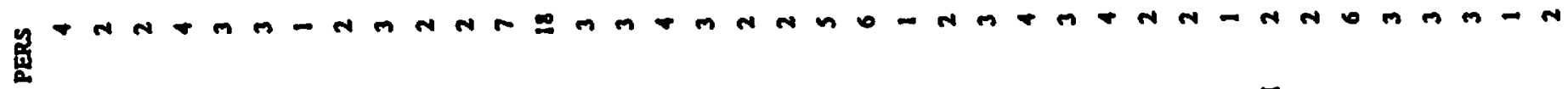

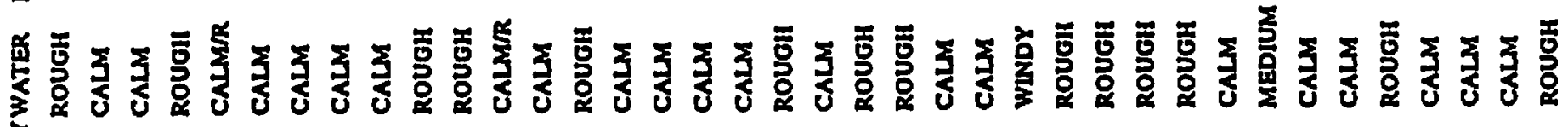

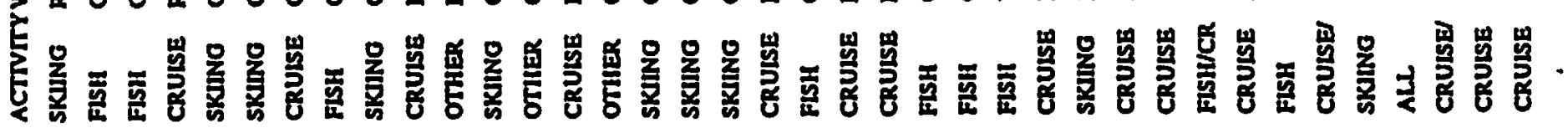

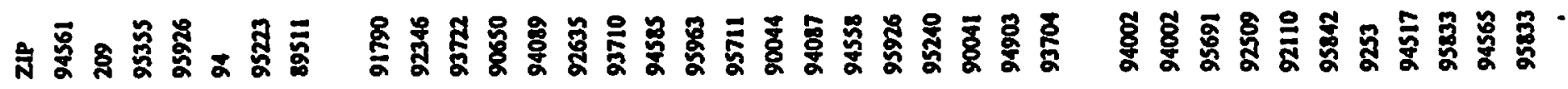

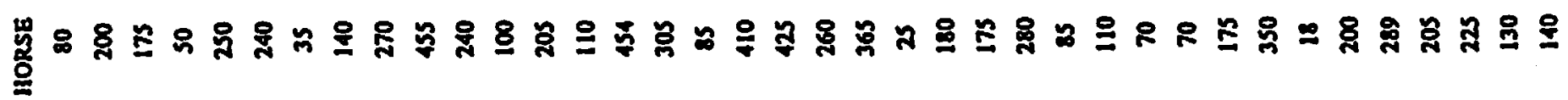

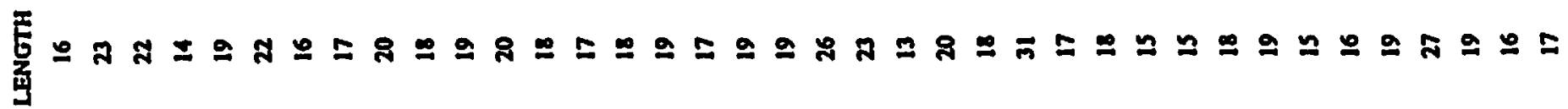

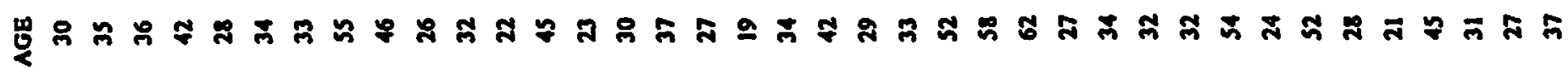

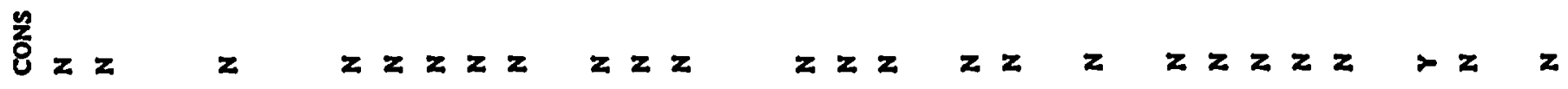

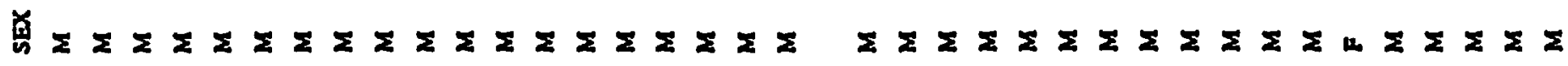

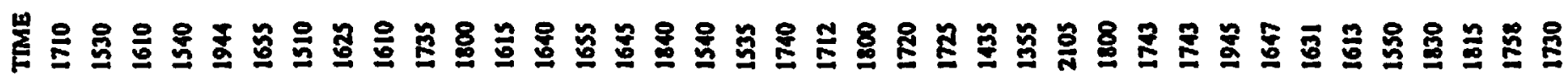

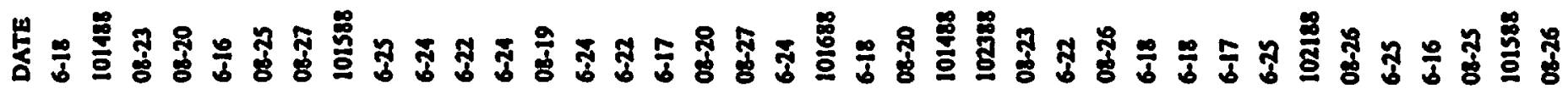

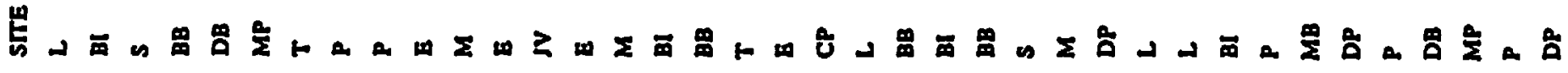

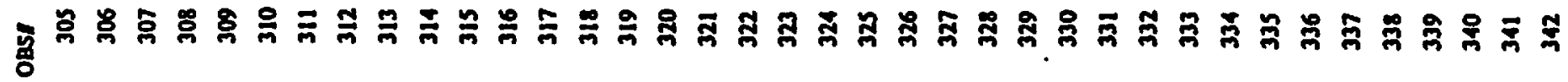




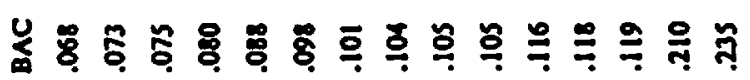

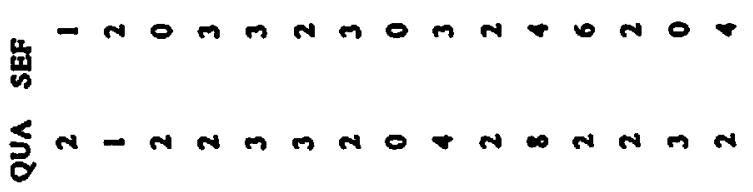

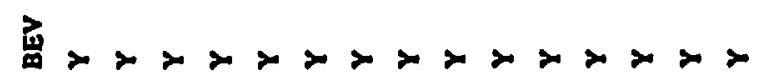

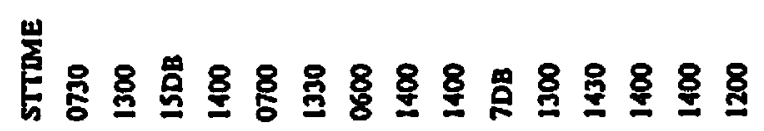

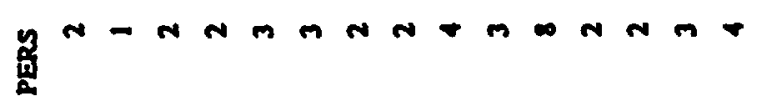

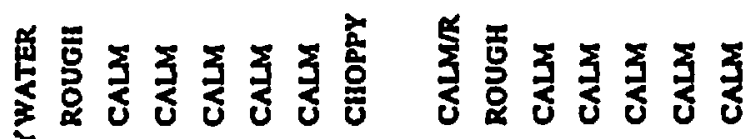

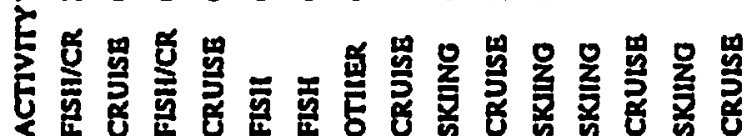

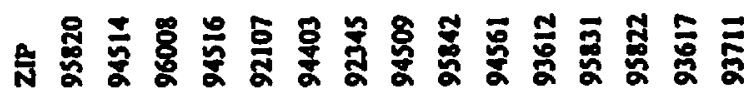

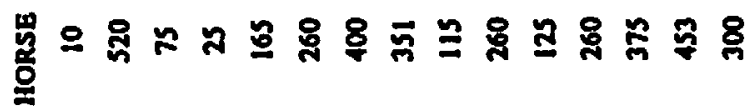

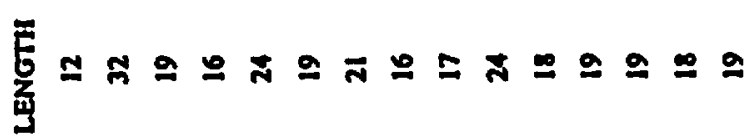

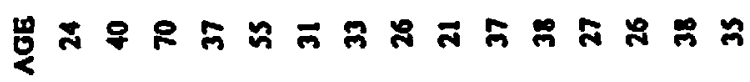

旁 $x+z z z x z x+x$

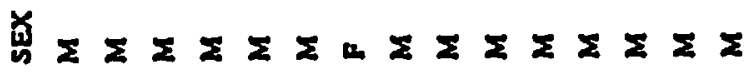

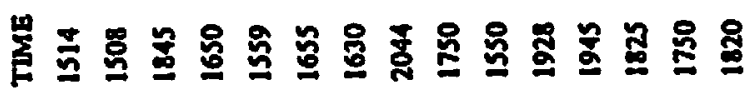

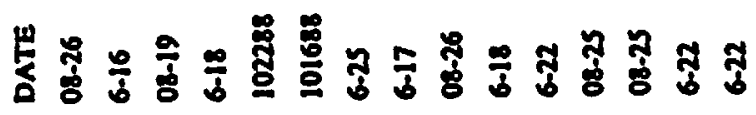

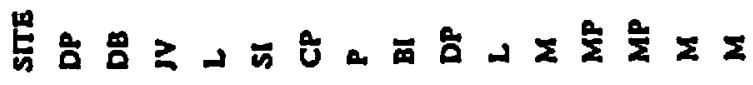

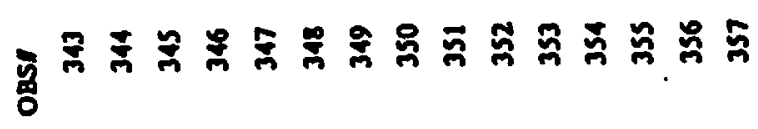




\section{APPENDIX C}

This appendix gives an abbreviated listing of the boating accident database developed earlier by VNTSC under this project. The columns contain the following data items:

1. Observation Number

2. Age of victim $(0=$ unknown $)$

3. Sex of victim $(0=$ unknown $)$

4. Was this victim the operator? ( 0 or $9=$ unknown)

5. Length of boat $(99=$ unknown $)$

6. Month in which accident occurred

7. Number of persons on board ( $99=$ unknown)

8. Time of day $(99=$ unknown $)$

9. $\mathrm{BAC}$ of victim (999. = unknown)

This listing is limited to California (1984 and 1985) and to the above 8 data items. 


\begin{tabular}{|c|c|c|c|c|c|c|c|c|}
\hline$\underline{O b s}$ & Victim ARe & Victim Sex & Operalor & Length & Month & $\mathbf{P}-\mathbf{O}-\mathbf{B}$ & Time & BAC \\
\hline 1 & 18 & $\mathrm{M}$ & 0 & 14 & 11 & 04 & 14 & 0. \\
\hline 2 & 15 & $\mathbf{M}$ & -0 & 14 & 11 & 04 & 14 & 0. \\
\hline 3 & 22 & $\mathbf{M}$ & $\mathbf{N}$ & 18 & 05 & 06 & 18 & 0. \\
\hline 4 & 33 & $\mathbf{M}$ & $\mathbf{N}$ & 12 & 01 & 03 & 12 & 0. \\
\hline 5 & 49 & $\mathbf{M}$ & $\mathbf{Y}$ & 16 & 12 & 02 & 16 & 0. \\
\hline 6 & 47 & $\mathbf{M}$ & $Y$ & 16 & 02 & 03 & 13 & 0. \\
\hline 7 & 40 & $\mathbf{M}$ & $\mathbf{Y}$ & 13 & 05 & 01 & 13 & 0. \\
\hline 8 & 67 & $\mathbf{M}$ & $Y$ & 16 & 06 & 03 & 09 & 0. \\
\hline 9 & -0 & $M$ & $Y$ & 17 & 08 & 01 & 10 & 0. \\
\hline 10 & 52 & $\mathbf{F}$ & $\mathbf{N}$ & 16 & 08 & 05 & 22 & 0. \\
\hline 11 & 70 & -0 & $N$ & 18 & 02 & 03 & 99 & 0. \\
\hline 12 & 70 & $\mathbf{M}$ & $Y$ & 18 & 02 & 03 & 99 & 0. \\
\hline 13 & 29 & $\mathbf{M}$ & $\mathbf{Y}$ & 10 & 01 & 03 & 99 & 0. \\
\hline 14 & -0 & $M$ & $\mathbf{Y}$ & 40 & 01 & 03 & 16 & 0. \\
\hline 15 & 20 & $F$ & $\mathbf{N}$ & 20 & 10 & 09 & 03 & 0. \\
\hline 16 & 56 & $\mathbf{M}$ & $\mathbf{Y}$ & 19 & 12 & 05 & 99 & 0. \\
\hline 17 & 53 & $\mathbf{M}$ & $\mathbf{N}$ & 40 & 03 & 05 & 12 & 0. \\
\hline 18 & 32 & $\mathbf{F}$ & $\mathbf{Y}$ & 07 & 07 & 02 & 13 & 0. \\
\hline 19 & 31 & $F$ & $\mathbf{Y}$ & 18 & 03 & 02 & 99 & 0. \\
\hline 20 & 59 & $\mathbf{M}$ & -0 & 15 & 06 & 04 & 15 & 0. \\
\hline 21 & 56 & $\mathbf{M}$ & $\mathbf{N}$ & 14 & 08 & 03 & 17 & 0. \\
\hline 22 & 32 & $M$ & $\mathbf{Y}$ & 12 & 12 & 02 & 09 & 0. \\
\hline 23 & 30 & $M$ & $\mathbf{Y}$ & 27 & 02 & 03 & 14 & 0. \\
\hline 24 & 85 & $\mathbf{M}$ & $\mathbf{Y}$ & 12 & 04 & 02 & 07 & 0. \\
\hline 25 & 99 & $\mathbf{M}$ & -0 & 16 & 06 & 03 & 09 & 0. \\
\hline 26 & 80 & $\mathbf{M}$ & $\mathbf{N}$ & 18 & 07 & 03 & 10 & 0. \\
\hline 27 & 24 & $\mathbf{M}$ & $\mathrm{N}$ & 14 & 03 & 04 & 12 & 0. \\
\hline 28 & 22 & $M$ & $Y$ & 06 & 06 & 02 & 11 & 0. \\
\hline 29 & 68 & $M$ & $\mathbf{Y}$ & 15 & 04 & 02 & 08 & 0. \\
\hline 30 & 07 & $\mathbf{M}$ & $\mathbf{N}$ & 15 & 03 & 03 & 21 & 0. \\
\hline 31 & 12 & $\mathbf{M}$ & $\mathbf{N}$ & 15 & 03 & 03 & 21 & 0. \\
\hline 32 & 14 & $\mathbf{M}$ & -0 & 14 & 11 & 04 & 14 & 0. \\
\hline 33 & 30 & $M$ & $N$ & 18 & 06 & 04 & 17 & 0. \\
\hline 34 & 64 & $\mathbf{M}$ & $\mathbf{Y}$ & 09 & 06 & 01 & 06 & 0. \\
\hline 35 & 65 & $\mathbf{M}$ & -0 & 15 & 06 & 04 & 15 & 0. \\
\hline 36 & 70 & $\mathbf{M}$ & $\mathbf{Y}$ & 17 & 06 & 01 & 07 & 0. \\
\hline 37 & 53 & $\mathbf{M}$ & $\mathbf{Y}$ & 99 & 02 & 02 & 99 & 0. \\
\hline 38 & 30 & $\mathbf{M}$ & -0 & 99 & 08 & 99 & 11 & 0. \\
\hline 39 & 59 & $\mathbf{M}$ & $\mathbf{N}$ & 16 & 03 & 03 & 07 & 0. \\
\hline 40 & 39 & $M$ & $\mathbf{Y}$ & 18 & 08 & 01 & 99 & 0. \\
\hline 41 & 67 & $\mathbf{M}$ & -0 & 12 & 04 & 02 & 07 & 0. \\
\hline 42 & 25 & $\mathbf{M}$ & $\mathbf{Y}$ & 99 & 07 & 03 & 18 & 0. \\
\hline 43 & 35 & $\mathbf{M}$ & $Y$ & 99 & 04 & 01 & 18 & 0. \\
\hline 44 & 16 & $\mathbf{M}$ & $\mathbf{Y}$ & 16 & 12 & 03 & 14 & 0. \\
\hline 45 & 27 & $\mathbf{M}$ & $\mathbf{Y}$ & 10 & 08 & 01 & 17 & 0. \\
\hline 46 & 26 & $\mathbf{M}$ & $\mathbf{Y}$ & 15 & 06 & 02 & 14 & 0. \\
\hline 47 & 54 & $\mathbf{M}$ & $\mathbf{Y}$ & 14 & 04 & 03 & 13 & 0. \\
\hline 48 & 18 & $\mathbf{M}$ & $\mathbf{Y}$ & 99 & 06 & 02 & 18 & 0. \\
\hline 49 & 50 & $\mathbf{F}$ & $\mathbf{N}$ & 18 & 07 & 14 & 18 & 0. \\
\hline 50 & 19 & $\mathbf{M}$ & $\mathbf{N}$ & 99 & 06 & 02 & 18 & 0. \\
\hline 51 & 47 & $\mathbf{M}$ & $\mathbf{N}$ & 19 & 12 & 05 & 99 & 0. \\
\hline 52 & 17 & $\mathbf{M}$ & $\mathbf{Y}$ & 14 & 08 & 02 & 99 & 0. \\
\hline 53 & 48 & $\mathbf{M}$ & $\mathbf{Y}$ & 36 & 04 & 07 & 16 & 0.02 \\
\hline
\end{tabular}




\begin{tabular}{|c|c|c|c|c|c|c|c|c|}
\hline 54 & 34 & $\mathbf{M}$ & $\mathbf{Y}$ & 16 & 04 & 04 & 99 & 0.02 \\
\hline 55 & 18 & $\mathbf{M}$ & $\mathbf{Y}$ & 14 & 11 & 03 & 99 & 0.02 \\
\hline 56 & 99 & $\mathbf{M}$ & -0 & 16 & 06 & 03 & 09 & 0.02 \\
\hline 57 & 82 & $\mathbf{M}$ & $\mathbf{Y}$ & 99 & 10 & 01 & 16 & 0.03 \\
\hline 58 & 63 & $\mathbf{M}$ & $\mathbf{N}$ & 20 & 05 & 03 & 07 & 0.03 \\
\hline 59 & 27 & $\mathbf{M}$ & $\mathbf{Y}$ & 16 & 03 & 03 & 13 & 0.03 \\
\hline 60 & 23 & $\mathbf{M}$ & $\mathbf{Y}$ & 99 & 11 & 02 & 11 & 0.03 \\
\hline 61 & 61 & $\mathbf{M}$ & $\mathbf{Y}$ & 14 & 05 & 03 & 23 & 0.03 \\
\hline 62 & 48 & $\mathbf{M}$ & $\mathbf{Y}$ & 16 & 02 & 03 & 13 & 0.04 \\
\hline 63 & 20 & $\mathbf{F}$ & $\mathbf{N}$ & 18 & 06 & 01 & 16 & 0.04 \\
\hline 64 & 27 & $\mathbf{M}$ & $\mathbf{Y}$ & 14 & 12 & 04 & 08 & 0.05 \\
\hline 65 & 24 & $\mathbf{M}$ & $\mathbf{N}$ & 16 & 03 & 03 & 13 & 0.05 \\
\hline 66 & 24 & $\mathbf{M}$ & $\mathbf{Y}$ & 13 & 05 & 99 & 17 & 0.05 \\
\hline 67 & 20 & $\mathbf{M}$ & $\mathbf{N}$ & 16 & 08 & 05 & 22 & 0.05 \\
\hline 68 & 61 & $\mathbf{M}$ & $\mathbf{N}$ & 16 & 03 & 03 & 07 & 0.06 \\
\hline 69 & 20 & $\mathbf{M}$ & $\mathbf{N}$ & 99 & 07 & 02 & 13 & 0.07 \\
\hline 70 & 30 & $\mathbf{M}$ & $\mathbf{N}$ & 27 & 02 & 03 & 14 & 0.07 \\
\hline 71 & 25 & $\mathbf{M}$ & $\mathbf{N}$ & 23 & 07 & 04 & 10 & 0.07 \\
\hline 72 & 24 & $\mathbf{F}$ & $\mathbf{N}$ & 44 & 08 & 03 & 20 & 0.07 \\
\hline 73 & 24 & $\mathbf{M}$ & $\mathbf{Y}$ & 18 & 08 & 01 & 19 & 0.08 \\
\hline 74 & 51 & $\mathbf{M}$ & $\mathbf{Y}$ & 15 & 06 & 04 & 15 & 0.08 \\
\hline 75 & 32 & $\mathbf{M}$ & $\mathbf{N}$ & 99 & 04 & 03 & 16 & 0.08 \\
\hline 76 & 52 & $\mathbf{M}$ & $\mathbf{Y}$ & 33 & 03 & 05 & 99 & 0.08 \\
\hline 77 & 27 & $\mathbf{M}$ & $\mathbf{N}$ & 20 & 02 & 04 & 10 & 0.09 \\
\hline 78 & 64 & $\mathbf{M}$ & $\mathbf{Y}$ & 14 & 06 & 01 & 14 & 0.09 \\
\hline 79 & 24 & $\mathbf{M}$ & $\mathbf{N}$ & 20 & 10 & 09 & 03 & 0.09 \\
\hline 80 & 23 & $\mathbf{M}$ & $\mathbf{Y}$ & 16 & 11 & 02 & 15 & 0.1 \\
\hline 81 & -0 & $\mathbf{M}$ & $\mathbf{N}$ & 18 & 06 & 03 & 15 & 0.1 \\
\hline 82 & 22 & $\mathbf{M}$ & $\mathbf{N}$ & 20 & 10 & 09 & 03 & 0.1 \\
\hline 83 & 27 & $\mathbf{M}$ & $\mathbf{N}$ & 20 & 10 & 09 & 03 & 0.11 \\
\hline 84 & 42 & $\mathbf{M}$ & -0 & 17 & 02 & 02 & 99 & 0.12 \\
\hline 85 & 84 & $\mathbf{M}$ & $\mathbf{Y}$ & 21 & 01 & 01 & 14 & 0.12 \\
\hline 86 & 20 & $\mathbf{M}$ & $\mathbf{Y}$ & 06 & 07 & 02 & 15 & 0.14 \\
\hline 87 & 47 & $\mathbf{M}$ & $\mathbf{Y}$ & 44 & 09 & 06 & 01 & 0.14 \\
\hline 88 & 19 & $\mathbf{M}$ & $\mathbf{Y}$ & 17 & 01 & 02 & 17 & 0.14 \\
\hline 89 & 24 & $\mathbf{F}$ & $\mathbf{N}$ & 20 & 10 & 09 & 03 & 0.14 \\
\hline 90 & 41 & $\mathbf{M}$ & $\mathbf{Y}$ & 26 & 05 & 01 & 13 & 0.15 \\
\hline 91 & 50 & $\mathbf{M}$ & $\mathbf{Y}$ & 08 & 10 & 02 & 99 & 0.15 \\
\hline 92 & 55 & $\mathbf{M}$ & -0 & 17 & 02 & 02 & 15 & 0.16 \\
\hline 93 & 36 & $\mathbf{M}$ & $\mathbf{N}$ & 15 & 07 & 06 & 16 & 0.16 \\
\hline 94 & -0 & $\mathbf{M}$ & $\mathbf{N}$ & 12 & 08 & 02 & 20 & 0.17 \\
\hline 95 & 33 & $\mathbf{M}$ & $\mathbf{N}$ & 16 & 03 & 05 & 06 & 0.18 \\
\hline 96 & 25 & $\mathbf{M}$ & $\mathbf{N}$ & 14 & 12 & 02 & 19 & 0.18 \\
\hline 97 & 28 & $\mathbf{M}$ & $\mathbf{Y}$ & 16 & 08 & 05 & 22 & 0.19 \\
\hline 98 & 67 & $\mathbf{M}$ & $\mathbf{Y}$ & 12 & 05 & 01 & 17 & 0.19 \\
\hline 99 & -0 & $\mathbf{M}$ & $\mathbf{N}$ & 19 & 07 & 02 & 13 & 0.19 \\
\hline 100 & 36 & $\mathbf{M}$ & $\mathbf{Y}$ & 12 & 05 & 02 & 22 & 0.19 \\
\hline 101 & 63 & $\mathbf{M}$ & $\mathbf{Y}$ & 45 & 11 & 06 & 07 & 0.22 \\
\hline 102 & 58 & $\mathbf{M}$ & $\mathbf{N}$ & 33 & 03 & 05 & 99 & 999. \\
\hline 103 & 32 & $\mathbf{M}$ & $\mathbf{Y}$ & 14 & 02 & 01 & 16 & 999. \\
\hline 104 & 12 & $\mathbf{F}$ & $\mathbf{N}$ & 17 & 05 & 06 & 17 & 999. \\
\hline 105 & 32 & $\mathbf{M}$ & $\mathbf{Y}$ & 18 & 06 & 01 & 06 & 999. \\
\hline 106 & 55 & $\mathbf{M}$ & $Y$ & 16 & 06 & 03 & 21 & 999. \\
\hline 107 & -0 & $\mathbf{F}$ & $\mathbf{N}$ & 40 & 01 & 03 & 16 & 999. \\
\hline
\end{tabular}




\begin{tabular}{|c|c|c|c|c|c|c|c|c|}
\hline 108 & 33 & $\mathbf{M}$ & $\mathbf{N}$ & 20 & 02 & 04 & 10 & 999. \\
\hline 109 & 13 & $M$ & $\mathbf{N}$ & 21 & 09 & 13 & 06 & 999. \\
\hline 110 & 13 & $\mathbf{M}$ & $\mathbf{N}$ & 26 & 03 & 12 & 13 & 999. \\
\hline 111 & 31 & $\mathbf{M}$ & $\mathbf{Y}$ & 12 & 05 & 02 & 03 & 999. \\
\hline 112 & 53 & $\mathbf{M}$ & $\mathbf{N}$ & 33 & 03 & 05 & 99 & 999. \\
\hline 113 & 24 & $\mathbf{M}$ & $\mathbf{Y}$ & 15 & 03 & 04 & 12 & 999. \\
\hline 114 & 13 & $\mathbf{M}$ & $\mathbf{Y}$ & 07 & 03 & 01 & 14 & 999. \\
\hline 115 & 62 & $\mathbf{M}$ & $\mathbf{N}$ & 16 & 08 & 06 & 19 & 999. \\
\hline 116 & 71 & $\mathbf{M}$ & $\mathbf{N}$ & 36 & 10 & 06 & 13 & 999. \\
\hline 117 & 43 & $\mathbf{M}$ & $\mathbf{Y}$ & 12 & 01 & 01 & 99 & 999. \\
\hline 118 & 65 & $\mathbf{M}$ & $\mathbf{N}$ & 14 & 08 & 02 & 03 & 999. \\
\hline 119 & 26 & $\mathbf{M}$ & -0 & 05 & 08 & 02 & 99 & 999. \\
\hline 120 & 38 & $\mathbf{F}$ & $\mathbf{Y}$ & 18 & 03 & 02 & 99 & 999. \\
\hline 121 & 47 & $\mathbf{M}$ & $\mathbf{Y}$ & 12 & 05 & 01 & 16 & 999. \\
\hline 122 & 42 & $\mathbf{M}$ & $\mathbf{Y}$ & 99 & 03 & 99 & 99 & 999. \\
\hline 123 & 25 & $\mathbf{M}$ & 9 & 13 & 10 & 02 & 99 & 999. \\
\hline 124 & 22 & $\mathbf{M}$ & 9 & 13 & 10 & 02 & 99 & 999. \\
\hline 125 & 27 & $\mathbf{M}$ & -0 & 22 & 09 & 02 & 99 & 999. \\
\hline 126 & 33 & $\mathbf{M}$ & $\mathbf{Y}$ & 99 & 11 & 01 & 12 & 999. \\
\hline 127 & 49 & $\mathbf{M}$ & $\mathbf{N}$ & 12 & 05 & 02 & 22 & 999. \\
\hline 128 & 28 & $\mathbf{M}$ & $\mathbf{Y}$ & 99 & 04 & 01 & 19 & 999. \\
\hline 129 & 58 & $\mathbf{M}$ & $N$ & 18 & 06 & 02 & 14 & 999. \\
\hline 130 & 56 & $\mathbf{M}$ & $\mathbf{N}$ & 33 & 03 & 05 & 99 & 999. \\
\hline 131 & 44 & $\mathbf{M}$ & $\mathbf{Y}$ & 32 & 11 & 01 & 99 & 999. \\
\hline 132 & 22 & $\mathbf{F}$ & $\mathbf{N}$ & 18 & 05 & 06 & 18 & 999. \\
\hline 133 & 28 & $\mathbf{M}$ & $\mathbf{N}$ & 21 & 08 & 03 & 17 & 999. \\
\hline 134 & -0 & $\mathbf{M}$ & -0 & 32 & 09 & 04 & 22 & 999. \\
\hline 135 & 62 & -0 & $\mathbf{Y}$ & 16 & 02 & 03 & 13 & 999. \\
\hline 136 & 53 & $\mathbf{M}$ & $\mathbf{Y}$ & 23 & 05 & 02 & 22 & 999. \\
\hline 137 & 27 & $\mathbf{M}$ & $\mathbf{Y}$ & 16 & 01 & 02 & 99 & 999. \\
\hline 138 & 50 & $\mathbf{M}$ & $\mathbf{N}$ & 27 & 09 & 03 & 15 & 999. \\
\hline 139 & 45 & $\mathbf{M}$ & $\mathbf{N}$ & 12 & 11 & 02 & 14 & 999. \\
\hline 140 & 67 & $\mathbf{M}$ & $\mathbf{N}$ & 30 & 11 & 07 & 15 & 999. \\
\hline 141 & 03 & $\mathbf{M}$ & $\mathbf{N}$ & 15 & 07 & 06 & 16 & 999. \\
\hline 142 & 22 & $\mathbf{M}$ & $N$ & 14 & 11 & 03 & 99 & 999. \\
\hline 143 & 21 & $\mathbf{M}$ & $\mathbf{N}$ & 14 & 11 & 03 & 99 & 999. \\
\hline 144 & 49 & $\mathbf{M}$ & $\mathbf{Y}$ & 12 & 03 & 01 & 16 & 999. \\
\hline 145 & 19 & $\mathbf{M}$ & $\mathbf{N}$ & 33 & 03 & 05 & 99 & 999. \\
\hline 146 & 39 & $\mathbf{M}$ & $\mathbf{N}$ & 19 & 12 & 05 & 99 & 999. \\
\hline
\end{tabular}




\section{REFERENCES}

1. Alcohol in Fatal Recreational Boating Accidents, Hoxie, P., Cardosi, K, Stearns, M., and Mengert, P. DOT-CG-D-04-88

2. The Role of the Drinking Driver in Traffic Accidents, Borkenstein, R.F., Crowther, R.F., Shumate, R.P. Ziel, W.B., and Zylman, R. Indiana University (1965).

3. A Comparison of Alcohol Involvement in Pedestrians and Pedestrian Casualties, Blomberg, R. D., Preusser, D. F., Haley, A., and Ulmer, R. of Dunlap and Associates, report prepared for The National Highway Traffic Safety Administration contract No. DOT-HS-00946.

4. An Introduction to Probability Theory and Its Applications Volume 1, Feller, W., John Wiley \& Sons, Inc., New York, 1966.

5. Stochastic Processes, Doob, J. L., John Wiley \& Sons, Inc., New York, 1953. 